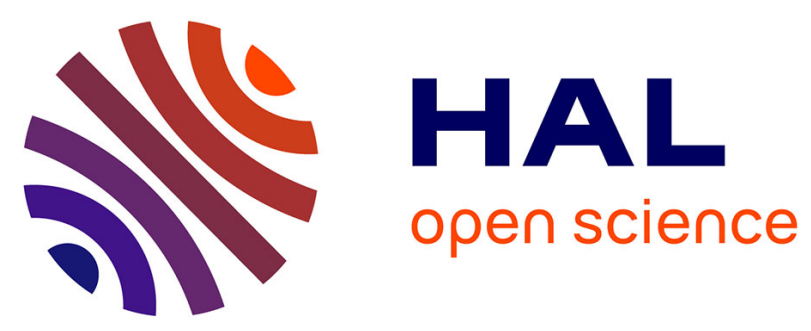

\title{
Transition Metals in Atmospheric Liquid Phases: Sources, Reactivity, and Sensitive Parameters
}

Laurent Deguillaume, Maud Leriche, Karine V. Desboeufs, Gilles Mailhot, Christian Cgo George, Nadine Chaumerliac

\section{To cite this version:}

Laurent Deguillaume, Maud Leriche, Karine V. Desboeufs, Gilles Mailhot, Christian Cgo George, et al.. Transition Metals in Atmospheric Liquid Phases: Sources, Reactivity, and Sensitive Parameters. Chemical Reviews, 2005, 105 (9), pp.3388 - 3431. 10.1021/cr040649c . hal-01819392

\section{HAL Id: hal-01819392 \\ https://hal.uca.fr/hal-01819392}

Submitted on 19 Nov 2020

HAL is a multi-disciplinary open access archive for the deposit and dissemination of scientific research documents, whether they are published or not. The documents may come from teaching and research institutions in France or abroad, or from public or private research centers.
L'archive ouverte pluridisciplinaire HAL, est destinée au dépôt et à la diffusion de documents scientifiques de niveau recherche, publiés ou non, émanant des établissements d'enseignement et de recherche français ou étrangers, des laboratoires publics ou privés.

\section{()ㅜ) $\Theta$}

Distributed under a Creative Commons Attribution - NoDerivatives| 4.0 International 


\title{
Transition Metals in Atmospheric Liquid Phases: Sources, Reactivity, and Sensitive Parameters
}

\author{
Laurent Deguillaume, ${ }^{\star}, \dagger$ Maud Leriche,${ }^{\dagger}$ Karine Desboeufs, ${ }^{\S}$ Gilles Mailhot, ${ }^{\ddagger}$ Christian George, ${ }^{\#}$ and \\ Nadine Chaumerliac ${ }^{\dagger}$
}

\begin{abstract}
Laboratoire de Météorologie Physique, Centre National de la Recherche Scientifique, Université Blaise Pascal, 24 avenue des Landais, 63177 Aubière Cedex, France; Laboratoire Inter-universitaires des Systèmes Atmosphériques, Centre National de la Recherche Scientifique, Université Paris 7 et Université Paris 12, 61 avenue du Général de Gaulle, 94010 Créteil Cedex. France; Laboratoire de Photochimie Moléculaire et Macromoléculaire, Centre National de la Recherche Scientifique, Université Blaise Pascal, 24 avenue des Landais, 63177 Aubière Cedex, France; and Laboratoire d'Application de la Chimie à l'Environnement, Centre National de la Recherche Scientifique, Université Claude Bernard, 43 Boulevard du 11 novembre 1918, 69622 Villeurbanne Cedex, France
\end{abstract}

Received February 1, 2005

\section{Contents}

1. Introduction

3388

2. TMl: From Aerosol Particles to Atmospheric Aqueous Phase

2.1. Characteristics of Transition Metals in Particulate Phase

2.2. Dissolution Processes

2.2.1. Effect of Particle Source

3391

3391

3392

2.2.2. Influence of $\mathrm{pH}$ on Dissolution Processes 3394

2.2.3. Photochemical Aging and Transition Metal 3395 Solubility

2.2.4. Kinetics of Dissolution

3395

3. Transition Metals in Atmospheric Liquid Phases 3396

3.1. Oxidation States and Chemical Forms of 3396 Transition Metal lons

3.1.1. Iron

3396

3.1.2. Copper and Manganese 3398

3.2. Concentrations of Transition Metals 3398

3.2.1. Iron

3398

3.2.2. Copper and Manganese

3402

3.3. Redox Speciation of Transition Metals in 3402 Atmospheric Liquid Phases

3.3.1. Definition

3402

3.3.2. Iron Speciation: Field Measurements 3402

3.3.3. Iron Speciation: A Whole Combination of 3407 Processes

3.3.4. Copper and Manganese Speciation 3408

4. Reactivity

4.1. Iron Reactivity in the Atmospheric Liquid Phase

4.1.1. Reactivity with $\mathrm{HO}_{x}$ Radicals

4.1.2. Reactivity with $S$ Compounds

4.1.3. Reactivity with Soluble Organic Compounds

4.2. Copper and Manganese Reactivity in the Atmospheric Liquid Phase

\footnotetext{
* Author to whom correspondence should be addressed [telephone (+33)4 734073 92; fax (+33)4 734051 36; e-mail L.Deguillaume@ opgc.univ-bpclermont.fr].

'Laboratoire de Météorologie Physique, Université Blaise Pascal.

$\S$ Université Paris 7 et Université Paris 12

¥Laboratoire de Photochimie Moléculaire et Macromoléculaire,

Université Blaise Pascal.

\# Université Claude Bernard.
}

4.3. Proposed Chemical Mechanism for in Cloud 3422 Chemistry Model

5. Summary and Concluding Remarks 3425

6. Acknowledgments 3427

7. References 3427

\section{Introduction}

The atmosphere is a complex medium in which several phases coexist: gas, aerosol particles, condensed water, liquid, and ice particles. All of the interactions that may occur between these various phases are included in the term "multiphase or heterogeneous chemistry". This chemistry involves studying each phase independently, examining the heterogeneous processes at the phase interfaces, and determining their consequences on the chemistry within each phase.

Clouds favor the development of atmospheric multiphase chemistry, as they are composed of all three atmospheric phases (i.e., gas, liquid, and solid phases that "catalyze" a full set of reactions). Consequently, studies of the processes occurring within cloud droplets or raindrops or at the surface of ice crystals are required to evaluate the role of multiphase chemistry on the atmosphere.

The evaluation of multiphase chemistry versus the overall tropospheric chemistry and its role in the earth's radiative budget is challenging because the physical nature and reactivity of condensed phases are still poorly known. However, it has been shown that multiphase chemistry within clouds has two major effects: an indirect effect by modifying cloud radiative properties and a direct effect on atmospheric chemistry. ${ }^{1,2}$

On the one hand, clouds can diffuse short-wavelength radiation from the sun and increase the albedo of the Earth/atmosphere system, whereas, on the other hand, they can absorb or diffuse infrared radiation emitted by the terrestrial surface, thus taking part in the greenhouse effect. ${ }^{3}$ The relative importance of these two effects is connected with optical cloud properties, themselves dependent on microphysical properties (granulometry, geometry) 


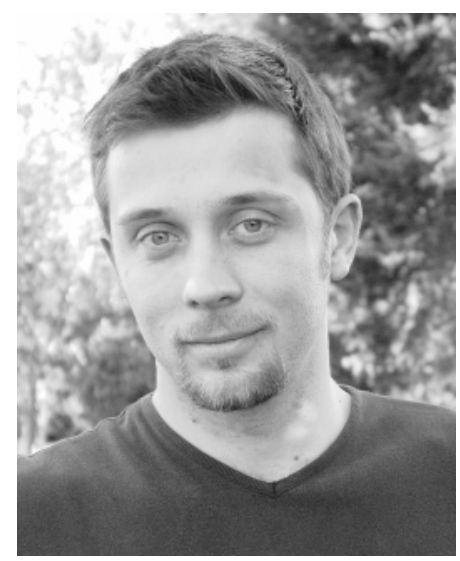

Laurent Deguillaume was born in Le Puy en Velay, France, in 1977. He received his B.Sc. in physics and chemistry in 1998 and his M.Sc. in atmospheric physics in 2000 from Blaise Pascal University (ClermontFerrand, France). He obtained his Ph.D. in atmospheric physics from Blaise Pascal University in 2003, working under the direction of Dr. Nadine Chaumerliac at the Laboratoire de Météorologie Physique. He is presently temporary assistant professor at Blaise Pascal University. His research focuses on multiphase chemistry inside clouds by a modeling approach. He participates in the Exchange program within the European Science Foundation activity entitled "Interdisciplinary Tropospheric Research: from the laboratory to global change". From July 2005, he will carry out postdoctoral research on mesoscale chemistry modeling at the Laboratoire Inter-Universitaire des Systèmes Atmosphérique in Paris.

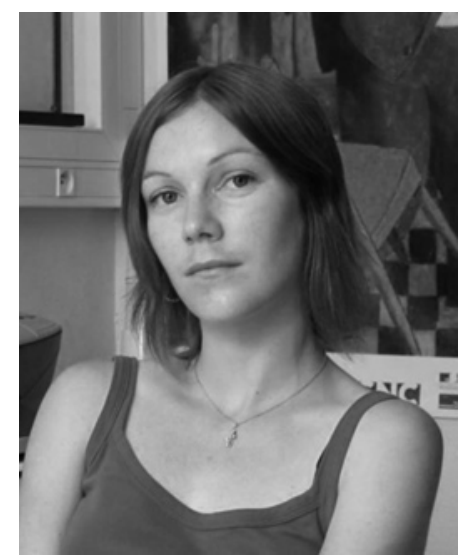

Maud Leriche was born in Le Havre, France, in 1974. She received her B.Sc. in physics from Pierre et Marie Curie University (Paris, France) in 1995 and, then, her M.Sc. in atmospheric physics from the Blaise Pascal University (Clermont-Ferrand, France) in 1997. She obtained her Ph.D. in atmospheric physics and chemistry from Blaise Pascal University in 2000 with Dr. Nadine Chaumerliac, studying multiphase chemistry inside clouds. After a temporary position as assistant professor at Blaise Pascal University and a visiting fellowship from NATO at Harvard University with Professor Daniel Jacob, she joined the Centre National de la Recherche Scientifique in 2002, where she is presently a researcher at the Laboratoire de Météorologie Physique at Clermont-Ferrand. Her research interests are mainly in the areas of atmospheric cloud chemistry including the cloud processing of aerosols and the coupling between microphysical and chemical processes in clouds. She is involved in the international AMMA program looking at the redistribution of soluble chemical species by convective clouds.

and cloud phase (liquid, mixed, iced). In the atmosphere, clouds are formed on aerosol particles called cloud condensation nuclei (CCN) or ice nuclei (IN). The ability of an aerosol to serve as a CCN or as an IN depends on its size, its water-soluble fraction, and the local supersaturation of water vapor relative to liquid water. ${ }^{4}$ When clouds are forming, the CCN or IN soluble fraction will be modified by the uptake of soluble gases into the droplets, by the redistribution

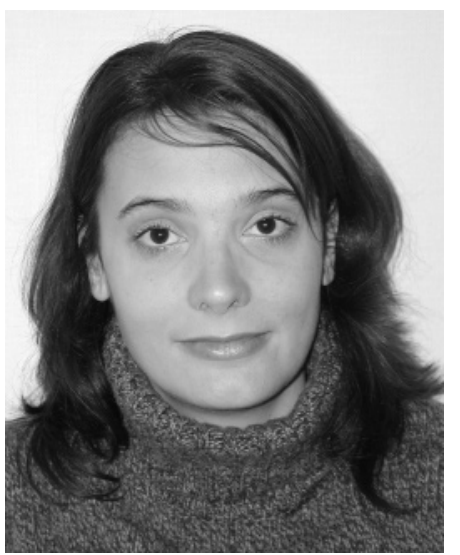

Karine V. Desboeufs received her M.Sc. in atmospheric chemistry in 1997 and her Ph.D. in 2001 from the Paris 7 University with Professor JeanLouis Colin. Her graduate research focused on the dissolution processes of aerosol particles in cloud droplets and, more particularly, on the release of dissolved trace metals from dust particles. After her Ph.D., she worked as a CNES postdoctoral researcher at the Observatoire de Physique du Globe de Clermont-Ferrand (OPGC), where she performed atmospheric dust transport modeling to study interactions of dust particles with clouds. Currently, she is an assistant professor in chemistry at the Paris 7 University, and she develops her research in the LISA (Laboratoire Interuniversitaire des Systèmes Atmosphériques). Her research interests are iron biogeochemistry and its atmospheric cycling.

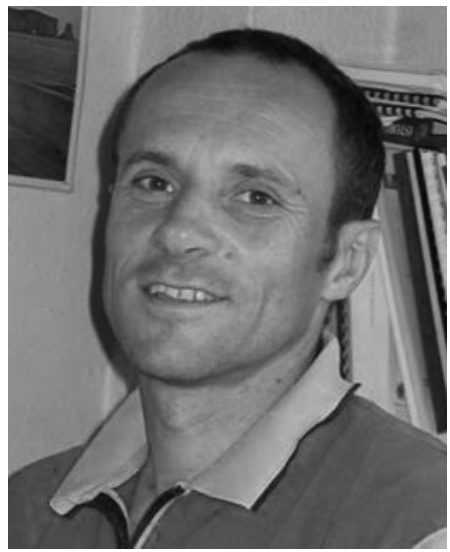

Gilles Mailhot obtained his Ph.D. in physical chemistry in 1991 from the University Blaise Pascal at Clermont-Ferrand. He studied polymerization photoindiced by charge transfer in a coordination complex. After a postdoctoral fellowship under the supervision of Pr. Gabor Somorjai at the University of California in Berkeley, in 1995 he joined the Centre National de Recherche Scientifique, where he is presently a researcher at the Laboratoire de Photochimie Moléculaire et Macromoléculaire (Clermont-Ferrand, France). His research interests are principally in the areas of photochemistry. He especially focuses on pollutant decomposition in aquatic environments (continental waters, atmospheric liquid phases) photoinduced by complexes and metallic oxides.

of chemical species through microphysical processes taking place within the dimensional spectrum of hydrometeors, and finally by the chemical reactivity. ${ }^{5}$ As a consequence, multiphase chemistry has an indirect effect on cloud radiative properties via its impact on the physicochemical properties of aerosol particles at the origin of the cloud droplets. ${ }^{6}$ Generally, aerosols resulting from various condensation/ evaporation cycles are more likely to favor the formation of a new cloud. ${ }^{5}$ This indirect effect of multiphase chemistry on cloud optical properties should be considered when looking at the first and second indirect effects of aerosol particles on the earth's radiative budget as defined by Twomey ${ }^{7}$ and Albrecht. ${ }^{8}$ 


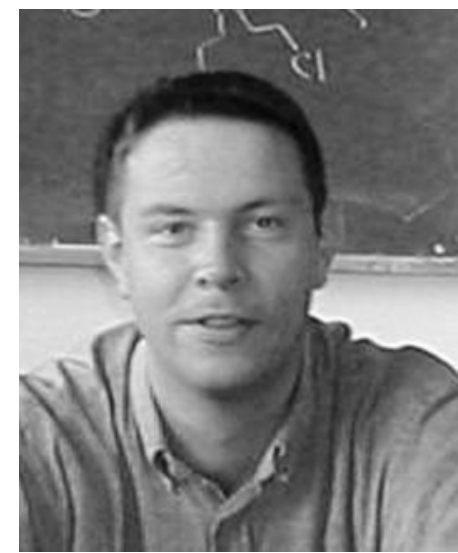

Christian George obtained his Ph.D. in physical chemistry in 1993 from the University Louis Pasteur at Strasbourg, working under the direction of Professor Ph. Mirabel. After a postdoctoral fellowship with Dr. C. Zetzsch at the Fraunhofer Institute in Hanover, in 1995 he joined the Centre National de Recherche Scientifique, where he is presently a researcher at the Laboratoire d'Application de la Chimie à l'Environnement. His research interests are principally in the areas of multiphase and/or heterogeneous atmospheric chemistry.

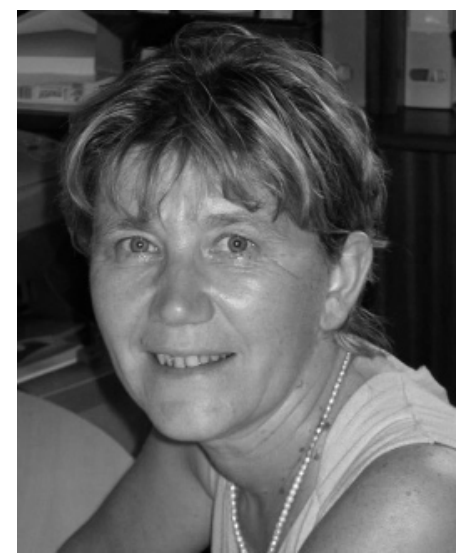

Nadine Chaumerliac was born in France in 1955. She studied mathematics and physics at the University of Clermont-Ferrand (France) and obtained her Ph.D. in meteorology in 1983. In 1986, she entered CNRS, and her main research interest is in atmospheric chemistry modeling with a special focus on clouds. She has been an invited researcher at NCAR in 1992 in the Atmospheric Chemistry Division in the group of Sasha Madronich and Guy Brasseur. She has long-standing experience in cloud and mesoscale modeling, which has been applied to atmospheric chemistry problems such as wet deposition, biomass burning, and ozone photooxidation. She organized an Advanced Study Course in Tropospheric Chemistry and Space Observation (EUR17780EN). She was a coordinator in various projects such as the modeling part of EXPRESSO/IGAC, the EUMAC project of EUROTRAC, and she participated in several EC projects and is part of the ACCENT Network of Excellence. She is Directeur de Recherche in CNRS and since 2000, she has been the leader of the LaMP, CNRS laboratory in Clermont-Ferrand (France).

Concerning the cloud effect on atmospheric chemistry, it is recognized that clouds play an important role in the chemical cycles of many atmospheric compounds. The first studies on the atmospheric chemical processes in homogeneous or heterogeneous aqueous phase (on the surface of the ice crystals or water droplets, for instance) were primarily carried out to cope with emergencies such as acid rain ${ }^{9}$ or the ozone hole in the stratosphere. ${ }^{10}$ They showed that the radiative, dynamic, and chemical processes occurring within clouds affect, for example, the concentrations of various chemical species such as ozone and nitrogen oxides. Three original aspects of the chemical reactivity within the cloud can be emphasized. First, the homogeneous chemical reactions within clouds are usually faster than the equivalent reactions in gas phase, and reactions that do not take place in the gas phase, such as those involving ionic species, can be of primary importance. Second, the photochemical processes inside the cloud droplets are much stronger than in interstitial air. ${ }^{11}$ Finally, the interactions between the aqueous and solid phases give rise to reactions that cannot occur in the homogeneous aqueous phase, for instance, the heterogeneous reactions at the surface of droplets constituting hydrometeors. ${ }^{12}$

Describing the impact of clouds on atmospheric chemistry is a central issue of atmospheric science. Because the interactions between the ice phase and cloud chemistry (low temperature, surface properties, ...) are poorly known, this work will be restricted to warm liquid clouds. However, describing such complex processes requires combing through several approaches that combine laboratory, field, and modeling capabilities.

The reactivity of atmospheric chemical compounds in homogeneous and/or heterogeneous phases, as well as the mass transfer processes between gas and condensed phases (described by such parameters as Henry's law constants, the accommodation coefficient, and the uptake coefficient), can be studied in the laboratory. The difficulty is to reproduce atmospheric processes in which exchanges between the different phases and chemical reactions are far from their equilibrium state (in terms of condensation/ evaporation cycles, potential deviation from Henry's law, and dependence on variable droplet size). Moreover, laboratory studies endeavor to determine reactivity constants and reaction pathways for a single specific chemical species, whereas the chemical system of the reaction is characterized by a great number of chemical compounds. Thus, global studies of the complex chemical processes in the atmosphere cannot be carried out in the laboratory to provide a scientifically sound base for modeling.

A second approach is in situ (or field) experimentation, which aims at understanding the chemical processes within the cloud through chemical, microphysical, and meteorological measurements. Here, the main difficulty is to coordinate these three types of measurements in time and space. Certain campaigns have attempted such an investigation: the CHEMDROP campaign on fogs in the Po Valley in Italy ${ }^{13}$ or the CIME experiment on orographical clouds at the top of the Puy de Dôme mountain. ${ }^{14,15}$ These measurements brought out strong size-linked variations in the chemical composition of droplets. For these reasons, new instruments, such as the Counter Virtual Impactor (CVI) ${ }^{16}$ and cascade impactors, ${ }^{17,18}$ were developed to sample cloud droplets according to their size. However, these measuring devices provide time-integrated measurements that mask the physicochemical processes, the characteristic times of which are shorter than the time step in sampling.

The final means for studying cloud impact on atmospheric chemistry is by modeling the physicochemical processes in the atmosphere. Although 
these models remain theoretical, they make it possible to simulate various reaction pathways for given chemical species within clouds, complex interactions between microphysical, chemical, radiative, and dynamic processes, and the influence of environmental parameters on multiphase chemistry. The structure of the numerical models allows sensitivity analyses to be carried out, for example, on dubious parameters. This tool integrates laboratory measurements and aids better understanding of in situ measurements by linking them with the laboratory studies.

These three approaches demonstrate that there exist many chemical reactions in cloudwater with potentially major environmental effects. Several studies have highlighted the particular role of transition metals and their complexes on the chemistry of the atmospheric aqueous phase ${ }^{19-23}$ Many in situ measurements underscore significant concentrations of transition metals in the various atmospheric aqueous phases (wet aerosols, cloud, fog, rain, or snow). ${ }^{24-30}$ The source of these metals is the dissolution of the soluble fraction of aerosols in the aqueous phase. Moreover, laboratory studies have shown that transition metal ions (TMI) are highly reactive in solution. ${ }^{27,31-33}$ Their reactivity, dependent on many factors such as $\mathrm{pH}$, their oxidation state, and their concentrations, is still prone to much uncertainty. The difficulty is to find a way to evaluate the impact of this chemistry on a medium as complex as the multiphase system of the atmosphere.

The aim of this paper is to provide an overview of the transition metal ion chemistry in the atmosphere and to point out the main uncertainties that still exist as to the physical and chemical processes involved. First, section 2 deals with the source of TMI in atmospheric liquid phases and describes the way they are transferred. This source is found in aerosol particles, which contain transition metals in various chemical forms. Second, in section 3, the available measurements of TMI concentrations and speciation in atmospheric liquid phases are presented. Speciation discriminates the main oxidation states of a chemical species and is a sensitive parameter for the chemistry of TMI in liquid atmospheric phases. Third, section 4, the reactivity of TMI in atmospheric liquid phases is described. This makes it possible to propose a reaction mechanism for cloud chemistry modeling. Finally, the concluding remarks will underscore future needs in this field.

\section{TMI: From Aerosol Particles to Atmospheric Aqueous Phase}

After oxygen and silicon, metals are the most abundant elements on the earth's surface. ${ }^{34}$ Among these metals 30 chemical elements, with atomic numbers ranging from 21 to 30 , from 39 to 48 , and from 71 to 80 , are commonly called transition metals. This name arises from their positions in the periodic table of the chemical elements. Transition metals are chemically defined as "elements that form at least one ion with a partially filled 'd' sublevel orbital". These elements therefore have several oxidation states that allow them to catalyze chemical reactions and form complexes. Transition metals are ubiquitous in atmo- spheric liquid phases (damp aerosol, cloud, fog, rain). Analysis of rain and cloud samples shows that transition metals do not contribute markedly to the overall concentration of impurities (or pollutants) in water ${ }^{35}$ and are hence present as traces. Among the TMI commonly found in atmospheric waters, it has been emphasized that iron $(\mathrm{Fe})$, copper $(\mathrm{Cu})$, and manganese $(\mathrm{Mn})$ are the major metals involved in the chemical processes occurring within these systems, as will be seen in sections 3 and 4 .

\subsection{Characteristics of Transition Metals in Particulate Phase}

The only source of metals in the atmospheric aqueous phase is the dissolution of aerosol particles incorporated in water droplets. The common particles containing trace metals are soil dust, fly ash from power plants, and exhaust from combustion engines and industrial operations. ${ }^{36-38}$ The concentrations and speciations of metals in atmospheric aerosols depend on their sources as shown in Table 1, in which

Table 1. Weight Percent of Transition Metals in the Studied Particulate Samples: Analogue of Saharan Dust, Urban Particles, Coal Fly Ash, and Oil Fly Ash ${ }^{59}$

\begin{tabular}{lcccc}
\hline \multicolumn{1}{c}{ species } & $\begin{array}{c}\text { analogues of } \\
\text { Saharan dust }\end{array}$ & $\begin{array}{c}\text { urban } \\
\text { particles }\end{array}$ & $\begin{array}{c}\text { coal } \\
\text { fly ash }\end{array}$ & $\begin{array}{c}\text { oil } \\
\text { fly ash }\end{array}$ \\
\hline $\begin{array}{l}\text { particle size } \\
\text { range }(\mu \mathrm{m})\end{array}$ & {$[2,20]$} & {$[0.03,10]$} & $<100$ & $<100$ \\
aluminum & 8.4 & 3.42 & 15.83 & 1.4 \\
silicium & 22.8 & 12.53 & 21.65 & 3.7 \\
cadmium & 0.005 & 0.0097 & 0.00025 & 0.003 \\
cobalt & 0.000085 & 0.0018 & 0.0015 & 0.023 \\
chromium & 0.03 & 0.0032 & 0.021 & 0.03 \\
copper & 0.005 & 0.061 & 0.007 & 0.021 \\
iron & 7.7 & 3.91 & 8.8 & 3.50 \\
manganese & 0.13 & 0.086 & 0.22 & 0.04 \\
nickel & 0.01 & 0.0082 & 0.0043 & 1.28 \\
vanadium & 0.05 & 0.0127 & 0.013 & 4.66 \\
zinc & 0.01 & 0.476 & 0.021 & 0.12 \\
\hline
\end{tabular}

analogues of Saharan dust are loess of Cap Verde, which are aeolian dust from Niger, deposited during the Holocene $;^{39,40}$ urban particles are a mixture of anthropogenic pollution and natural material (sludges, fly ash, and dust); coal fly ash is emitted by coal combustion, whereas oil fly ash is produced from fuel.

The elemental composition of dust is related to the composition of its soil source. Thus, iron, which is very abundant in crustal material, is the major transition metal found in dust. ${ }^{41}$ We note that this iron abundance in dust leads to a global iron cycle between dust, ocean biogeochemistry, and climate. ${ }^{42}$ Atmospheric photochemistry, which alters dust properties, may influence atmospheric iron cycling.

The iron in atmospheric particles occurs as structural iron trapped in the crystal lattice of aluminosilicate minerals [either in iron(II) or iron(III) oxidation states] and as iron oxides or hydroxides [in iron(III) oxidation state]. ${ }^{43-49}$ The iron oxides found in aerosols are mostly hematite $\left(\mathrm{Fe}_{2} \mathrm{O}_{3}\right)$ and goethite $(\alpha-\mathrm{FeOOH}){ }^{50}$ In dust the total iron content is between 2 and $8 \%$, of which 30 and $70 \%$ are, respectively, made up of iron oxides rather than aluminosilicate phases, depending on the mineralogy of the source material. ${ }^{50}$ Manganese and copper are mainly 
Table 2. Solubility Review of Different Transition Metals from Field Measurements and Laboratory Experiments

\begin{tabular}{|c|c|c|c|c|}
\hline \multirow[b]{2}{*}{ element } & \multicolumn{2}{|c|}{ field measurements } & \multicolumn{2}{|c|}{ laboratory experiments } \\
\hline & solubility range (\%) & ref & solubility range $(\%)$ & ref \\
\hline cadmium & $\begin{array}{l}6-100 \\
9-100 \\
66-95 \\
75-92\end{array}$ & $\begin{array}{l}\text { Morselli et al. }{ }^{302} \\
\text { Millet et al. }{ }^{89} \\
\text { Gatz et al. }{ }^{03} \\
\text { Guieu et al. } .^{304}\end{array}$ & $\begin{array}{l}10.1-96.6 \\
48-91 \\
58\end{array}$ & $\begin{array}{l}\text { Desboeufs et al.59 } \\
\text { Lindberg and Harris }{ }^{75} \\
\text { Nimmo et al. } .^{70}\end{array}$ \\
\hline copper & $\begin{array}{r}2 \\
9 \\
9 \\
12 \\
19 \\
20 \\
30 \\
49\end{array}$ & $\begin{array}{l}\text { Jickells et al. }{ }^{69} \\
\text { Lim et al. }{ }^{33} \\
\text { Chester et al. }{ }^{82} \\
\text { Morselli et al. }{ }^{302} \\
\text { Sedlak et al. }{ }^{88} \\
\text { Chester et al. }{ }^{305} \\
\text { Gatz et al. }{ }^{303} \\
\text { Guieu et al. } .^{304}\end{array}$ & $\begin{array}{l}20 \\
27.5-98.3 \\
57\end{array}$ & $\begin{array}{l}\text { Hoffmann et al. }{ }^{63} \\
\text { Desboeufs et al }{ }^{59} \\
\text { Nimmo et al. }{ }^{135}\end{array}$ \\
\hline iron & $\begin{array}{r}0.018 \\
0.02 \\
1 \\
1.3 \\
1.6 \\
3 \\
3.6 \\
6.1 \\
11 \\
22\end{array}$ & $\begin{array}{l}\text { Özsoy and Saydam }{ }^{110} \\
\text { Freydier et al.71 } \\
\text { Chester et al. }{ }^{305} \\
\text { Sedlak et al. } \\
\text { Colin et al. }{ }^{65} \\
\text { Millet et al. }{ }^{89} \\
\text { Deutsch et al. }{ }^{146} \\
\text { Zhu et al. }{ }^{307} \\
\text { Guieu et al. }{ }^{304} \\
\text { Kieber et al. }{ }^{78}\end{array}$ & $\begin{array}{c}0.02-0.98 \\
0.04-35.7 \\
0.05-1.25 \\
0.3-12 \\
2 \\
3.45-12.08 \\
12-23\end{array}$ & $\begin{array}{l}\text { Seames et al. }{ }^{306} \\
\text { Desboeufs et al. }{ }^{59} \\
\text { Williams et al. } \\
\text { Spokes et al. } \\
\text { Hoffmann et al. }{ }^{63} \\
\text { Zhu et al. }{ }^{102} \\
\text { Zhuang et al. }{ }^{60}\end{array}$ \\
\hline manganese & $\begin{array}{c}15-100 \\
20-52 \\
20 \\
50-100 \\
60-67 \\
90.7-100\end{array}$ & $\begin{array}{l}\text { Jickells et al. }{ }^{69} \\
\text { Chester et al. }{ }^{305} \\
\text { Hoffmann et al. }{ }^{63} \\
\text { Freydier et al. }{ }^{71} \\
\text { Guieu et al. }{ }^{304} \\
\text { Deutsch et al. }{ }^{103}\end{array}$ & $\begin{array}{l}0.3-23.8 \\
1.2-97.1 \\
1.5-54 \\
25 \\
70-92\end{array}$ & $\begin{array}{l}\text { Williams et al. }{ }^{68} \\
\text { Desboeufs et al. }{ }^{59} \\
\text { Spokes et al. }{ }^{72} \\
\text { Statham and Chester }{ }^{79} \\
\text { Lindberg and Harris }^{75}\end{array}$ \\
\hline zinc & $\begin{array}{l}15-99 \\
10-100 \\
20-100 \\
22-100 \\
27-97 \\
50-89 \\
69-76 \\
87-95.5 \\
92-98 \\
96-97\end{array}$ & $\begin{array}{l}\text { Losno et al. }{ }^{80} \\
\text { Freydier et al. }{ }^{71} \\
\text { Morselli et al. } .^{302} \\
\text { Millet et al. }{ }^{89} \\
\text { Jickells et al. }{ }^{69} \\
\text { Chester et al. }{ }^{305} \\
\text { Guieu et al. } .^{304} \\
\text { Colin et al. }{ }^{65} \\
\text { Lim et al. }{ }^{3} \\
\text { Gatz et al. }{ }^{303}\end{array}$ & $\begin{array}{l}11-100 \\
73 \\
74-95\end{array}$ & $\begin{array}{l}\text { Desboeufs et al. }{ }^{59} \\
\text { Hoffmann et al. } \\
\text { Lindberg and Harris }\end{array}$ \\
\hline
\end{tabular}

present in dust in trace quantities, either as oxides or as substitutes in a mineral network. ${ }^{41}$ Metals can also be adsorbed on minerals. ${ }^{51}$

For anthropogenic particles, high-temperature processes result in the release of volatile vapor-phase metals, which then undergo condensation or gas-toparticle conversion. The elemental composition is a function of the initial combustible composition. For instance, coal is typically rich in aluminum silicates and iron, whereas oil will be mainly organic with a high content in nickel, zinc, etc. Thus, metals of anthropogenic origin are predominantly associated with oxide phases. ${ }^{52-54}$ However, a significant fraction is also present as adsorbed metallic iron/ manganese ${ }^{55}$ or covalent organic complexes. ${ }^{56}$ Speciation of the metals in urban and diesel particles has shown that most of the metallic elements in diesel particulate matter appear to occur as sulfates, whereas in urban aerosols the occurrences are more varied, containing oxide and perhaps aluminosilicate in addition to sulfate..$^{57}$ The iron fraction in urban aerosols is usually between 6 and $8 \%$, whereas in rural areas it is halved. ${ }^{37}$

To sum up, iron comes essentially from mineral sources (soil dust or mineral fly ash); cadmium, copper, nickel, vanadium, and zinc originate mainly in combustion and industrial processes; the origin of manganese is mixed, derived both from aluminum silicates and from combustion particles. ${ }^{58,59}$ While being transported away from their sources, however, metal content and speciation are modified by atmospheric processes of cloud evapocondensation cycles, photochemistry, and possibly organic complexation. ${ }^{60-62}$

The TMI concentrations found in atmospheric waters depend on the dissolution of trace metals from these matrices. In work on aerosol dissolution, the solubility concept is usually brought to bear. Solubility is generally calculated as the ratio of dissolved concentration to dissolved plus particulate concentration. Table 2 reviews the solubilities found in the literature.

Metal solubilities are seen to vary by up to 2 orders of magnitude. Because their solubility may be very low, the main components in the aerosol are not necessarily the most important ones for the aqueous phase. ${ }^{63}$ It is therefore of prime importance to quantify the factors that govern aerosol dissolution in the aqueous phase in order to forecast the metal composition in the droplets.

\subsection{Dissolution Processes}

\subsubsection{Effect of Particle Source}

Generally, Wilkinson et al. ${ }^{64}$ showed that large variations in cloud water composition are due to 
variations in the marine and terrestrial/anthropogenic sources of particles, general weather patterns, atmospheric circulation, and seasonal effects. At any rate, all trace metal concentrations are associated with anthropogenic pollutant-laden air. By backtrajectory analyses, Colin et al ${ }^{65}$ showed that the soluble fraction of metals is higher in air masses of anthropogenic and marine origin. Conversely, insoluble fractions are higher in events in which crustal emission is the dominant source. Because scavenged aerosols are often a mix of anthropogenic and natural particles, evaluation of the crustal enrichment factor $\left(\mathrm{EF}_{\text {crust }}\right)$ has been widely used to compare the anthropogenic contribution to samples with their natural origin, that is, average crustal rocks. The elemental $\mathrm{EF}_{\text {crust }}$ for the metals in the end-member aerosol was calculated from the formula

$$
\mathrm{EF}_{\text {crust }}=\frac{([\mathrm{X}] /[\mathrm{Al}])_{\text {atmo }}}{([\mathrm{X}] /[\mathrm{Al}])_{\text {crust }}}
$$

where $[\mathrm{X}]$ is the aerosol's elemental concentration in $\mathrm{X},[\mathrm{Al}]$ is the aerosol aluminum concentration, and $([\mathrm{X}] /[\mathrm{Al}])_{\text {crust }}$ is the elemental crustal ratio. ${ }^{66} \mathrm{~A}$ calculated $\mathrm{EF}_{\text {crust }}$ of $>10$ would indicate enrichment due to a noncrustal aerosol source; $\mathrm{EF}_{\text {crust }}$ values of $\leq 10$ would, on the other hand, describe a crustal source for aerosol elemental composition. Luck and Ben Othman ${ }^{67}$ used a leaching experiment to show that the soluble fraction is correlated with the $\mathrm{EF}_{\text {crust }}$ values: the stronger the $\mathrm{EF}_{\text {crust }}$ pattern of metals, the more soluble they are. In the same type of experiments, Williams et al. ${ }^{68}$ emphasized that iron with an enrichment factor of $<1$ has a solubility under $1 \%$, whereas manganese, which has a pronounced enrichment factor, is more soluble (Table 2). Similarly, Jickells et al. ${ }^{69}$ and Nimmo et al. ${ }^{70}$ suggested that particles with a strong anthropogenic chemical signature (very high $\mathrm{EF}_{\text {crust }}$ ) have high trace metal solubilities. On the contrary, Saharan dust with low $\mathrm{EF}_{\text {crust }}$ is associated with low solubilities. This was confirmed by Freydier et al. ${ }^{71}$ who showed that the ratio of the dissolved metal concentration to the total metal concentration in rainwater decreases as the quantity of crustal dust increases. Elements with mixed sources show intermediate solubilities. ${ }^{69}$ These conclusions have been confirmed in laboratory leaching experiments. Results of leaching Saharan and urban aerosols under imposed $\mathrm{pH}$ indicate that solubility is directly related to the aerosol source, with iron solubility always 6\% for Saharan aerosol but reaching $12 \%$ for urban particles. ${ }^{72} \mathrm{~A}$ study by Desboeufs et al. ${ }^{62}$ compared the solubility of a Saharan aerosol-like material with that of petroleum fly ash and found, respectively, 0.04 and 38\% for iron and 2 and $97 \%$ for manganese.

Chester et al. ${ }^{73}$ used a sequential leaching method to separate trace metals according to their binding associations: (1) an exchangeable association (environmentally mobile), (2) a carbonate and oxide association, and (3) organic matter and silicate associations (environmentally immobile fractions). In this way they showed that solubility is associated with metal solid-state speciation rather than aerosol source.
Thus, metals speciated in carbonate and metal oxide fractions, organic matter, and silicate fractions are poorly soluble, whereas significantly exchangeable metals (adsorbed metals, salts, ...) are the most soluble of all. $52,53,56,73,74$ Another study by Desboeufs et al. ${ }^{59}$ stated that the nature of the solid matrix, rather than the anthropogenic pattern, is the most important factor governing solubility. High solubility values $(35 \%)$ are obtained for carbonaceous particles (where the metals are generally adsorbed), whereas solubility values from aluminum silicate aerosol matrices (e.g., silicated fly ash from coal combustion or terrestrial aerosols) are generally under $10 \%$. Some metals tend to be associated with submicrometer particles as a result of their abundance in hightemperature processes, whereas metals from crustal weathering and sea-salt generation, because of the processes that generate them, tend to be associated with large particles $(1 \mu \mathrm{m})$. Thus, Hlavay et al. ${ }^{52}$ showed that the loosely bound and hence highly soluble fraction of metals corresponds to the fine fraction of size distribution. The range of solubility found by Lindberg and Harris ${ }^{75}$ is limited to solubility values of $>50 \%$ for aerosol samples from local coal combustion emission (coal-fired power plant). In this case, their observations show a general increase in metal solubility as particle size decreases. This trend can be explained by a combination of factors: (1) a basic difference in the chemistry of source material contributing to each size fraction, (2) the greater surface area-to-volume ratio of smaller particles, and (3) high overall concentrations of metals in small particles. For crustal matter, solubility is also associated with the crystalline structure of the mineral network. Crystalline hydroxides such as hematite $(\alpha-$ $\left.\mathrm{Fe}_{2} \mathrm{O}_{3}\right)$, goethite $(\alpha-\mathrm{FeOOH})$, maghemite $\left(\gamma-\mathrm{Fe}_{2} \mathrm{O}_{3}\right)$, or magnetite $\left(\mathrm{Fe}_{3} \mathrm{O}_{4}\right)$ are much less soluble than amorphous iron hydroxides such as ferrihydrite $\left[\mathrm{Fe}(\mathrm{OH})_{3}\right]$ and clay minerals. For example, Zhu et al. ${ }^{76}$ found that the solubility of iron derived from ferric hydroxide can be $10^{5}$ higher than when coming from hematite in the same conditions.

Finally, these studies emphasize that particles from anthropogenic sources contribute significantly to metal distribution in atmospheric droplets due to their high metal content and solubility. However, even if anthropogenic iron sources are globally significant, it appears that the crustal source can be important as well. For example, Takeda et al. ${ }^{58}$ observed an increase in dissolved iron concentrations when wet deposition is simultaneous with a dust event. Similarly, the crustal origin of iron clearly appears in the works of Al-Momani, ${ }^{77}$ where an intense incursion of Saharan dust at the rural sampling site caused a basic precipitation $\mathrm{pH}$ and high iron concentration. Calculations of air mass trajectories indicated that the rain events with low iron concentrations originated in the ocean, whereas the higher iron concentrations were observed in rain events that had traversed Australian regions where dust plumes are usual. ${ }^{78}$ Thus, anthropogenic aerosols constitute the major source of metals when the atmosphere is influenced anthropogenically, whereas dust is a more important source in areas where man has little impact. 


\subsubsection{Influence of $\mathrm{pH}$ on Dissolution Processes}

From both rainwater sampling and laboratory experiments, various studies have shown that dissolved-particulate speciation of trace metals in rainwater is $\mathrm{pH}$-dependent. Typically, the environmental or experimental results show that solubility values increase as the $\mathrm{pH}$ of mineral dust decreases. For example, Williams et al., ${ }^{68}$ who have worked on different fly ashes, showed that the fraction of metals leached (iron, manganese, copper, and zinc) increases with decreasing $\mathrm{pH}$ over the range of $\mathrm{pH} 2.5-5$. This behavior is also observed for atmospheric dustderived iron, where $\sim 55 \%$ of the iron dissolves in artificial rainwater at a $\mathrm{pH}$ of 3.8 and $\sim 25-30 \%$ dissolves at a $\mathrm{pH}$ of $4.8 .^{60}$ Statham and Chester ${ }^{79}$ also found that the fraction of manganese released from Saharan dust on contact with rainwater, on a time scale of a few minutes, increased with decreasing $\mathrm{pH}$ from $20 \%$ at $\mathrm{pH} 5.1$ to $59 \%$ at $\mathrm{pH} 2$. Nevertheless, this $\mathrm{pH}$ effect is more or less marked according to the nature of the particles. Spokes et al. ${ }^{72}$ obtained results showing that iron solubility for "Saharan dusts" increases by a factor of 5 when the $\mathrm{pH}$ goes from 6 to 2, whereas it remains unchanged for "urban material" when the $\mathrm{pH}$ drops from 5 to 2 . In the same $\mathrm{pH}$ ranges manganese solubility is 3 times greater for Saharan dust and twice as high for urban particles. Thus, the effect of $\mathrm{pH}$ on solubility for a given matrix is different according to the element under consideration.

Spokes et al. ${ }^{72}$ showed that responses to imposed $\mathrm{pH}$ changes are relatively rapid ( 1 $\mathrm{min})$. Yet, for metals in excess of their crustal abundance, the most striking feature of the percent solubility/pH plots, is the presence of a classic $\mathrm{pH}$ adsorption edge that separates a low $\mathrm{pH}$-high percent solubility region from a high $\mathrm{pH}-$ low percent solubility region. ${ }^{80-84}$ This $\mathrm{pH}$-edge may be initiated at $\mathrm{pH}$ values as low as 3.5 and extended up to a $\mathrm{pH}$ of $\sim 5.8 .{ }^{85}$ This typical feature has also been observed for zinc, with a $\mathrm{pH}$ edge value of $\sim 6,{ }^{80,83}$ for lead ( $\mathrm{pH} 5.6$ for Lim et al. ${ }^{83}$ and $\mathrm{pH} 5.3$ for Chester et al. ${ }^{82}$ ) and for copper $(\mathrm{pH}$ 5.6 for Lim et al. ${ }^{83}$ and Chester et al. ${ }^{82}$ ) (Figure 1a). This $\mathrm{pH}$-edge is not observable for crustal elements for which the solubility is normally related to the dissolution kinetics. ${ }^{86}$ Typically, $\mathrm{pH}$-dependent dissolution for minerals is explained in the geochemical literature by a protonation/deprotonation mechanism $^{87}$ : Adsorption of protons onto the surface loosens the $\mathrm{Al}-$ or $\mathrm{Si}-\mathrm{O}$ bonds of the crystal matrix or the critical bonds between the oxide and metal ions. Thus, the dissolution rates correspond to the detachment of metal ions or $\mathrm{Si} / \mathrm{Al}$ from the surface. Dissolution rates are much less $\mathrm{pH}$-dependent in nearly neutral conditions, whereas below $\mathrm{pH} 4$ and above $\mathrm{pH} 10$ the dissolution rate exhibits strong $\mathrm{pH}$ dependence $^{88}$ (Figure 1b). Such $\mathrm{pH}$ dependence has direct implications on the assessment of solubility. Whereas such elements as magnesium, lead, and calcium are usually found in the soluble phase, and others, such as aluminum, are prevalent in the insoluble fraction, the presence of trace metals (cadmium, copper, manganese, and iron) in the soluble or insoluble phase depends largely on water $\mathrm{pH}^{89}$ We can con-
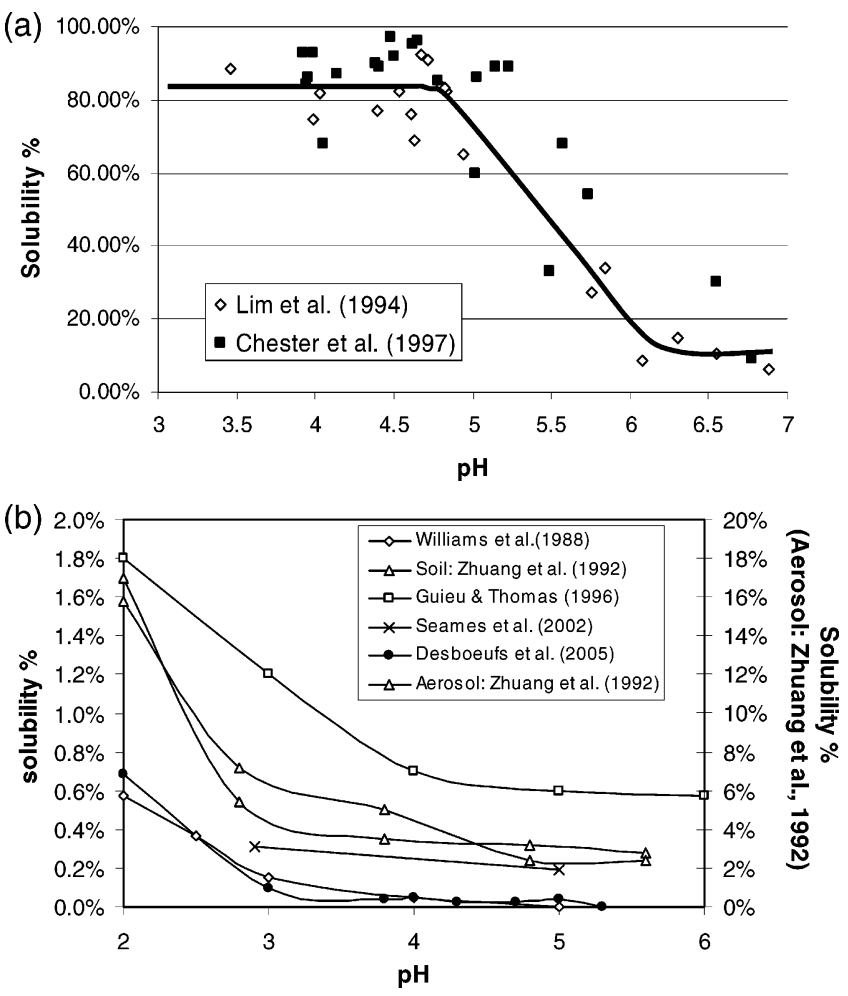

Figure 1. $\mathrm{pH}-$ solubility relationships for (a) copper in excess of its crustal abundance in rainwaters (the line represents the estimated $\mathrm{pH}$ absorption edge) and for (b) iron derived from dust dissolution during leaching experiments.

clude that it is extremely important to take the $\mathrm{pH}$ range and variation into account when studying the relationship between trace metal concentrations and droplet $\mathrm{pH}$.

Several authors have shown that during experimental leaching the $\mathrm{pH}$ in droplets may be influenced by the dissolution of aerosol particles. Thus, Statham and Chester ${ }^{79}$ and Desboeufs et al. ${ }^{90}$ found a significant neutralizing effect of Saharan aerosol particles on water. On the contrary, an acidifying effect was observed in a petroleum fly ash leaching experiment. ${ }^{91,90}$ The neutralizing effect of crustal aerosols is typically associated with their high carbonate content. ${ }^{92}$ The acidic $\mathrm{pH}$ is attributed to the release of sulfur or nitrogen oxides adsorbed on highly reactive carbonaceous particles or to the dissolution of sulfate and nitrate aerosol particles, producing $\mathrm{H}_{2}-$ $\mathrm{SO}_{4}$ or $\mathrm{HNO}_{3}$ in solution. Thus, during a droplet's lifetime, dissolution of aerosol can have an effect on its $\mathrm{pH}$ and hence on the dissolution of trace metals. ${ }^{79,90,93}$ For example, we have seen that trace metal concentrations are higher in urban areas. Table 1, however, reveals low concentrations of trace metals in the measurements of Alabdula'aly and Khan. ${ }^{94}$ They demonstrated that these low concentrations are directly related to the high alkalinity of the samples $(\mathrm{pH}$ 7) due to the presence of a cement factory close to the sampling site. Along the same lines, Chester et al., ${ }^{82}$ studying a sequential collection of a single rain event, observed a $\mathrm{pH}$ "dip" followed by a return to the initial $\mathrm{pH}$ as the $\mathrm{pH}$-influencing components became exhausted as a result of the scavenging of urban-rich material. In previous studies Chester et al. ${ }^{95}$ inferred that the very low $\mathrm{pH}$ regime induced 
at the surface of a particle acting as a condensation nucleus by dissolution of sulfate or nitrate salts may enhance the release of metals from the solid phase.

Moreover, Lefebvre-Drouet and Rouseau ${ }^{96}$ pointed out that during dissolution taking place in the presence of organic acids, the acidity level governs the dissolution of crystallized iron oxides, whereas complexation is the main factor in the dissolution of amorphous compound. Laboratory experiments have shown that the solubility of trace metals can be strongly affected by the concentration of organic ligands in an aqueous/silicate system. ${ }^{97}$ Galloway et al. ${ }^{98}$ reported that organic (formic and acetic) acids can contribute as much as $65 \%$ of the free acidity in precipitation sampled from remote marine regions. According to Benjamin and Leckie, ${ }^{99}$ the presence of organic ligands in precipitation may alter the partitioning of metals in rainwater through the following processes: (1) solubilization of particulate metal according to the complexing power of ligands, (2) reduction of metal adsorption by the formation of ligand-like complexes, and (3) enhancement of metal adsorption by formation of metallic complexes. All metals released in rainwater from dust or urban particles are organically complexed to some degree. ${ }^{70}$

\subsubsection{Photochemical Aging and Transition Metal Solubility}

During laboratory experiments, transition metals from Saharan dust have been observed to dissolve more readily in daylight than in the dark. ${ }^{79,100}$ The work of Hoffmann et al. ${ }^{63}$ emphasized that dissolved iron(III) concentrations were not affected by sunlight, whereas dissolved iron(II) concentrations increased under the same conditions to values $\sim 40$ times higher for urban particles. Studying iron speciation in rainwater, Kieber et al. ${ }^{78}$ observed a diurnal iron variability: concentrations of iron(II) were highest from noon to 6:00 p.m., the period of greatest light intensity. From 6:00 p.m., the maximum iron(II) concentration declined through the evening to an early morning minimum. They explained these variations as reflecting photochemically initiated dissolution of particulate iron, and this was confirmed by Sofikitis, ${ }^{101}$ who measured a more rapid dissolution rate for iron(II) than for iron(III) in the mineral particles. This effect of light was also observed directly on particulate iron by Zhu et al., ${ }^{102}$ who found a clear day/night pattern in the concentration of soluble iron(II) from wind-transported mineral dust, with day values about twice those at night. Moreover, Lefebvre-Drouet and Rousseau ${ }^{96}$ showed that the solubility of iron is enhanced by adding a reducing agent to the aqueous phase. Deutsch et al. ${ }^{103}$ also found that manganese in rainwater and snow exists entirely as soluble manganese(II), its reduced form. Hofmann et al. ${ }^{35}$ calculated that this manganese(II) is in molecular form and positively charged.

The aerosol particles can have a residence time in the atmosphere of $\sim 1$ week and hence can be transported over thousands of kilometers. Lindberg and Harris $^{75}$ observed that solubility increases as a combustion plume ages. Solubility values for plume aerosols collected, respectively, $250 \mathrm{~m}$ and $7 \mathrm{~km}$ downwind from a power plant were as follows: cadmium, 55 and 90\%; manganese, 55 and $90 \%$; zinc, 50 and $80 \%$. Aerosols are typically exposed to $\sim 10$ condensation/evaporation cloud cycles before removal in rain. From laboratory cloud process simulation, Desboeufs et al. ${ }^{62}$ showed that the condensation/ evaporation cycle increases the solubility of aerosol particles and notably the release of trace metals. They also showed that solubility depends only on the last cloud cycle, and in particular, on the factor controlling the $\mathrm{pH}$ during this process. Spokes et al. ${ }^{72}$ demonstrated through alternations of low and high $\mathrm{pH}$ that this solubilization is not reversible for iron in urban aerosols or for manganese in Saharan and urban aerosols, whereas the solubility of concentrations of dissolved iron from Saharan dust can be controlled by $\mathrm{pH}$. The increase in the solubility of processed aerosols could be explained by the change in specific surface area and morphology observed on the aerosol particles after water leaching..$^{91}$ Notably, an amorphous phase, more soluble than crystallized mineral, ${ }^{96}$ appears. ${ }^{62}$ Zhuang et al. ${ }^{60}$ also observed that at a given $\mathrm{pH}$ the solubility of iron in the dust collected in remote marine zones was 5-17 times greater that that of iron from the soil or Chinese loess. They postulated that (1) the mixing of mineral dust with acid aerosol as a result of coalescence processes within clouds might be a mechanism to increase the solubility of atmospheric iron in cloud water and (2) photochemical reduction of iron(III) to iron(II) during the long-range transport of particles may be an important mechanism increasing the solubility of iron. Thus, the mobilization of metals might be strongly dependent on the past history of the aerosol particles in the atmosphere. ${ }^{76}$ Moreover, several works have shown that aerosols sampled far from their source consist of a mixture of different aerosol types, in particular, crustal core coated with soluble compounds. ${ }^{104-108}$ This mixing could have an indirect effect on dissolution, as it implies a modification of aqueous conditions. For example, the mixing of terrestrial particles has been emphasized by the reaction between $\mathrm{SO}_{2}$ or sulfate with water-soluble inorganic components, which are carbonate/bicarbonate contained in mineral dust, ${ }^{109}$ and subsequent acidification of the droplet will make possible the dissolution of crustal particles.

\subsubsection{Kinetics of Dissolution}

Özsoy and Saydam ${ }^{110}$ showed that iron solubility in acid rain moving over Europe and the Mediterranean Sea is $\sim 56.7 \%$ (average $\mathrm{pH} 4.4$ ), whereas it reaches only $3.32 \%$ in red rain (average $\mathrm{pH}$ 6.6) originating, according to back-trajectories, in North African mineral dust source zones. Both observed solubilities are governed by the $\mathrm{pH}$ dependence and nature of the particles, which act on $\mathrm{pH}$ and on the solid-state speciation of iron. Similarly, Colin et al. ${ }^{65}$ observed a relationship between elemental solubility and the back-trajectories of air masses: Higher solubilities are observed for air masses affected by industrial sites. However, it appears that rainwater $\mathrm{pH}$ goes down as industrial impact goes up. This makes it difficult to know whether discrepancies in solubility are due to the particle source or a direct $\mathrm{pH}$ effect. ${ }^{65}$ It is therefore necessary to get an 
accurate quantification of the processes governing metal dissolution as a function of the different factors bearing on it in order to estimate metal concentrations and speciation in the atmospheric aqueous phase. Consequently, it is helpful to parametrize the metals' behavior in the droplets under realistic conditions. It has been emphasized that for all $\mathrm{pH}$ values there is a very rapid initial dissolution, over 50 of the equilibrium concentrations being attained in the first $10 \mathrm{~min}$, followed by a slower rate of dissolution for wind-transported dust, ${ }^{79,86}$ fly ash, ${ }^{68}$ rural aerosol, ${ }^{111}$ and urban particles. ${ }^{70}$ This latter dissolution rate is reduced as the $\mathrm{pH}$ decreases. ${ }^{90}$ We have seen that analyses of particulate phase show that certain elements are concentrated on the particle surfaces. The surface enrichment would explain why there is a rapid initial dissolution of metals followed by a slower dissolution rate, which would correspond to initial leaching of surface deposits followed by a slow leaching from the inner part of the material. The first step of the dissolution process thus gives a continuously increasing metal concentration in the aqueous phase throughout the cloud droplet's lifetime. ${ }^{59} \mathrm{On}$ the contrary, the concentrations dissolved in the second, slow, step are very small and irrelevant in cloud chemistry. ${ }^{59}$

In terms of chemical kinetics, Hoffmann et al. ${ }^{63}$ considered that these two steps of the dissolution process correspond to a double-first-order reaction kinetic, depending, for urban particles, only on the surface area of the solid phase. They calculated rate constants $\left(\mathrm{s}^{-1}\right)$, which turned out to be dependent on the ratio of the amount of solid by weight to the volume of the aqueous phase. The rate constants for the dissolution of the various species vary over 3 orders of magnitude. More generally, the results of Desboeufs et al., ${ }^{112}$ who worked with dust, fly ash, and urban particles, also emphasize that at constant $\mathrm{pH}$ a dissolution in two kinetic steps of first-order reactions is observed. However, this kinetic does not depend on surface area, but on the labile fraction of element in the particles and, hence, on the nature of particles. They demonstrate that dissolution rate constants for metals are a function of the source of the metals. Moreover, their work on kinetics demonstrated the $\mathrm{pH}$ dependence of the dissolution rate to be linear and V-shaped, which is typical of the $\mathrm{pH}_{\mathrm{pzc}}$ influence. ${ }^{68,86}$ From these quantitative measurements, a parametrization has been formulated that makes it possible to estimate the rate of dissolution and the dissolved concentrations under fixed conditions.

\section{Transition Metals in Atmospheric Liquid Phases}

\subsection{Oxidation States and Chemical Forms of Transition Metal lons}

\subsubsection{Iron}

In aqueous solution iron is mainly found under two oxidation states, +II and +III, and iron(II) is much more soluble than iron(III). To a minor extent iron is also present in aqueous solution under the oxida-

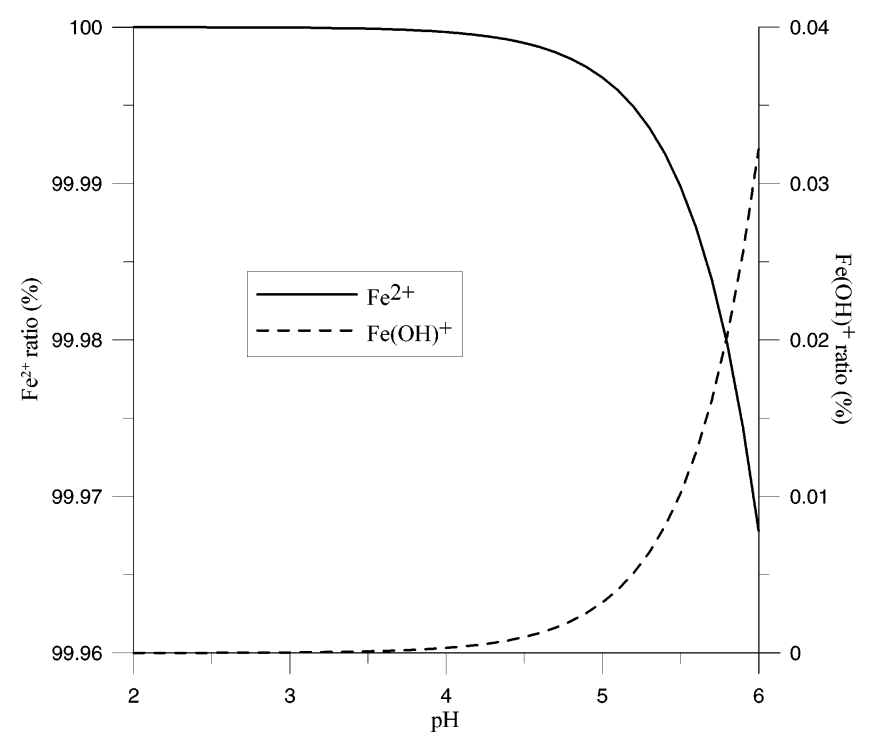

Figure 2. Distribution of iron(II) species as a function of $\mathrm{pH}\left(T=25^{\circ} \mathrm{C}, I=0 \mathrm{M}\right)$.

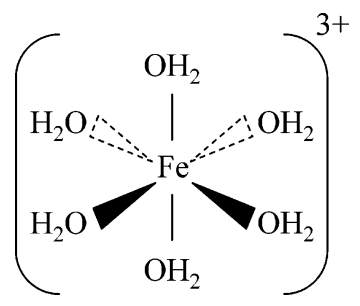

Figure 3. Octahedral structure of the complex [Fe$\left.\left(\mathrm{H}_{2} \mathrm{O}\right)_{6}\right]^{3+}$.

tion state +IV. In this review, by convention, iron(II) and iron(III) will represent the dissolved iron. In the atmospheric liquid phase, iron under its +II oxidation state is mainly present as $\mathrm{Fe}^{2+}$, as is indicated in Figure 2, which gives the ratios of $\mathrm{Fe}^{2+}$ and $\mathrm{Fe}(\mathrm{OH})^{+}$concentrations over total iron(II) concentration according to the $\mathrm{pH}$ of the solution.

A recent study based on irradiation of rainwater samples ${ }^{113}$ points out the possible complexation of iron(II) by organic ligands restricting the oxidation of iron(II) under dark conditions.

The simplest form of iron(III) is the monomer [Fe$\left.\left(\mathrm{H}_{2} \mathrm{O}\right)_{6}\right]^{3+}$, corresponding to the $\mathrm{Fe}^{3+}$ cation surrounded by six water molecules, more commonly called $\mathrm{Fe}^{3+}$ (Figure 3). Hereafter, for the sake of simplification, the water molecules will no longer be mentioned in the chemical formulas.

In the absence of soluble organic compounds, iron(III) is mainly found in aqueous solution as low molecular weight species complexed with the hydroxide anion, such as

- the monomer $\left[\mathrm{Fe}\left(\mathrm{H}_{2} \mathrm{O}\right)_{5}(\mathrm{OH})\right]^{2+}$ or $\mathrm{Fe}(\mathrm{OH})^{2+}$, in which a water molecule is substituted by a hydroxide group;

- the monomer $\left[\mathrm{Fe}\left(\mathrm{H}_{2} \mathrm{O}\right)_{4}(\mathrm{OH})_{2}\right]^{+}$or $\mathrm{Fe}(\mathrm{OH})_{2}{ }^{+}$, in which two water molecules are substituted by two hydroxide groups; and

- the dimer $\left[(\mathrm{Fe})_{2}\left(\mathrm{H}_{2} \mathrm{O}\right)_{8}(\mathrm{OH})_{2}\right]^{4+}$ or $(\mathrm{Fe})_{2}(\mathrm{OH})_{2}{ }^{4+}$, the structure of which is described in Figure 4.

Iron(III) can also be present as water-soluble polymers $\left[\mathrm{Fe}_{n}(\mathrm{OH})_{m}\left(\mathrm{H}_{2} \mathrm{O}\right)_{x}\right]^{(3 n-m)+}$ such as ${ }^{114,115}$ 


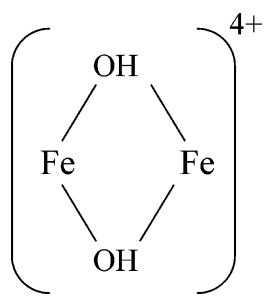

Figure 4. Structure of the dimer $\left[(\mathrm{Fe})_{2}(\mathrm{OH})_{2}\right]^{4+}$.
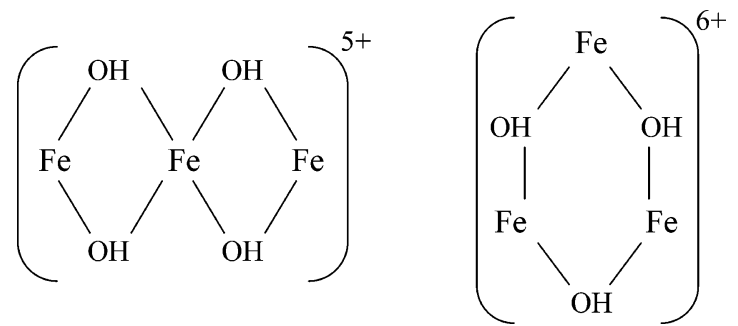

Figure 5. Structures of the trimer complexes $\left[\mathrm{Fe}_{3}(\mathrm{OH})_{4}\right]^{5+}$ and $\left[\mathrm{Fe}_{3}(\mathrm{OH})_{3}\right]^{6+}$.

- trimer complexes, which seem to exist in two possible dihydroxy forms shown in Figure $5,\left[\mathrm{Fe}_{3}-\right.$ $\left.(\mathrm{OH})_{3}\left(\mathrm{H}_{2} \mathrm{O}\right)_{12}\right]^{6+}$ or $\left[\mathrm{Fe}_{3}(\mathrm{OH})_{3}\right]^{6+}$ and $\left[\mathrm{Fe}_{3}(\mathrm{OH})_{4^{-}}\right.$ $\left.\left(\mathrm{H}_{2} \mathrm{O}\right)_{14}\right]^{5+}$ or $\left[\mathrm{Fe}_{3}(\mathrm{OH})_{4}\right]^{5+}$; and

- oligomers, polymers, and soluble iron(III) aggregates.

Iron(III) can precipitate and form oxides such as $\alpha$ - and $\gamma-\mathrm{FeO}(\mathrm{OH})$ (goethite and lepidocrocite), $\alpha$ - and $\gamma-\mathrm{Fe}_{2} \mathrm{O}_{3}$ (hematite and maghemite), or $\mathrm{Fe}(\mathrm{OH})_{3}$ (ferrihydrite). In atmospheric aqueous solution, dissolved iron is unlikely to be found in oxide form.

Iron(III) species have different chemical and photochemical reactivities. The partitioning between these iron(III) species depends on three factors: $\mathrm{pH}$, initial iron(III) concentration, and ionic strength. For a fixed initial iron(III) concentration, partitioning between different chemical forms is governed by equilibria 1 and 2 :

$$
\begin{aligned}
\mathrm{Fe}^{3+}+\mathrm{H}_{2} \mathrm{O} & \leftrightarrow \mathrm{Fe}(\mathrm{OH})^{2+}+\mathrm{H}^{+}, K= \\
6.0 & \times 10^{-3}\left(\text { Brandt and van Eldik }{ }^{27}\right)
\end{aligned}
$$

$$
\begin{aligned}
\mathrm{Fe}(\mathrm{OH})^{2+}+\mathrm{H}_{2} \mathrm{O} \leftrightarrow \mathrm{Fe}(\mathrm{OH})_{2}^{+}+\mathrm{H}^{+}, K= \\
7.6 \times 10^{-4}\left(\text { Brandt and van Eldik }^{27}\right)
\end{aligned}
$$

For $\mathrm{pH}$ lower than 6 (typical cloud droplet $\mathrm{pH}$ ), the three ferric ions $\mathrm{Fe}^{3+}, \mathrm{Fe}(\mathrm{OH})^{2+}$, and $\mathrm{Fe}(\mathrm{OH})_{2}{ }^{+}$coexist in aqueous solution. The partitioning of these three iron(III) monomeric complexes according to the $\mathrm{pH}$ of the solution is represented in Figure 6. This figure was established for an ionic strength equal to zero.

Faust and Hoigné 116 performed similar calculations at an ionic strength of $0.03 \mathrm{M}$ and got a different partitioning of these monomeric iron(III) species, because the ionic strength modifies the equilibrium constant values. ${ }^{27}$ For example, at $\mathrm{pH} 4$ with an ionic strength of $0.03 \mathrm{M}$, the monomeric complex $\mathrm{Fe}(\mathrm{OH})^{2+}$ represents $92 \%$ of the iron(III) monomeric species in solution. ${ }^{116}$ At typical atmospheric $\mathrm{pH}$ (between 3 and 5 ) the most abundant iron species depends on the ionic strength: $\mathrm{Fe}(\mathrm{OH})_{2}{ }^{+}$is the predominant species for ionic strength near zero, whereas the $\mathrm{Fe}(\mathrm{OH})^{2+}$

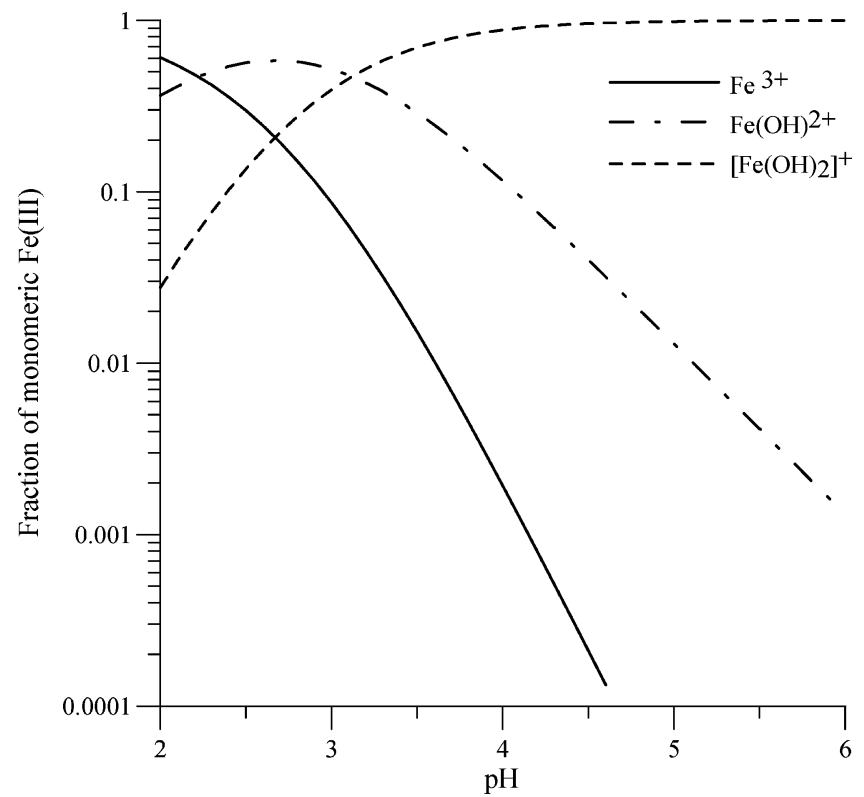

Figure 6. Distribution of iron(III) species as a function of $\mathrm{pH}\left(T=25^{\circ} \mathrm{C}, I=0 \mathrm{M}\right)$.

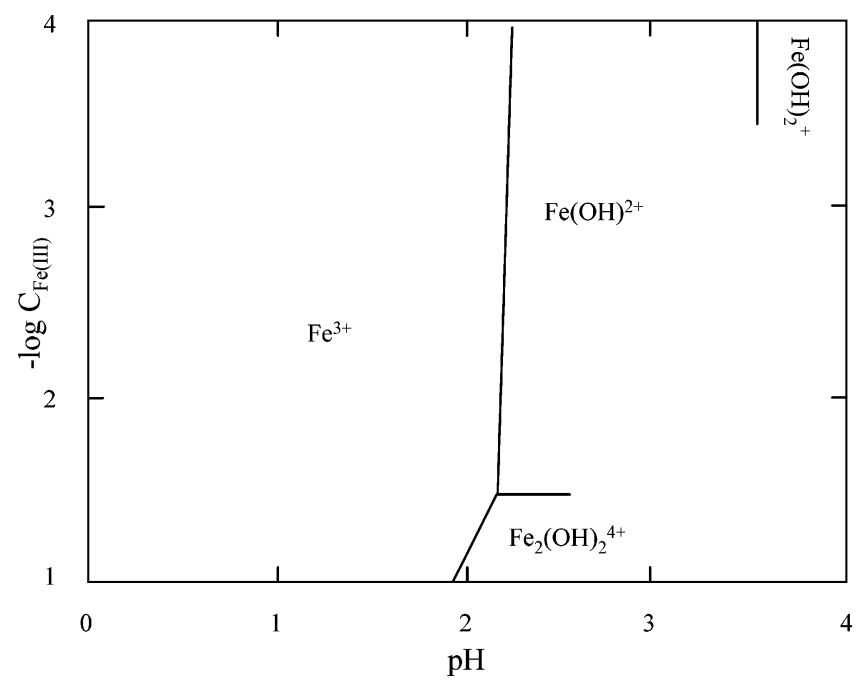

Figure 7. Predominant fields of iron(III) species as a function of $\mathrm{pH}$ and of iron(III) initial concentrations. Reprinted with permission from ref 114. Copyright 1984 American Chemical Society.

fraction rises and becomes paramount as the ionic strength increases.

Figure 7 represents the predominant fields of these complexes according to the $\mathrm{pH}$ and the initial iron(III) concentrations. ${ }^{114}$ The dimeric complex is present only for very acid solutions with high iron concentration $\left(>10^{-2} \mathrm{M}\right)$. This dimeric complex is therefore irrelevant for describing processes occurring in the atmospheric liquid phase. Moreover, the trimeric complex needs higher iron concentrations and lower acidity to exist in solution than dimeric complex ${ }^{117}$ and, then, is also irrelevant in this context.

Iron(III) in aqueous systems may exist in several forms. ${ }^{118}$ Inorganic ligands other than water or hydroxide anions (e.g., $\mathrm{NH}_{4}{ }^{+}, \mathrm{SO}_{4}{ }^{2-}, \mathrm{NO}_{3}{ }^{-}$, and $\mathrm{Cl}^{-}$) and organic ligands (organic acids such as oxalate, acetate, formate, and citrate) can replace some of the water molecules to form a mixed complex of iron(III). In the atmospheric liquid phases, the significance of 
this mixed complex depends on the concentrations of the potential ligands and on the value of the associated stability constant. So far there have been no measurements to determine the chemical forms of iron in so complex a medium as the atmospheric liquid phase. A few studies, however, have used thermodynamic data to try to work out the partitioning of the different chemical iron complexes. Weschler et al. ${ }^{119}$ first tried to determine which complexes might be most expected in atmospheric droplets, as a function of the concentrations of potential ligands in rainwater, the $\mathrm{pH}$ values, and the stability constants of the complexes. They concluded that for rainwater the most probable iron(III) complexes are formed with sulfite and sulfate ions. Hofmann et al., ${ }^{35}$ using similar calculation, showed that $90-95 \%$ of iron(III) is in the form of dihydroxo complex and that very little iron is associated with $\mathrm{SO}_{4}{ }^{2-}$ ions. In their review on transition metal-catalyzed oxidation of sulfur(IV), Brandt and van Eldik ${ }^{27}$ showed that there exist various forms of metal-sulfito complexes (see references therein), but the atmospheric stability and the possible influence of metal-sulfito complexes on atmospheric processes are still unknown. However, all of these theoretical studies neglect the potential complexing capacity of organic compounds with iron. Siefert et al. ${ }^{29}$ calculated the speciation of iron(III) complexes for the concentrations found in seven fog water samples taken in the United States. They show that the predominant iron(III) species are iron(III)oxalate and iron(III)-hydroxy species. For certain samples characterized by high $\mathrm{pH}$ and low oxalate concentrations, calculated iron(III)-oxalate complexes are insignificant. However, their results depend on the stability constant values they are using and on potentially complexing agents considered in their calculation. Willey et al. ${ }^{120}$ showed that iron(III) occurs predominantly complexed with oxalate in continental summer rain, whereas in continental winter rain iron-oxalato and $\mathrm{Fe}(\mathrm{OH})_{2}{ }^{+}$are almost equal in concentration. For marine rain, they show that $\mathrm{Fe}(\mathrm{OH})_{2}{ }^{+}$predominates due to low potential organic ligands. Weschler et al. ${ }^{119}$ noted that a portion of iron can be strongly complexed with chelate ligands (a ligand bound to the metal ion by more than one of its atoms is called a chelate ligand), such as humic substances. These substances are emitted into the atmosphere from the decay of leaves, wood, algae, etc. that can be extracted into aqueous solution. These compounds are excellent chelate ligands. Weschler et al., ${ }^{119}$ Willey et al., ${ }^{120}$ and Kieber et al. ${ }^{121}$ postulated that a fraction of iron may be linked with humic substances in rainwater. Macromolecular substances in aerosols and cloud and fog waters have been characterized in different studies ${ }^{122-125}$ as humic-like substances (HULIS). In conclusion, these studies show that the most important iron(III) complexes in atmospheric liquid water are iron(III)hydroxy species and iron(III)-organic complexes. However, because of the lack of knowledge on the organic compounds speciation in atmospheric liquid phase, it is difficult to draw conclusions on the nature of iron(III)-organic complexes, even if oxalate complexes seem to be usually observed. Finally, further investigations of the chemical speciation of these organic compounds including macromolecular substances are needed.

\subsubsection{Copper and Manganese}

In aqueous solution, manganese is mainly found in the oxidation state $+\mathrm{II}$, which is more soluble than manganese(III). Manganese in its oxidation state of $+\mathrm{III}$ is a very strong oxidizing agent. In the laboratory manganese(III) is not easily usable because it decomposes quickly and forms manganese of two other oxidation states: +IV and +II. Davies ${ }^{126} \mathrm{em}$ phasized that solutions of manganese(III) can be stabilized by increasing the acidity of the medium, by increasing the manganese(II) concentrations, or by the formation of complexes. Manganese can thus be found in its oxidation state of + III in atmospheric aqueous phase phases where the $\mathrm{pH}$ is rather acid and where potential ligands are available.

In aqueous solution, copper is mainly present in the oxidation state of + II, which is the more soluble one. Copper(II) can be reduced to copper(I) in the atmospheric liquid phase, which is a strong reducing agent, but just as for manganese, it is quickly reoxidized to copper(II) by dissolved oxygen.

Although several studies have pointed out that copper and manganese can form many complexes with organic and inorganic ligands in aqueous medium, ${ }^{127-129}$ the chemistry of manganese and copper complexes in the atmospheric liquid phases is poorly documented. In the atmosphere, manganese(III) is present as sulfito complexes, ${ }^{27}$ which can initiate the autoxidation of sulfite to sulfate ${ }^{130,131}$ (cf. section 4.1.2). Several studies have shown that copper is probably complexed by organic ligands ${ }^{132-136}$ and by sulfur, ${ }^{27,137-139}$ but no information is given about their partitioning.

\subsection{Concentrations of Transition Metals}

The comparison of quantitative evaluation of transition metals in the atmospheric liquid phase at various locations and atmospheric conditions would require the use of mixing ratios. However, all available field studies present their results in terms of concentrations and, most of the time, do not provide combined chemical and microphysical data. Moreover, the scope of this review concerns the reactivity of these chemical compounds, for which the use of concentration values is more adequate. For these two reasons, in the following parts, the review on measurements of transition metals in atmospheric liquid phase presents concentration data. The reader should keep in mind this point in the following discussion.

\subsubsection{Iron}

From an atmospheric point of view, iron is probably the most significant transition metal because of its concentration, which is in general much higher than that of the other metals. Its concentration is $\sim 10^{-6}$ mol L ${ }^{-1},^{140}$ but many field experiments indicate that iron concentration can vary from $10^{-9}$ to $10^{-6} \mathrm{~mol} \mathrm{\textrm {L } ^ { - 1 }}$ in raindrops and from $10^{-6}$ to $10^{-3} \mathrm{~mol} \mathrm{~L}^{-1}$ in cloud droplets. ${ }^{141}$

Table 3 summarizes the various and recently available measurements of concentrations for both 
Table 3. Total and Dissolved Iron Concentrations in Rainwater and Fog, Snow, and Cloud Waters (Minimum-Maximum and/or Averaged Value)

\begin{tabular}{|c|c|c|c|c|c|c|c|}
\hline location & $\begin{array}{c}\text { type of } \\
\text { environment }\end{array}$ & $\mathrm{pH}$ & $\begin{array}{c}\text { total } \\
\text { iron }(\mu \mathrm{M})\end{array}$ & $\begin{array}{l}\text { dissolved } \\
\text { iron }(\mu \mathrm{M})\end{array}$ & $\begin{array}{l}\text { dissolved } \\
\text { iron/total } \\
\text { iron }(\%)\end{array}$ & $\begin{array}{l}\text { aqueous } \\
\text { phase }\end{array}$ & ref \\
\hline \multirow[t]{2}{*}{ United Kingdom } & rural & & $0.89-1.79$ & & & rain & Cawse et al. ${ }^{308}$ \\
\hline & rural & & 3.58 & & & rain & Peirson et al. ${ }^{309}$ \\
\hline Germany & urban & & 4.12 & & & rain & Betz $^{310}$ \\
\hline northern Nigeria & rural & & 23.30 & & & rain & Beavington and Cawse ${ }^{311}$ \\
\hline Germany & urban & & 3.80 & & & rain & Gravenhorst et al. ${ }^{312}$ \\
\hline Dakotas and Minnesota & rural (agric area) & $4.89-5.53$ & $0.68-2.85$ & & & rain & Thornton and Eisenreich ${ }^{313}$ \\
\hline Lewes, DE & coastal & & 0.27 & & & rain & Church et al. ${ }^{314}$ \\
\hline Pasadena, CA & urban & 4.4 & 4 & & & rain & Waldman et al. ${ }^{315}$ \\
\hline Mt. Wilson, U.S. & rural & 5.0 & 0.5 & & & & \\
\hline Ontario, Canada & rural & & 0.76 & & & rain & Chan et al. ${ }^{316}$ \\
\hline Leeds, U.K. & urban & & $0.36-1.18$ & & & rain & Radojevic and Clarke ${ }^{317}$ \\
\hline American Samoa & coastal/remote & & 0.016 & & & rain & Arimoto et al. ${ }^{318}$ \\
\hline near the North Sea, U.K. & coastal & 4.52 & $9-670$ & & & rain & Balls $s^{319}$ \\
\hline North Atlantic Ocean & coastal & & 0.35 & & & rain & Church et al. ${ }^{320}$ \\
\hline Aspvreten, Sweden & coastal & & $0.2-3$ & & & rain & $\operatorname{Ross}^{321}$ \\
\hline Bredkälen, Sweden & rural & & $0.03-1.81$ & & & & \\
\hline Tasman Sea, New Zealand & coastal/remote & & 0.047 & & & rain & Arimoto et al. ${ }^{153}$ \\
\hline Rawawa Beach, New Zealand & coastal/remote & & 0.021 & & & & \\
\hline north side, Bantry Bay, Ireland & coastal & $3.8-5.1$ & $0.14 \pm 0.14$ & & & rain & Lim et al. ${ }^{322}$ \\
\hline Darmstadt, Germany & urban & 4.43 & 0.63 & $0.22^{a}$ & 35 & rain & Hofmann et al. ${ }^{35}$ \\
\hline Gross-Rohrheim, Germany & rural & 4.81 & 0.43 & $0.25^{a}$ & 58 & & \\
\hline Dortmund, Germany & semirural & 5.29 & 0.39 & & & rain & Brandt et al. ${ }^{323}$ \\
\hline Witten, Germany & urban & 5.18 & 0.64 & & & & \\
\hline Krakau, Poland & urban & 6.63 & 0.43 & & & rain & Brandt et al. ${ }^{323}$ \\
\hline Plynlimon, Wales & rural & $3.49-6.9$ & & $0.0009-6.68$ & & rain & Wilkinson et al. ${ }^{64}$ \\
\hline Tour du Valat, France & coastal & & 2.6 & $0.29 \pm 0.5$ & $11 \pm 16$ & rain & Guieu et al. ${ }^{304}$ \\
\hline Lamto, Ivory Coast & rural & $4.5-6.4$ & & $<0.02-0.19$ & & rain & Freydier et al. ${ }^{71}$ \\
\hline Kollo, Niger & rural & $4.9-7.3$ & & $<0.02-3.18$ & & & \\
\hline Lannemezan, France & rural & & & $0.03-0.19$ & & & \\
\hline Jaipur, India & urban & 7.57 & & $5.3^{b}$ & & rain & Manoj et al. ${ }^{324}$ \\
\hline Kota, India & urban & 7.47 & & $4.1^{b}$ & & & \\
\hline \multirow[t]{3}{*}{ Wilmington, $\mathrm{NC}$} & $\begin{array}{l}\text { coastal/ } \\
\text { continental }\end{array}$ & 4.6 & $\begin{array}{l}0.3 \text { year } \\
0.6 \text { spring }\end{array}$ & $0.07^{b}$ & 2 & rain & Willey et al. ${ }^{120}$ \\
\hline & & 4.0 & $\begin{array}{l}0.3 \text { summer } \\
0.12 \text { fall }\end{array}$ & & & & \\
\hline & & 4.7 & 0.13 winter & & & & \\
\hline Riyadh, Saudi Arabia & urban & 7.41 & & $0.007-0.40$ & & rain & Alabdula'aly and Khan ${ }^{94}$ \\
\hline Paradize, New Zealand & remote & 4.91 & & $0.037^{e}$ & & rain & Halstead et al. ${ }^{154}$ \\
\hline \multirow[t]{4}{*}{ Erdemli, Turkey ${ }^{g}$} & coastal & $3.5-7.6$ & $0.12-534.1$ & $0.04-26.1^{b}$ & $0.018-99.3$ & rain & Özsoy and Saydam ${ }^{110}$ \\
\hline & & & $3.98^{e}$ & $0.36^{b}$ & 9.6 & & \\
\hline & & & $24.31^{f}$ & $1.47^{b}$ & 25.3 & & \\
\hline & & & $17.33^{g}$ & $1.02^{b}$ & 6.18 & & \\
\hline \multirow[t]{2}{*}{ Raipur, India } & urban & 5.8 & & $0.8-4-3$ & & rain & Patel et al. ${ }^{155}$ \\
\hline & rural & & & 1.3 & & & \\
\hline New Zealand & coastal/remote & & 0.172 & 0.065 & 38 & rain & Kieber et al. ${ }^{78}$ \\
\hline \multirow[t]{4}{*}{ Wilmington, NC } & & & 0.257 (all data) & 0.68 & 26 & rain & Kieber et al. ${ }^{147}$ \\
\hline & & & 0.300 (annual) $^{i}$ & 0.75 & 25 & & \\
\hline & continental & & 0.281 & 0.99 & 35 & & \\
\hline & coastal & & 0.213 & 0.55 & 26 & & \\
\hline Ajlune, Jordan & rural & 6.35 & & $1.64 \pm 1.86$ & & rain & Al-Momani 77 \\
\hline Bermuda Atlantic Time & coastal/remote & 4.4 & 0.314 (Aug) & 0.235 & 75 & rain & Kieber et al. ${ }^{121}$ \\
\hline Series Station & & 4.9 & 0.213 (March) & 0.106 & 50 & & \\
\hline Goslar, Germany & semirural & 6.2 & 0.38 & & & melted snow & Brandt et al. ${ }^{323}$ \\
\hline Dortmund, Germany & semirural & $4.6-5.73$ & $0.28-1.95$ & & & & \\
\hline Witten, Germany & urban & 6.43 & 0.82 & & & & \\
\hline Hajnowka, Poland & rural & 7.06 & 0.25 & & & melted snow & Brandt et al. ${ }^{323}$ \\
\hline Katowic, Poland & urban & 7.15 & 6.27 & & & & \\
\hline Spatind, Norway & rural & 6.30 & 3.64 & & & melted snow & Brandt et al. ${ }^{323}$ \\
\hline $\begin{array}{l}\text { Los Angeles and Bakers- } \\
\text { field, CA }\end{array}$ & urban & $2.2-4.0$ & 26 & & & $\begin{array}{l}\text { fog } \\
3 \text { sites }\end{array}$ & Waldman et al. ${ }^{325}$ \\
\hline Pasadena, CA & Urban & $2.25-5.25$ & $1.6-37.6$ & & & fog & Munger et al. ${ }^{167}$ \\
\hline Lennox, CA & urban & $2.52-5.78$ & $0.58-4.90$ & & & fog & \\
\hline Bakersfield, CA & urban & $2.5-6$ & $0.02-0.2$ & & & fog & Jacob et al. ${ }^{326}$ \\
\hline California coast & coastal & $2.66-6.17$ & $0.0004-0.02$ & & & $\begin{array}{l}\text { fog } \\
8 \text { sites }\end{array}$ & Jacob et al. ${ }^{327}$ \\
\hline suburb of Zürich, Switzerland & urban & $3.21-5.70$ & $0.5-2$ & & & fog & Behra and Sigg25 \\
\hline Zindelen, Zürich, Switzerland & $\begin{array}{l}\text { continental }+ \\
\text { anthropogenic } \\
\text { influence }\end{array}$ & $\begin{array}{l}2.9-7.1 \\
4.8^{e}\end{array}$ & $0.3-91.4$ & & & fog & Joss and Baltensperger ${ }^{241}$ \\
\hline Po Valley, Italy & urban & & $0.5-41.9$ & & & fog & Fuzzi et al. ${ }^{148}$ \\
\hline San Pedro Hill, CA & coastal/urban & $2.2-4.2$ & $1-11.3$ & $0.5-11.3^{a}$ & & fog & Erel et al. ${ }^{143}$ \\
\hline Henninger Flats, CA & rural & $2.5-3.1$ & $2.2-27$ & $2.3-11.6^{a}$ & & & \\
\hline Dübendorf, Switzerland & urban & $4.23-4.56$ & $22.3-231$ & $7-134.3^{b}$ & & fog & Kotronarou and Sigg26 \\
\hline & & 4.37 & $11.9-35.5$ & $10-29.4^{b}$ & & 4 events & \\
\hline & & 6.00 & $11.1-21.1$ & $3.2-6.2^{b}$ & & & \\
\hline & & 6.15 & $9.8-11.5$ & $2.7-3.9^{b}$ & & & \\
\hline
\end{tabular}


Table 3. (Continued)

\begin{tabular}{|c|c|c|c|c|c|c|c|}
\hline location & $\begin{array}{c}\text { type of } \\
\text { environment }\end{array}$ & $\mathrm{pH}$ & $\begin{array}{c}\text { total } \\
\text { iron }(\mu \mathrm{M})\end{array}$ & $\begin{array}{l}\text { dissolved } \\
\text { iron }(\mu \mathrm{M})\end{array}$ & $\begin{array}{l}\text { dissolved } \\
\text { iron/total } \\
\text { iron }(\%)\end{array}$ & $\begin{array}{l}\text { aqueous } \\
\text { phase }\end{array}$ & ref \\
\hline Whiteface Mountain, U.S. & rural & $3.1-4.4$ & $0.32-0.95$ & & & fog & Khwaja et al. ${ }^{328}$ \\
\hline Strasbourg, France & urban & $2.27-6.16$ & $\begin{array}{l}30-1138 \\
306.4\end{array}$ & $\begin{array}{l}13.3-647.2 \\
80\end{array}$ & 26 & fog & Millet et al. ${ }^{89}$ \\
\hline San Pietro, Po Valley, Italy & urban & $2.58-5.78$ & & $1-4.6^{b}$ & & fog & Schwanz et al. ${ }^{142}$ \\
\hline San Joaquin Valley, CA & urban & $6.57-7.09$ & & $5.4-9.8^{c}$ & & fog & Rao and Collett ${ }^{145}$ \\
\hline Bakersfield, CA & urban & $5.39-6.87$ & $\begin{array}{l}0.480-0.640 \\
0.560\end{array}$ & $0.2-0.4$ & $45-65$ & $\begin{array}{l}\text { fog/stratus } \\
\text { cloud }\end{array}$ & Siefert et al. ${ }^{29}$ \\
\hline San Pedro Hill, CA & coastal/urban & $3.2-4.2$ & $\begin{array}{l}0.580-4.900 \\
1.930\end{array}$ & $0.2-1.3$ & $10-47$ & & \\
\hline Whiteface Mountain, NY & rural & $2.92-5.37$ & $\begin{array}{l}<0.020-7.000 \\
1.360\end{array}$ & $0.02-0.7$ & $1-9$ & & \\
\hline Henninger Flats, U.S. & rural & $2.86-2.96$ & $8.15-18.9$ & & & cloud & Waldman et al. ${ }^{315}$ \\
\hline Japan & $\begin{array}{l}\text { rural with anthro- } \\
\text { pogenic influence }\end{array}$ & & 86.4 & & & cloud & Hosono et al. ${ }^{329}$ \\
\hline $\begin{array}{l}\text { Kleiner Feldberg, Frank- } \\
\text { furt, Germany }\end{array}$ & rural & & $0.5-3.4$ & & & cloud & Wobrock et al. ${ }^{330}$ \\
\hline near Munich, Germany & urban & $3.84-6.77$ & $0.09-8.3$ & $0.09-2.15^{c}$ & & cloud & Sinner et al. ${ }^{144}$ \\
\hline Great Dun Fell, U.K. & rural & & 1.8 & & & cloud & Bizjak et al. ${ }^{331}$ \\
\hline Whiteface Mountain, U.S. & rural & $3.1-4.4$ & $0.32-0.95$ & & & cloud & Khwaja et al. ${ }^{328}$ \\
\hline Plynlimon, Wales & rural & $2.92-6.9$ & & $\begin{array}{l}0.0009-41.6 \\
0.73\end{array}$ & & cloud & Wilkinson et al. ${ }^{64}$ \\
\hline Great Dun Fell, U.K. & rural & $3.1-5.8$ & $\begin{array}{l}0.7-24 \\
3.9\end{array}$ & $0.06-1.6^{b}$ & $1-40$ & cloud & Sedlak et al. ${ }^{28}$ \\
\hline Whiteface Mountain, U.S. & rural & $2.9-4.0$ & & $0.08-1.57^{d}$ & & cloud & Arakaki et al. ${ }^{151}$ \\
\hline $\begin{array}{l}\text { Kleiner Feldberg, Frankfurt, } \\
\text { Germany }\end{array}$ & rural & $4.13-4.89$ & $\begin{array}{l}0.2-13.3 \\
0.3-4.9\end{array}$ & $\begin{array}{l}0.05-1.1^{c} \\
0.09-0.54^{c}\end{array}$ & $\begin{array}{l}3.6-40.4 \\
8.2-47.2\end{array}$ & $\begin{array}{l}\text { cloud } \\
2 \text { campaigns }\end{array}$ & Deutsch et al. ${ }^{146}$ \\
\hline Puy de Dome, France & & & & $\begin{array}{l}0.1-9.1^{b} \\
1.8^{b}\end{array}$ & & cloud & Parazols et al. ${ }^{150}$ \\
\hline & marine & 5.9 & & $0.9 \pm 0.7^{b}$ & & & \\
\hline & rural & 5.0 & & $1.6 \pm 0.4^{b}$ & & & \\
\hline & anthropogenic & 3.7 & & $5.3 \pm 3.2^{b}$ & & & \\
\hline & Saharian & 7.3 & & $5.5^{b}$ & & & \\
\hline Whiteface Mountain, NY & rural & $\begin{array}{l}2.85-3.76 \\
2.73-3.77\end{array}$ & $\begin{array}{l}0.6-20.7^{j} \\
0.3-8.3^{k} \\
0.5-7.8^{l} \\
3.0^{m}\end{array}$ & & & cloud & Moore et al. ${ }^{30}$ \\
\hline Davis, CA & agric field & $\begin{array}{l}5.66-6.94 \\
5.47-6.64\end{array}$ & $\begin{array}{l}0.8-7.6^{j} \\
1.6-14.7^{k} \\
0.21-3.28^{l} \\
0.87^{m}\end{array}$ & & & & \\
\hline
\end{tabular}

${ }^{a}$ Dissolved iron. ${ }^{b}$ Filtered iron $=$ dissolved iron + colloidal iron. ${ }^{c}$ Dissolved iron $=$ iron(II) + iron(III). ${ }^{d}$ Dissolved iron(II). ${ }^{e}$ Geometrical average. ${ }^{f}$ Arithmetical average. ${ }^{g}$ Volume weighted mean value. ${ }^{i}$ From March 1998 to March 1999 : without hurricanes or El Niño. ${ }^{j}$ Large drop $\approx 30 \mu \mathrm{m}$ in diameter. ${ }^{k}$ Small drop $\approx 10 \mu \mathrm{m}$ in diameter. ${ }^{l}$ Large/small drop ratio. ${ }^{m}$ Mean of large/small drop ratio.

total iron (particulate iron + dissolved iron) and dissolved iron in the atmospheric aqueous phases (rain, snow, fog, and cloud) (see also Galloway et al. ${ }^{24}$ and references therein for earlier studies).

These measurements show that the concentrations found can vary by 1 order of magnitude, even for the same type of sampling site. However, the dissolved concentrations of trace metals have background levels and maxima that are higher in urban site samples than in those from rural or coastal zones. Moreover, these measurements give an indication of the dissolved iron reaction. There are still many uncertainties in this way of measuring dissolved iron in natural water. In the literature, the dissolved fraction of a trace compound is generally defined as the part passing through a porous membrane with a pore diameter between 0.4 and $0.5 \mu \mathrm{m}$. For iron, this definition is doubtful, because it does not take into account colloidal iron, which passes through the pores of the membrane in considerable quantities. Moreover, reducing the effective diameter of the pores of the membrane during filtration just leads to a loss of soluble iron. Colloidal compounds are defined as particles having diameters varying between 1 and
$1000 \mathrm{~nm}$. Consequently, the traditional definition of dissolved iron includes iron in colloidal form. Using conventional analytical methods for measuring dissolved chemical concentrations, it is impossible to distinguish the fraction of colloidal iron from the actually dissolved iron. Studies that use filters with membrane pores between 0.4 and $0.5 \mu \mathrm{m}$ in diameter measure the dissolved plus the colloidal iron. ${ }^{26,28,78,110,120,}$ ${ }_{142}$ These measurements correspond to "filtered iron", defined as iron $_{\text {filt }}=$ dissolved iron + colloidal iron. The studies using "ultrafiltration" 35 in addition to a membrane pore diameter of $\sim 0.025 \mu \mathrm{m}^{143}$ are assumed to measure dissolved iron only. Sinner et al., ${ }^{144}$ Rao and Collett, ${ }^{145}$ and Deutsch et al. ${ }^{146}$ simultaneously determined dissolved iron(II) and iron(III) concentrations. In all of these studies, the total dissolved iron is determined as the sum of dissolved iron(II) and iron(III). Table 3 indicates which kind of dissolved iron has been actually measured. Hofmann et al..$^{35}$ examined two ultrafiltered rain samples collected in Germany and reported the fraction of colloidal iron as $0 \%$ in one sample and $13 \%$ in the other. Kieber et al. ${ }^{147}$ assessed the importance of colloidal iron during 22 rain events collected at 
Wilmington, NC,. Because colloids range in size from $10^{-6}$ to $10^{-9} \mathrm{~m}$, colloidal iron concentrations were defined as the difference between 0.4 and $0.1 \mu \mathrm{m}$ filtered iron. Taking all of the data into account, they showed that colloidal iron represents $24 \%$ of the total dissolved iron or $13 \%$ of total iron. In studying Hurricane Bonnie as a particular marine-dominant rain event, the contribution of colloidal iron to dissolved iron (18\%) was found to be lower than in the other rain events. These last two studies indicated that colloidal material makes up a small but variable component of the total iron in rain.

Field measurements of total iron in fogs and clouds exhibit high variability: between 9.8 and $231 \mu \mathrm{M}$ in Dübendorf, Switzerland (a suburb of Zurich), ${ }^{26}$ and from 0.5 to $41.9 \mu \mathrm{M}$ in the Po Valley in Italy. ${ }^{148}$ All of these studies were performed in the atmospheric boundary layer and near such sources of heavy pollution as big cities or industrial areas. Measurements taken in areas such as the Palos Verdes peninsula, California, ${ }^{143}$ or Great Dun Fell in England ${ }^{28}$ far from direct sources of pollution, exhibit lower total iron concentrations: between 1.0 and 11.3 $\mu \mathrm{M}$ for the American site and between 0.7 and $24 \mu \mathrm{M}$ for the British one. At Great Dun Fell dissolved iron concentrations were also measured and varied between 0.06 and $1.6 \mu \mathrm{M}$, which represents between 1 and $40 \%$ of total iron. Rao and Collett ${ }^{145}$ measured dissolved iron concentrations in cloud water sampled using a two-stage impactor with diameters for small droplets between 4 and $23 \mu \mathrm{m}$. Their samples were collected from coastal stratus and stratocumulus clouds, orographic clouds, and radiation fogs in different areas of the United States. Samples taken in orographic clouds and in coastal clouds showed higher iron concentrations in large drops, whereas iron concentrations were higher in the small drops of fogs. The larger iron concentration observed in large drops in rural areas is explained by the crustal origin of the coarse particle mode. In fogs, iron is mainly in the accumulation particle mode, which originates from local industrial sources. Similar measurements were performed by Moore et al.$^{30}$ with the Colorado State University 5-Stage Cloud Water Collector during field campaigns on orographic clouds (Whiteface Mountain, NY) and on radiation fogs (Davis, CA). On the one hand, this study showed higher iron concentrations in larger drops for the orographic cloud sampled in a rural area, whereas higher concentrations of iron were observed in small drops of the radiation fogs sampled in a polluted area. The latter result, which applies only to fogs, is linked to a small amount of crustal/large aerosol precursor. Measurements were taken at the top of the Puy de Dôme mountain (elevation, 1465 m; central France): 149,150 147 cloud water samples during 34 cloud events were collected over a period of 4 years. The total dissolved iron concentrations ranged from 0.1 to 9.1 $\mu \mathrm{M}$, and the most frequently encountered concentrations were for the tropospheric background, ranging from 0.2 to $1.6 \mu \mathrm{M}$. For a liquid water content (LWC) of $0.3 \mathrm{~g} \mathrm{~m}^{-3}$ (average value at the Puy de Dôme for marine events), the iron concentration corresponded to $3-30 \mathrm{ng} \mathrm{m}^{-3}$ of air during the marine events.
However, in different meteorological conditions (under continental flux), a subsequent continental or anthropogenic component can be superimposed and iron concentrations could reach several hundreds of $\mathrm{ng} \mathrm{m}{ }^{-3}$. The concentration measured at this location was generally quite low in comparison with measurements at other free tropospheric and marine sites ${ }^{28,143}$ and were in the same range as experiments performed in southern Germany ${ }^{144}$ and in samples from Whiteface Mountain. ${ }^{151}$ The concentration of dissolved iron is linked to the air mass origin: during polluted events, concentrations of dissolved iron could reach nearly $10 \mu \mathrm{M}$, whereas under marine conditions, the mean value of dissolved iron was $\sim 1 \mu \mathrm{M}$. This correlation between the air mass origin and the iron concentration has been confirmed by the good correlation between conductivity and total dissolved iron concentration. For particular Saharan dust events, the relatively low concentration of dissolved iron $(5.5 \mu \mathrm{M})$ as compared to the iron content of Saharan aerosol at the same site ${ }^{152}$ reflects the fact that a small fraction of iron in desert dust can be dissolved in water..$^{59}$

Iron concentrations in rainwater also show strong variability. In general, due to the more dilute solution, iron concentrations in rainwater are lower than those measured in cloud and fog waters. Willey et al. ${ }^{120}$ showed a seasonal and diurnal variability for iron concentrations measured in precipitation sampled in Wilmington, NC. Total iron concentrations and particulate iron concentrations are higher during spring and summer than in fall and winter. Because average wind intensity is stronger during winter when the concentrations of total iron are lowest, the team concluded that resuspension of soil particles by wind is not a dominant factor in seasonal iron variation. The diurnal variation in this study shows that particulate iron concentrations are on average 3 times higher during the afternoon than the rest of the day. This pattern probably reflects the importance of convection, prevalent during the afternoon. Kieber et al. ${ }^{78}$ showed that the volume-weighted total iron concentration measured in rainwater in southern New Zealand during summer is half of the value for summer rain in Wilmington, $\mathrm{NC},{ }^{120,147}$ a result that reflects the continental influence in Wilmington. Moreover, they showed that total iron concentrations in southern New Zealand are higher than in previous studies done in the north. ${ }^{153}$ This result is explained by the influence of summer dust plumes coming from Australia and affecting southern New Zealand to a greater extent than the north. In addition, Halstead et al. ${ }^{154}$ performed measurements of total iron concentrations in New Zealand in fall and winter and got lower values than those of Kieber et al. ${ }^{78}$ This demonstrates seasonal variability. Kieber et al. ${ }^{147}$ sought to evaluate the influence of a storm origin on iron concentrations measured in Wilmington (United States) rains by subdividing rain events according to their coastal or continental origin. They showed that continental storms have greater total iron concentrations than coastal storms, suggesting significant terrestrial inputs of iron into the troposphere. They also measured total iron concentration during El 
Niño rains during the winter of 1997-1998; these samples contained significantly less total iron concentration than all of the other rain events, including coastal storms. The authors suggest that these lower concentrations result from smaller terrestrial and anthropogenic inputs in the marine-dominant El Niño rains. Patel et al. ${ }^{155}$ measured dissolved iron concentrations in rainwater for two types of air mass and found that the concentration level decreased by $16-63 \%$ between the urban and rural sites studied. Kieber et al. ${ }^{121}$ investigated the seasonal variation in total iron concentration in rainwater sampled at the Bermuda Atlantic Time Series Station (BATS). They observed a higher total iron concentration in August than in March. Analysis of the back-trajectory for the sampled events indicates that the air mass in August came from the westerlies off Africa and hence contained high concentrations of Saharan dust, whereas most of the March air masses came from North America. The signature of a North American origin for air masses in the March rainwater at BATS is confirmed by the similarity in total iron concentrations observed at BATS and at North American coastal sampling sites. ${ }^{120,147}$ These observations on the total iron concentrations measured at BATS suggest that there is a higher content of iron in African dust particles than in continental particles.

Generally, the most polluted clouds, fogs, and precipitations present the highest total iron concentrations. The amount of iron in the atmospheric liquid phase is the result of the interaction between many factors, such as synoptic weather conditions, type of air mass, emissions, etc. Measurements of the dissolved iron fraction exhibit great variability and depend on additional factors such as solution $\mathrm{pH}$, aerosol particle type, and cloud lifetime.

\subsubsection{Copper and Manganese}

Manganese and copper are the two other important transition metals in atmospheric aqueous chemistry. Copper partly governs $\mathrm{HO}_{x}$ concentration in the liquid phase, and manganese can have a significant influence on sulfate production. Available measurements of their total (dissolved + particulate) and dissolved concentrations in different atmospheric liquid phases (raindrops, clouds, and fogs) are listed in Table 4 for copper and in Table 5 for manganese.

These studies show that total copper and manganese concentrations are generally lower than iron concentrations (between 10 and 100 times lower). Some studies, however, have yielded higher concentrations for copper than for iron. Moore et al. ${ }^{30}$ observed total copper concentrations as high as 1.2 $\mu \mathrm{M}$ in radiation fogs at Davis, CA; measurements previously done in San Joaquin Valley fogs had shown copper concentrations of up to $1.3 \mu \mathrm{M} .^{156-158}$ For these series of measurements, iron concentrations were in the same range as copper, and the high copper concentrations were attributed to agricultural pest control. Globally, polluted clouds, fogs, and rains exhibit the highest concentrations of copper and manganese. Due to the dilution effect and because impaction scavenging of aerosol particles is less efficient than nucleation scavenging, ${ }^{159}$ concentra- tions in rainwater are typically lower than those observed in fog and cloud water samples. The study by Moore et al. ${ }^{30}$ is the only one to focus on the connection between copper and manganese concentrations and the drop in radius size. They showed that under rural conditions (orographic clouds at Whiteface Mountain, NY), manganese concentrations are higher in the larger drops. This is explained by the crustal origin of the coarse particle mode, which leads to the formation of large drops. Under polluted conditions (radiation fogs at Davis, CA), small drops exhibit higher manganese concentrations, because manganese, like iron, is mainly in the accumulation particle mode, which originates from local industrial sources. For copper, relatively elevated concentrations were observed in both large and small drops in radiation fogs at Davis, and size dependence varied both between and within the events. The authors indicate that further investigations of copper concentrations are needed in polluted areas such as Davis, CA.

The recent study of Kieber et al. ${ }^{136}$ has shown that the majority of copper in rainwater sampled in North Carolina in the United States is dissolved. The opposite is true for iron, almost $75 \%$ of which is in the particulate phase. An earlier study also found the majority of copper in rainwater in the dissolved form (76\%). ${ }^{82}$ A similar conclusion was obtained by Sedlak et al., ${ }^{28}$ who found that $65 \%$ of the copper was in dissolved form in cloud water at Great Dun Fell, U.K. These series of studies show that copper in atmospheric liquid phases is preferentially dissolved rather than in particulate phase.

A large fraction of copper seems to be present as organic and inorganic complexes in the atmospheric liquid phases ${ }^{132,134-136}$ as well as in surface water. ${ }^{160-163}$ Laboratory experiments have shown that organically and inorganically complexed copper can be a significant sink of $\mathrm{HO}_{2} / \mathrm{O}_{2}{ }^{-}$in seawater ${ }^{161,162}$ and in aqueous solutions representative of atmospheric water ${ }^{164}$ but to a minor extent compared to free copper ions.

Just as for iron, these measurements exhibit a high variability due to interactions between several factors, such as meteorological conditions, type of air mass, and emissions. The measured dissolved fractions also cover a wide range, depending on $\mathrm{pH}$, aerosol particle type, and cloud lifetime.

\subsection{Redox Speciation of Transition Metals in Atmospheric Liquid Phases}

\subsubsection{Definition}

In this section the term speciation will refer to the distinction among various oxidation states of a chemical element. The term $f(\mathrm{Fe}(\mathrm{II}))$ represents the ratio between the concentration of iron in its oxidation state $(+\mathrm{II})$ and the concentration of dissolved iron:

$$
f(\mathrm{Fe}(\mathrm{II}))=\frac{[\operatorname{iron}(\mathrm{II})]}{([\operatorname{iron}(\mathrm{II})]+[\operatorname{iron}(\mathrm{III})])}
$$

\subsubsection{Iron Speciation: Field Measurements}

The reactivity of dissolved iron depends on its oxidation state and on the presence of complexes. In 
Table 4. Total and Dissolved Copper Concentrations in Rainwater and Fog, Snow, and Cloud Waters (Minimum-Maximum and/or Averge Value)

\begin{tabular}{|c|c|c|c|c|c|c|c|}
\hline location & $\begin{array}{c}\text { type of } \\
\text { environment }\end{array}$ & $\mathrm{pH}$ & $\begin{array}{c}\text { total } \\
\text { copper }(\mu \mathrm{M})\end{array}$ & $\begin{array}{l}\text { dissolved } \\
\text { copper }(\mu \mathrm{M})\end{array}$ & $\begin{array}{l}\text { dissolved } \\
\text { copper/total } \\
\text { copper }(\%)\end{array}$ & $\begin{array}{l}\text { aqueous } \\
\text { phase }\end{array}$ & ref \\
\hline North Dakota and Minnesota & $\begin{array}{l}\text { rural (agric } \\
\text { area) }\end{array}$ & $4.89-5.53$ & $0.03-0.06$ & & & rain & Thornton and Eisenreich ${ }^{313}$ \\
\hline $\begin{array}{l}\text { southeast of the Appalachian } \\
\text { Mountains, U.S. }\end{array}$ & rural & & $0.0006-0.0038$ & & & rain & Lindberg and Turner ${ }^{332}$ \\
\hline Lewes, DE & coastal & & 0.01 & & & rain & Church et al. ${ }^{314}$ \\
\hline \multicolumn{8}{|l|}{ Ontario, Canada } \\
\hline south & rural & & 0.025 & & & rain & Chan et al. ${ }^{316}$ \\
\hline center & & & 0.022 & & & & \\
\hline north & & & 0.025 & & & & \\
\hline area near the North Sea, U.K. & coastal & 4.52 & $0.3-13$ & & & rain & Balls $^{319}$ \\
\hline Aspvreten, Sweden & coastal & & $0.0095-0.27$ & & & rain & $\operatorname{Ross}^{321}$ \\
\hline Bredkälen, Sweden & rural & & $0.0063-0.09$ & & & & \\
\hline Darmstadt, Germany & urban & 4.43 & & 0.03 & & rain & Hofmann et al. ${ }^{35}$ \\
\hline Gross-Rohrheim, Germany & rural & 4.81 & & 0.03 & & & \\
\hline north side, Bantry Bay, Ireland & coastal & $3.8-5.1$ & $0.013 \pm 0.013$ & & & rain & Lim et al. ${ }^{322}$ \\
\hline Dortmund, Germany & semirural & 5.29 & 0.44 & & & rain & Brandt et al. ${ }^{323}$ \\
\hline Witten, Germany & urban & 5.18 & 0.37 & & & & \\
\hline Krakau, Poland & urban & 6.63 & 0.31 & & & rain & Brandt et al. ${ }^{323}$ \\
\hline Capo Cavello, Corsica, France & coastal & $4-6.3$ & $<0.007-0.12$ & $0.004-0.096$ & 48 & rain & Lim et al. ${ }^{83}$ \\
\hline Tudor Hill, Bermuda & coastal & & $<0.001-0.026$ & $<0.0007-0.021$ & 84 & & \\
\hline Hungary & rural & & & $0.057-0.17$ & & $\begin{array}{l}\text { rain } \\
3 \text { sites }\end{array}$ & Horvath et al. ${ }^{333}$ \\
\hline Norwich, U.K. & urban & & $0.0095-0.03$ & & & rain & Spokes et al. 134 \\
\hline Dexter, MI & semirural & & & 0.013 & & rain & Landis and Keeler 334 \\
\hline Preston, U.K. & urban & & 0.04 & 0.01 & 26 & rain & Nimmo and Fones ${ }^{135}$ \\
\hline Grange-over-sands, U.K. & coastal & & 0.033 & 0.095 & 32 & & \\
\hline Cap Ferrat peninsula, France & coastal & & $\begin{array}{l}0.009-0.21 \\
0.067\end{array}$ & $\begin{array}{l}0.003-0.21 \\
0.051\end{array}$ & $\begin{array}{l}33-96 \\
76\end{array}$ & rain & Chester et al. ${ }^{82}$ \\
\hline Plynlimon, Wales & rural & $3.49-6.9$ & & $\begin{array}{l}0.0013-6.7244 \\
0.026\end{array}$ & & rain & Wilkinson et al. ${ }^{64}$ \\
\hline Cap Ferrat, Tour du & coastal & & 0.059 & $0.036-0.05$ & 82 & rain & Guieu et al. ${ }^{304}$ \\
\hline Valat, France & & & 0.026 & 0.02 & $71 \pm 21$ & & \\
\hline Paris, France & urban & & & $0.02-0.05$ & & rain & Garnaud et al. ${ }^{335}$ \\
\hline Arcachon, France & coastal & & & 0.033 & & rain & Maneux et al. ${ }^{336}$ \\
\hline Porspoder, France & coastal & & & 0.007 & & rain & Cabon 337 \\
\hline Jaipur, India & urban & 7.47 & & 0.32 & & rain & Manoj et al. ${ }^{324}$ \\
\hline Kota, India & urban & 7.57 & & 0.12 & & & \\
\hline Higashi-Hiroshima, Japan & urban & 4.55 & & $\begin{array}{l}0.001-0.164 \\
0.01\end{array}$ & & rain & Takeda et al. ${ }^{58}$ \\
\hline North Sea coast & coastal & 4.4 & & 0.27 & & rain & Jambers et al. ${ }^{338}$ \\
\hline Paradize, New Zealand & remote & 4.91 & & 0.0002 & & rain & Halstead et al. ${ }^{154}$ \\
\hline Chesapeake Bay, U.S. & coastal & & & 0.017 & & rain & Kim et al. ${ }^{339}$ \\
\hline Raipur, India & $\begin{array}{l}\text { urban } \\
\text { rural }\end{array}$ & 5.8 & & $\begin{array}{l}1.07-9.38 \\
1.10\end{array}$ & & rain & Patel et al. ${ }^{155}$ \\
\hline Massif, central France & rural & $4.29-6.31$ & & $0.007-0.394$ & & rain & Roy and Négrel ${ }^{340}$ \\
\hline Montpellier, France & coastal & & & $0.008-0.046$ & & rain & Luck and Ben Othman ${ }^{67}$ \\
\hline Ajlune, Jordan & rural & 6.35 & & $0.05 \pm 0.02$ & & rain & Al-Momani 77 \\
\hline $\begin{array}{l}\text { Cap Gris-Nez, Eastern } \\
\text { Channel, France }\end{array}$ & coastal & & & 0.001 & & rain & Deboudt et al. ${ }^{341}$ \\
\hline Goslar, Germany & semirural & 6.2 & 0.24 & & & melted snow & Brandt et al. ${ }^{323}$ \\
\hline Dortmund, Germany & semirural & $4.6-5.73$ & $0.13-0.24$ & & & & \\
\hline Witten, Germany & urban & 6.43 & 0.12 & & & & \\
\hline Hajnowka, Poland & rural & 7.06 & 0.32 & & & melted snow & Brandt et al. ${ }^{323}$ \\
\hline Katowic, Poland & urban & 7.15 & 0.15 & & & & \\
\hline Spatind, Norway & rural & 6.30 & 0.91 & & & melted snow & Brandt et al. 323 \\
\hline Pasadena, CA & urban & $2.25-5.25$ & $0.02-2.2$ & & & fog & Munger et al. ${ }^{167}$ \\
\hline Lennox, CA & urban & $2.52-5.78$ & $0.14-22$ & & & fog & \\
\hline Dübendorf, Zürich, Switzerland & urban & $2-6$ & $\begin{array}{l}0.3-10.6 \\
1.9\end{array}$ & & & fog & Johnson et al. ${ }^{342}$ \\
\hline Zindelen, Zürich, Switzerland & urban & $\begin{array}{l}2.9-7.1 \\
4.8^{f}\end{array}$ & $0-7$ & & & fog & Joss and Baltensperger ${ }^{241}$ \\
\hline Dübendorf, Switzerland & urban & & $\begin{array}{l}0.127-13.5 \\
1.34\end{array}$ & $\begin{array}{l}0.021-4.88^{a} \\
0.69^{a}\end{array}$ & $\begin{array}{l}4-97 \\
52\end{array}$ & fog & Xue et al. ${ }^{133}$ \\
\hline Dübendorf, Switzerland & urban & $\begin{array}{l}4.23-4.56 \\
4.37 \\
6.00 \\
6.15\end{array}$ & $\begin{array}{l}0.8-8.7 \\
0.7-1.2 \\
0.6-0.9 \\
0.2-1.1\end{array}$ & $\begin{array}{l}0.8-6.8 \\
0.3-1.2 \\
0.3-0.9 \\
0.2-0.6\end{array}$ & & fog & Kotronarou and Sigg ${ }^{26}$ \\
\hline Whiteface Mountain, U.S. & rural & $3.1-4.4$ & $\begin{array}{l}0.03-0.121 \\
0.071\end{array}$ & & & fog & Khwaja et al. ${ }^{328}$ \\
\hline Bakersfield, CA & urban & $5.39-6.87$ & $0.011-0.024$ & $0.005-0.015$ & $50-80$ & fog/stratus & Siefert et al. ${ }^{29}$ \\
\hline San Pedro Hill, CA & coastal/urban & $3.2-4.2$ & $0.051-0.21$ & $0.05-0.15$ & $45-100$ & cloud & \\
\hline Whiteface Mountain, NY & rural & $2.92-5.37$ & $0.072-0.371$ & $0.025-0.17$ & $10-100$ & & \\
\hline San Pietro, Po Valley, Italy & urban & $2.58-5.78$ & $0.6-3.3$ & & & fog & Schwanz et al. ${ }^{142}$ \\
\hline near Munich, Germany & urban & $3.84-6.77$ & $0.06-0.58$ & & & cloud & Sinner et al. ${ }^{144}$ \\
\hline
\end{tabular}


Table 4. (Continued)

\begin{tabular}{|c|c|c|c|c|c|c|c|}
\hline location & $\begin{array}{c}\text { type of } \\
\text { environment }\end{array}$ & $\mathrm{pH}$ & $\begin{array}{c}\text { total } \\
\text { copper }(\mu \mathrm{M})\end{array}$ & $\begin{array}{c}\text { dissolved } \\
\text { copper }(\mu \mathrm{M})\end{array}$ & $\begin{array}{c}\text { dissolved } \\
\text { copper/total } \\
\text { copper }(\%)\end{array}$ & $\begin{array}{l}\text { aqueous } \\
\text { phase }\end{array}$ & ref \\
\hline Great Dun Fell, U.K. & rural & & $\begin{array}{l}0.004-0.11 \\
0.026\end{array}$ & $0.0042-0.031$ & $20-100$ & cloud & Sedlak et al. ${ }^{28}$ \\
\hline Plynlimon, Wales & rural & $2.92-6.9$ & & $\begin{array}{l}0.0013-6.7244 \\
0.08\end{array}$ & & cloud & Wilkinson et al. ${ }^{64}$ \\
\hline $\begin{array}{l}\text { Kleiner Feldberg, Frank- } \\
\text { furt, Germany }\end{array}$ & rural & $4.13-4.89$ & $0.063-0.3$ & & & cloud & Deutsch et al. ${ }^{146}$ \\
\hline Davis, CA & agric field & $\begin{array}{l}5.66-6.94 \\
5.47-6.64\end{array}$ & $\begin{array}{l}0.01-1.2^{b} \\
0.008-0.75^{c} \\
0.35-22.7^{d} \\
3.29^{e}\end{array}$ & & & cloud & Moore et al. ${ }^{30}$ \\
\hline
\end{tabular}

${ }^{a}$ Copper(I) concentration. ${ }^{b}$ Large drop $\approx 30 \mu \mathrm{m}$ in diameter. ${ }^{c}$ Small drop $\approx 10 \mu \mathrm{m}$ in diameter. ${ }^{d}$ Large/small drop ratio. ${ }^{e}$ Mean of large/small drop ratio. ${ }^{f}$ Average.

Table 5. Total and Dissolved Manganese Concentrations in Rainwater and Fog, Snow, and Cloud Waters (Minimum-Maximum and/or Average Value)

\begin{tabular}{|c|c|c|c|c|c|c|c|}
\hline location & $\begin{array}{c}\text { type of } \\
\text { environment }\end{array}$ & $\mathrm{pH}$ & $\begin{array}{c}\text { total } \\
\underset{(\mu \mathrm{M})}{\operatorname{mangane}}\end{array}$ & $\begin{array}{l}\text { dissolved } \\
\text { manganese } \\
(\mu \mathrm{M})\end{array}$ & $\begin{array}{c}\text { dissolved } \\
\text { manganese/ } \\
\text { total } \\
\text { manganese }(\%)\end{array}$ & $\begin{array}{l}\text { aqueous } \\
\text { phase }\end{array}$ & ref \\
\hline U.K. & rural & & 0.15 & & & rain & Peirson et al. ${ }^{309}$ \\
\hline U.S. & urban & & 0.22 & & & rain & $\operatorname{Betz}^{310}$ \\
\hline Nigeria & rural & & 0.51 & & & rain & Beavington and Cawse ${ }^{311}$ \\
\hline U.S. & urban & & 0.26 & & & rain & Gravenhorst et al. ${ }^{312}$ \\
\hline North Dakota and Minnesota & $\begin{array}{l}\text { rural } \\
\quad(\text { agric field })\end{array}$ & $4.89-5.53$ & $0.05-0.4$ & & & rain & Thornton and Eisenreich ${ }^{313}$ \\
\hline $\begin{array}{l}\text { southeast of the Appalachian } \\
\text { Mountains, U.S. }\end{array}$ & rural & & $0.02-0.06$ & & & rain & Lindberg and Turner ${ }^{332}$ \\
\hline Lewes, DE & coastal & & 0.025 & & & rain & Church et al. ${ }^{314}$ \\
\hline Ontario, Canada & & & & & & & \\
\hline $\begin{array}{l}\text { south } \\
\text { center } \\
\text { north }\end{array}$ & rural & & $\begin{array}{l}0.085 \\
0.05 \\
0.055\end{array}$ & & & rain & Chan et al. ${ }^{316}$ \\
\hline area near the North Sea, U.K. & coastal & 4.52 & $1.09-21$ & & & rain & Balls $^{319}$ \\
\hline Aspvreten, Sweden & coastal & & $0.036-0.11$ & & & rain & $\operatorname{Ross}^{321}$ \\
\hline Bredkälen, Sweden & rural & & $0.02-0.11$ & & & & \\
\hline Darmstadt, Germnay & urban & 4.43 & 0.054 & 0.053 & 99 & rain & Hofmann et al. ${ }^{35}$ \\
\hline Gross-Rohrheim, Germany & rural & 4.81 & 0.049 & 0.043 & 89 & & \\
\hline Dortmund, Germany & semirural & 5.29 & 0.1 & & & rain & Brandt et al. ${ }^{323}$ \\
\hline Witten, Germany & urban & 5.18 & 0.36 & & & & \\
\hline Krakau, Poland & urban & 6.63 & 0.5 & & & rain & Brandt et al. ${ }^{323}$ \\
\hline Hungary & rural & & & $0.07-0.17$ & & $\begin{array}{l}\text { rain } \\
3 \text { sites }\end{array}$ & Horvath et al. ${ }^{333}$ \\
\hline Dexter, MI & semirural & & & 0.12 & & rain & Landis and Keeler 334 \\
\hline Darmstadt, Germany & urban & $4.13-4.89$ & & $0.007-0.2$ & & rain & Deutsch et al. 103 \\
\hline Plynlimon, Wales & rural & $3.49-6.9$ & & $\begin{array}{l}0.0009-1.06 \\
0.014\end{array}$ & & rain & Wilkinson et al. ${ }^{64}$ \\
\hline $\begin{array}{l}\text { Cap Ferrat, Tour du } \\
\text { Valat, France }\end{array}$ & coastal & & $\begin{array}{l}0.13 \\
0.2\end{array}$ & $\begin{array}{l}0.09 \\
0.15\end{array}$ & $\begin{array}{l}60 \\
63 \pm 28\end{array}$ & rain & Guieu et al. ${ }^{304}$ \\
\hline Lamro, Ivory Coast & rural & $4.9-7.3$ & & $0.0009-0.322$ & & rain & Freydier et al. ${ }^{71}$ \\
\hline Kollo, Niger & rural & $4.5-6.4$ & & $0.008-0.484$ & & & \\
\hline Paradize, New Zealand & remote & 4.91 & & $0.0013^{f}$ & & rain & Halstead et al. ${ }^{154}$ \\
\hline North Sea Coast. U.K. & coastal & 4.4 & & 0.35 & & rain & Jambers et al. ${ }^{338}$ \\
\hline Higashi-Hiroshima, Japan & urban & 4.55 & & $\begin{array}{l}0.003-0.53 \\
0.03\end{array}$ & & rain & Takeda et al. ${ }^{58}$ \\
\hline Jaipur, India & urban & 7.57 & & 0.15 & & rain & Manoj et al. ${ }^{324}$ \\
\hline Kota, India & urban & 7.47 & & 0.31 & & & \\
\hline Raipur, India & $\begin{array}{l}\text { urban } \\
\text { rural }\end{array}$ & 5.8 & & $\begin{array}{l}0.16-4.27 \\
1.13\end{array}$ & & rain & Patel et al. ${ }^{155}$ \\
\hline Montpellier, France & coastal & & & $0.015-0.2$ & & rain & Luck and Ben Othman ${ }^{67}$ \\
\hline Ajlune, Jodran & rural & 6.35 & & $0.038 \pm 0.028$ & & rain & Al-Momani ${ }^{77}$ \\
\hline Goslar, Germany & semirural & 6.2 & 0.24 & & & melted snow & Brandt et al. ${ }^{323}$ \\
\hline Dortmund, Germany & semirural & $4.6-5.73$ & 0.6 & & & & \\
\hline Witten, Germany & urban & 6.43 & 0.61 & & & & \\
\hline Hajnowka, Poland & rural & 7.06 & 0.06 & & & melted snow & Brandt et al. ${ }^{323}$ \\
\hline Katowic, Poland & urban & 7.15 & 0.69 & & & & \\
\hline Spatind, Norway & rural & 6.30 & 0.09 & & & melted snow & Brandt et al. ${ }^{323}$ \\
\hline Pasadena, CA & urban & $2.25-5.25$ & $0.33-2.91$ & & & fog & Munger et al. ${ }^{167}$ \\
\hline Lennox, CA & urban & $2.52-5.78$ & $0.35-14.7$ & & & fog & \\
\hline Bakersfield, CA & urban & $2.5-6$ & $0.00055-0.0095$ & & & fog & Jacob et al. ${ }^{326}$ \\
\hline California coast & coastal & $2.66-6.17$ & $0.00055-0.024$ & & & $\begin{array}{l}\text { fog } \\
8 \text { sites }\end{array}$ & Jacob et al. ${ }^{327}$ \\
\hline Zindelen, Zürich, Switzerland & urban & $2.9-7.14 .8^{e}$ & $0-7.6$ & & & fog & Joss and Baltensperger 241 \\
\hline Po Valley, Italy & urban & & $1.1-11$ & & & fog & Fuzzi et al. ${ }^{148}$ \\
\hline Dübendorf, Switzerland & urban & $\begin{array}{l}4.23-4.56 \\
4.37 \\
6.00 \\
6.15\end{array}$ & $\begin{array}{l}1.3-2.9 \\
0.3-0.9 \\
1.6 \\
2.1-3.1\end{array}$ & & & $\begin{array}{l}\text { fog } \\
4 \text { events }\end{array}$ & Kotronarou and Sigg ${ }^{26}$ \\
\hline
\end{tabular}


Table 5. (Continued)

\begin{tabular}{|c|c|c|c|c|c|c|c|}
\hline location & $\begin{array}{c}\text { type of } \\
\text { environment }\end{array}$ & $\mathrm{pH}$ & $\begin{array}{c}\text { total } \\
\text { manganese } \\
(\mu \mathrm{M})\end{array}$ & $\begin{array}{c}\text { dissolved } \\
\text { manganese } \\
(\mu \mathrm{M})\end{array}$ & $\begin{array}{c}\text { dissolved } \\
\text { manganese/ } \\
\text { total } \\
\text { manganese }(\%)\end{array}$ & $\begin{array}{l}\text { aqueous } \\
\text { phase }\end{array}$ & ref \\
\hline Japan & rural & & 42.26 & & & fog & Hosono et al. ${ }^{329}$ \\
\hline Strasbourg, France & urban & $2.2-6.16$ & $\begin{array}{l}3.46-80 \\
19.8\end{array}$ & $\begin{array}{l}2.5-40 \\
12.7\end{array}$ & 65 & fog & Millet et al. ${ }^{89}$ \\
\hline Whiteface Mountain, U.S. & rural & $3.1-4.4$ & $\begin{array}{l}0.1-0.53 \\
0.24\end{array}$ & & & fog & Khwaja et al. ${ }^{328}$ \\
\hline San Pietro, Po Valley, Italy & urban & $2.58-5.78$ & $0.16-1.5$ & & & fog & Schwanz et al. ${ }^{142}$ \\
\hline Bakersfield, CA & urban & $5.39-6.87$ & $\begin{array}{l}0.001-0.034 \\
0.022\end{array}$ & & & $\begin{array}{l}\text { fog/stratus } \\
\text { cloud }\end{array}$ & Siefert et al. ${ }^{29}$ \\
\hline San Pedro Hill, CA & coastal/urban & $3.2-4.2$ & $\begin{array}{l}0.054-0.240 \\
0.105\end{array}$ & & & & \\
\hline Whiteface Mountain, NY & rural & $2.92-5.37$ & $\begin{array}{l}0.003-0.544 \\
0.104\end{array}$ & & & & \\
\hline $\begin{array}{l}\text { Kleiner Feldberg, Frank- } \\
\text { furt, Germany }\end{array}$ & rural & & $0.04-1.15$ & & & cloud & Wobrock et al. ${ }^{330}$ \\
\hline near Munich, Germany & urban & $3.84-6.77$ & $>1.42$ & & & cloud & Sinner et al. ${ }^{144}$ \\
\hline Great Dun Fell, U.K. & rural & & 0.64 & & & cloud & Bizjak et al. ${ }^{331}$ \\
\hline Plynlimon, Wales & rural & $2.92-6.9$ & & $\begin{array}{l}0.0009-20.5 \\
0.183\end{array}$ & & cloud & Wilkinson et al. ${ }^{64}$ \\
\hline $\begin{array}{l}\text { FELDEX'97 Kleiner } \\
\text { Feldberg, Frank- } \\
\text { furt, Germany }\end{array}$ & rural & $4.13-4.89$ & $0.033-0.94$ & & & cloud & Deutsch et al. ${ }^{146}$ \\
\hline Whiteface Mountain, NY & rural & $\begin{array}{l}2.85-3.76 \\
2.73-3.77\end{array}$ & $\begin{array}{l}0.03-3.1^{a} \\
0.02-0.5^{b} \\
0.7-10.1^{c} \\
3.7^{d}\end{array}$ & & & cloud & Moore et al. ${ }^{30}$ \\
\hline Davis, CA & agric field & $\begin{array}{l}5.66-6.94 \\
5.47-6.64\end{array}$ & $\begin{array}{l}0.04-0.5^{a} \\
0.08-0.7^{b} \\
0.16-1.4^{c} \\
0.62^{d}\end{array}$ & & & & \\
\hline
\end{tabular}

${ }^{a}$ Large drop $\approx 30 \mu \mathrm{m}$ in diameter. ${ }^{b}$ Small drop $\approx 10 \mu \mathrm{m}$ in diameter. ${ }^{c}$ Large/small drop ratio. ${ }^{d}$ Mean of large/small drop ratio. ${ }^{e}$ Average. ${ }^{f}$ Acidified rainwater.

the aqueous phase, the ratio between the concentrations of iron(II) and iron(III) is a good indicator of the oxidoreduction potential in hydrometeors, and, by determining the reactivity of iron, it thus influences tropospheric oxidant capacity. Several studies have looked into the evaluation of iron speciation in cloud and fog droplets as well as in rain and snow. ${ }^{25,28,142,143,146,165}$ Table 6 summarizes the measurements of the fraction of iron present as iron(II) in atmospheric liquid phases, which is a good indicator of the iron speciation.

Most of these studies show that a significant fraction (between 10 and 90\%) of the dissolved iron is present in its oxidation state of $+\mathrm{II}$ in fog and cloud droplets and in raindrops. Overall, this review of available measurements of iron speciation has turned up no correlation with the air mass type.

Willey et al. ${ }^{120}$ determined the seasonal variation of iron speciation, with the highest concentrations of iron(III) showing up during spring and summer. However, iron(II) concentration exhibits no significant seasonal variation, which seems surprising because iron(II) is efficiently produced through photochemical processes. Willey et al. ${ }^{120}$ assumed that the higher iron(III) concentrations during spring and summer originate from the dissolution of particulate iron rather than from iron(II) oxidation. Kieber et al. ${ }^{121}$ investigated the seasonal variation of iron speciation in rainwater sampled at the Bermuda Atlantic Time Series Station over the open ocean. They observed a higher abundance of iron(II) in August than in March, most likely resulting from increased solar radiation during the summer months at BATS.
Some of these studies examined the diurnal variation of iron speciation. Available measurements taken continuously over $24 \mathrm{~h}$ exhibit an iron(II) concentration higher during the day than during the night. ${ }^{25,29,143,146}$ The study of Siefert et al. ${ }^{29}$ exhibited higher daytime ratios of iron(II)/total iron than at night. Although these results are consistent with the photochemical reactions that reduce iron(III) into iron(II), iron(II) rarely accounted for $>50 \%$ of total iron even during the day. This result indicates that part of the iron is unavailable for photochemical reactions. The authors indicate that this iron fraction can either be in the aqueous phase as a complex of iron(III) with a ligand that does not undergo a charge tranfer redox reaction, or in the solid phase as an unreactive iron-oxyhydroxide, or bound in the matrix of an alumino-silicate mineral. The study of Willey et al. ${ }^{120}$ yielded a fraction of iron(II) during the afternoon, probably due to efficient photochemical conversion of iron(III) into iron(II). Kieber et al. ${ }^{147}$ found average iron(II) concentrations of $\sim 40 \mathrm{nM}$ in rainwater sampled during the austral summer in New Zealand, whereas iron(III) concentrations were not detectable (i.e., under the detection limit of 10 $\mathrm{nM}$ ). These weak iron(III) concentrations are due to the efficient production of iron(II) via photolysis of the iron(III) complexes. This process becomes dominant here because of the strong UV irradiation measured during these summertime measurement series. Kieber et al. ${ }^{121}$ observed a photochemically induced diurnal variation of iron(II) and iron(III) in rainwater sampled at BATS over the Atlantic ocean similar to the results of these previous studies. ${ }^{78,120,147}$ Özsoy and Saydam ${ }^{110}$ found similar results in rain- 
Table 6. Measured Iron(II)/[Iron(II) + Iron(III)] [f(Fe(II))] Ratios in the Atmospheric Liquid Phases (Minimum-Maximum and/or Average Value)

\begin{tabular}{|c|c|c|c|c|c|c|}
\hline location & air mass type & $\begin{array}{l}\text { aqueous } \\
\text { phase }\end{array}$ & date & $\begin{array}{l}\text { day/ } \\
\text { night }\end{array}$ & $\begin{array}{c}f(\mathrm{Fe}(\mathrm{II})) \\
(\%)\end{array}$ & ref \\
\hline suburb of Zürich, Switzerland & anthropogenic & cloud & Oct 1989 & $\begin{array}{l}\text { day } \\
\text { night }\end{array}$ & $\begin{array}{l}90^{a} \\
20-60^{a}\end{array}$ & Behra and Sigg 25 \\
\hline San Pedro Hill, Palos Verdes, CA & $\begin{array}{l}\text { marine with anthro- } \\
\text { pogenic influence }\end{array}$ & cloud & July 1991 & day & $70-80$ & Pehkonen et al. ${ }^{165}$ \\
\hline Dubendorf, Switzerland & anthropogenic & fog & $\begin{array}{l}\text { Nov } 1991 \\
\text { Feb } 1992 \\
\text { Nov } 1992\end{array}$ & & $\begin{array}{l}70-79 \\
93 \\
0-38\end{array}$ & Kotronarou et al. ${ }^{26}$ \\
\hline $\begin{array}{l}\text { plain of Henninger, Mount } \\
\text { Wilson, U.S. }\end{array}$ & continental & cloud & $\begin{array}{l}\text { June 27, } 1991 \\
\text { May } 30,1991\end{array}$ & $\begin{array}{l}\text { day } \\
\text { night }\end{array}$ & $\begin{array}{l}76 \\
26-55\end{array}$ & Erel et al. ${ }^{143}$ \\
\hline near Munich, Germany & anthropogenic & cloud & May-July 1992 & day & $1-60$ & Sinner et al. ${ }^{144}$ \\
\hline Great Dun Fell, U.K. & continental & cloud & May 1993 & $\begin{array}{l}\text { day } \\
\text { night }\end{array}$ & $\begin{array}{l}40-80^{b} \\
0-40^{b}\end{array}$ & Sedlak et al. ${ }^{28}$ \\
\hline San Pietro, Po Valley, Italy & anthropogenic & cloud & Nov 1994 & night & $45-60$ & Schwanz et al. ${ }^{142}$ \\
\hline $\begin{array}{l}\text { San Joaquin Valley CA } \\
\text { Whiteface Mountain, NY }\end{array}$ & $\begin{array}{l}\text { anthropogenic } \\
\text { continental }\end{array}$ & $\begin{array}{l}\text { fog } \\
\text { fog/stratus } \\
\text { clouds }\end{array}$ & Feb 1996 & $\begin{array}{l}\text { night } \\
\text { day } \\
\text { night }\end{array}$ & $\begin{array}{l}7-12 \\
28(2-100)^{a} \\
50-100^{d} \\
<3-<24^{a}\end{array}$ & $\begin{array}{l}\text { Rao and Collett }{ }^{145} \\
\text { Siefert et al. }{ }^{29}\end{array}$ \\
\hline San Pedro Hill, CA & $\begin{array}{l}\text { marine with anthro- } \\
\text { pogenic influence }\end{array}$ & & & night & $<3-<11^{a}$ & \\
\hline Bakersfield, CA & anthropogenic & & & night & $\begin{array}{l}<9-<13^{a} \\
<17-<23^{d}\end{array}$ & \\
\hline Wilmington, NC & $\begin{array}{l}\text { marine with anthro- } \\
\text { pogenic influence }\end{array}$ & rain & July 1997-June 1999 & $\begin{array}{l}\text { day } \\
\text { night }\end{array}$ & $\begin{array}{l}\text { av: } 56 \pm 10 \\
58 \\
40\end{array}$ & Willey et al. ${ }^{120}$ \\
\hline $\begin{array}{l}\text { Kleiner Feldberg, Frankfurt, } \\
\text { Germany }\end{array}$ & $\begin{array}{l}\text { continental with } \\
\text { anthropogenic } \\
\text { influence }\end{array}$ & cloud & Oct-Nov 1995 & $\begin{array}{l}\text { day } \\
\text { night }\end{array}$ & $\begin{array}{l}62 \\
50\end{array}$ & Deutsch et al. ${ }^{146}$ \\
\hline Erdemli, Turkey & $\begin{array}{l}\text { marine with anthro- } \\
\text { pogenic influence }\end{array}$ & rain & Feb 1996-June 1997 & $\begin{array}{l}\text { day } \\
\text { night }\end{array}$ & $\begin{array}{l}\text { av: } 78.2 \\
76^{e} \\
67^{f}\end{array}$ & Özsoy and Saydam 110 \\
\hline New Zealand & marine & rain & Jan-March 1999 & & av: $24 \mathrm{a}^{c}$ & Kieber et al. ${ }^{78}$ \\
\hline Wilmington, NC & $\begin{array}{l}\text { marine with anthro- } \\
\text { pogenic influence }\end{array}$ & rain & July 1997-June 1999 & & $\begin{array}{l}\text { all data: } 60 \\
\text { annual: } 56 \\
\text { continenal: } 54 \\
\text { coastal: } 65\end{array}$ & Kieber et al. ${ }^{147}$ \\
\hline Puy de Dome Mountain, France & continental & $\begin{array}{l}\text { fog } \\
\text { snow }\end{array}$ & Dec 2003 & $\begin{array}{l}\text { day } \\
\text { day }\end{array}$ & $\begin{array}{l}76 \\
84\end{array}$ & Sofikitis ${ }^{101}$ \\
\hline $\begin{array}{l}\text { Bermuda Atlantic Time Series } \\
\text { Station (BATS) }\end{array}$ & marine & rain & $\begin{array}{l}\text { Aug } 1999 \\
\text { March } 2000\end{array}$ & & $\begin{array}{l}48 \\
16\end{array}$ & Kieber et al. ${ }^{121}$ \\
\hline Puy de Dome Mountain, France & $\begin{array}{l}\text { marine } \\
\text { rural } \\
\text { anthropogenic } \\
\text { Saharian }\end{array}$ & cloud & Feb 2001-Jan 2005 & & $\begin{array}{l}75 \pm 24^{b} \\
77 \pm 19^{b} \\
74 \pm 16^{b} \\
80 \pm 12^{b} \\
7^{b}\end{array}$ & Parazols $^{150}$ \\
\hline
\end{tabular}

${ }^{a}$ Iron(II)/(total iron) ratio. ${ }^{b}$ Iron(II)/iron filt $_{\text {ratio. }}{ }^{c}$ [Iron(III)] below detection limit. ${ }^{d}$ Two samples. ${ }^{e}$ Forty-four collected samples. $f$ Twenty-nine collected samples.

water collected at Erdemli, Turkey, with iron(II) concentrations 1.7 times higher during the day than during the night and iron(III) concentrations in the same general range during the day and during the night. All of these studies on diurnal variation of iron speciation underscore the possible role of photolysis processes. On the contrary, the study of Parazols et al. ${ }^{150}$ investigating the iron chemistry in clouds showed that the iron speciation seemed to be an independent factor: light intensity does not influence the iron(II)/total dissolved iron ratio, which is constant at $\sim 0.75 \pm 0.24$. They proposed that a part of the iron present in cloud droplets is under colloidal form, stabilizing iron in its reduced oxidation state and preventing its further reoxidation. Below, we will show that iron speciation is the result of a series of complex processes as emphasized by in situ measurements.

Several studies have also focused on the dissolution of aerosol particles and the evaluation of dissolved iron(II) concentrations and total iron (insoluble and soluble) in the resulting solution. These studies provide an estimate of the iron speciation in atmospheric liquid water resulting from the dissolution of particulate matter, rather than from chemical reactivity. These results are summarized in Table 7 .

These studies showed that iron dissolved from aerosol particles can be in its +II oxidation state. Their conclusions are in agreement with measurements showing the presence of iron(II) in the atmospheric liquid phase, despite the fact that iron(II) in diluted solution is unstable and mostly oxidized to iron(III). In particular, Dedik et al. ${ }^{166}$ showed that iron(II) in solution is produced not only by photoreduction of iron(III) into iron(II) but also by the dissolution of iron(II) present in the particulate matter. Zhuang et al. ${ }^{60}$ suggested that the large iron(II) fraction in solution is related to the reduced dissolution of iron(III) species via heterogeneous photochemical pathways at the surface of solid particles. However, none of these studies 
Table 7. Soluble Iron(II)/Total Iron (Percent) Resulting from Dissolution of Different Aerosol Samples in Aqueous Solutions

\begin{tabular}{|c|c|c|c|c|c|}
\hline location & $\min -\max$ & av & sample & aqueous solution $\mathrm{pH}$ & ref \\
\hline \multirow[t]{2}{*}{ North Pacific } & $11-100$ & 56 & marine aerosols & acidified deionized water, $2-5.6$ & Zhuang et al. ${ }^{60}$ \\
\hline & & & urban aerosols & acidified deionized water, 2.2 & Spokes and Jickells ${ }^{343}$ \\
\hline Germany & & 6.0 & urban aerosols & acidified deionized water, 2.5 & Dedik et al. ${ }^{166}$ \\
\hline Xian, central China & $4-11$ & 5.0 & urban aerosols & acidified deionized water, $2-5.6$ & Zhuang et al. ${ }^{60}$ \\
\hline Barbade & & 1.0 & $\begin{array}{l}\text { crustal aerosols that have stayed } \\
\text { in a maritime area }\end{array}$ & acidic solution $1^{a}$ & Zhu et al. ${ }^{307}$ \\
\hline Barbade & $0.2-0.65$ & 1.6 & $\begin{array}{l}\text { crustal aerosols that have stayed } \\
\text { in a maritime area }\end{array}$ & acidic solution $1^{a}$ & Zhu et al. ${ }^{102}$ \\
\hline North Africa & & 0.9 & Saharan aerosols & acidified deionize & Spokes and Jickells ${ }^{343}$ \\
\hline Luochuan, China & & 0.4 & Chinese loess & acidified deionized water, $2-5.6$ & Zhuang et al. ${ }^{60}$ \\
\hline
\end{tabular}

gave any information concerning iron speciation in the particulate phase, which remains poorly investigated.

To summarize, measurements performed in cloud water, fogs, or precipitations exhibit a great variability in iron speciation. This variability is the result of the equilibrium between iron(II) and iron(III), which depends on several factors such as the presence of light, ${ }^{25,29,78,120,121,143,147}$ the presence of oxidizing compounds, ${ }^{78,120}$ and the presence of ligands. ${ }^{143,167}$ In other natural environments (lakes, rivers, etc.), iron is mainly in the form of iron(III) rather than iron(II). Moreover, iron(II) should not exist, theoretically, in a medium such as a cloud droplet saturated with dissolved oxygen. However, as demonstrated by atmospheric measurements, iron can be in its reduced form in tropospheric liquid water. The presence of iron in its +II oxidation state is due to iron(III) reduction, which can be obtained via photochemical or thermal pathways and also via the direct dissolution of iron(II) from solid aerosol particles in the liquid phase. Moreover, iron(II) oxidation is generally slower than the reduction of iron(III). In conclusion, field measurements allow highlighting the potential role of certain meteorological and physicochemical parameters (e.g., radiation, air mass type, and $\mathrm{pH}$ ) that control the speciation of iron in the atmospheric liquid phase. Despite the existing correlations, it remains difficult to draw conclusions solely from measurements of the two main oxidation state of iron, that is, iron(II) and iron(III), due to the large uncertainties associated with these measurements and the fact that iron speciation is interactively influenced by different factors $(\mathrm{pH}$, reactivity, radiation, etc.). Iron speciation is governed by a set of complex processes for which it is difficult to do any hierarchy. This is why it is essential to investigate the interaction between reactivity and radiation both in the laboratory and with the help of model simulations. The following subsection will synthesize our knowledge on iron speciation deduced from laboratory and modeling studies.

\subsubsection{Iron Speciation: A Whole Combination of Processes}

The main daytime source of iron(II) in atmospheric water, ocean water, and groundwater is the photoreduction of iron(III) species. ${ }^{168}$ The $\mathrm{HO}_{2}$ radical simultaneously plays the role of a reducing agent and an oxidant (depending on $\mathrm{pH}$ ) for iron, which could explain the stationary state of iron(II) concentrations. ${ }^{140,169}$ The ratio of the concentrations of iron(II) over iron(III) can be evaluated by a rough calculation limited to reactions of iron with $\mathrm{HO}_{2} / \mathrm{O}_{2}{ }^{-}$radicals. The reactions of iron with $\mathrm{HO}_{2} / \mathrm{O}_{2}{ }^{-}$radicals are represented by the following oxidoreduction reactions:

$$
\begin{gathered}
\mathrm{HO}_{2}+\mathrm{Fe}^{2+}\left(+\mathrm{H}_{2} \mathrm{O}\right) \rightarrow \mathrm{Fe}(\mathrm{OH})^{2+}+\mathrm{H}_{2} \mathrm{O}_{2}, k_{1}= \\
1.2 \times 10^{6} \mathrm{M}^{-1} \mathrm{~s}^{-1}\left(\text { Jayson et al. }{ }^{170}\right) \\
\mathrm{O}_{2}{ }^{-}+\mathrm{Fe}^{2+}\left(+\mathrm{H}_{2} \mathrm{O}, \mathrm{H}^{+}\right) \rightarrow \mathrm{Fe}(\mathrm{OH})^{2+}+\mathrm{H}_{2} \mathrm{O}_{2}, k_{2}= \\
1.0 \times 10^{7} \mathrm{M}^{-1} \mathrm{~s}^{-1}\left(\text { Rush and Bielski }{ }^{31}\right) \\
\mathrm{O}_{2}{ }^{-}+\mathrm{Fe}(\mathrm{III}) \rightarrow \mathrm{Fe}^{2+}+\mathrm{O}_{2}+\mathrm{OH}^{-}, k_{3}= \\
1.5 \times 10^{8} \mathrm{M}^{-1} \mathrm{~s}^{-1}\left(\text { Rush and Bielski }{ }^{31}\right)
\end{gathered}
$$

Because the kinetic constant of reactions of iron with $\mathrm{HO}_{2}$ is slower than those with $\mathrm{O}_{2}{ }^{-}$, these reactions are ignored in making a first approximation with a typical tropospheric $\mathrm{pH}$ value of $\sim 5$, which is close to the $\mathrm{p} K_{\mathrm{a}}$ of the acid/base pair $\mathrm{HO}_{2} / \mathrm{O}_{2}{ }^{-}$. Postulating iron in stationary state, we obtained the following value for the ratio of iron(II) over iron(III) concentrations:

$$
\frac{[\operatorname{iron}(\mathrm{II})]}{[\operatorname{iron}(\mathrm{III})]}=\frac{k_{5}}{k_{4}}=15
$$

Limiting ourselves to reactions of iron with $\mathrm{O}_{2}{ }^{-}$ radicals, we obtained an excess of iron(II).

The iron(II) reaction kinetics provides characteristic formation times ranging from a few seconds to 1 day, which are sufficiently short to allow iron(II) formation in clouds. ${ }^{168}$ Likewise, characteristic times of iron(II) oxidation in the liquid phase are on the order of a few minutes (Table 8).

Consequently, we can assume that iron probably undergoes repeated cycles of reduction and oxidation on a time scale of a few minutes. The very rapid iron(III) photoreduction associated with slower iron(II) oxidation suggests that the reduction and oxidation dynamics between the two iron oxidation states is probably dominated by a succession of equilibrium states quickly reached by photolytic pathways. Several studies have shown that photolysis plays a predominant role in iron speciation in the various 
Table 8. Iron(II) Sinks in the Atmospheric Liquid Phase during the Day (Faust ${ }^{168}$ )

\begin{tabular}{lccll}
\hline oxidant & typical [oxidant] $(\mathrm{M})$ in cloud droplets & $k_{\text {ox }}, \mathrm{Fe}^{2+}\left(\mathrm{M}^{-1} / \mathrm{s}^{-1}\right)$ & $k_{\text {ox }}, \mathrm{Fe}^{2+}$ [oxidant] $\left(\mathrm{s}^{-1}\right)$ & characteristic time \\
\hline $\mathrm{O}_{2}{ }^{-}$ & $10^{-10}-2.0 \times 10^{-9}$ & $1.0 \times 10^{7}$ & $(1-20) \times 10^{-3}$ & $50 \mathrm{~s}-16.6 \mathrm{~min}$ \\
$\mathrm{HO}_{2} / \mathrm{RO}_{2}$ & $10^{-9}-2.0 \times 10^{-8}$ & $(1.2-1.7) \times 10^{6}$ & $(1-30) \times 10^{-3}$ & $33.3 \mathrm{~s}-16.6 \mathrm{~min}$ \\
$\mathrm{H}_{2} \mathrm{O}_{2}$ & $10^{-6}-10^{-4}$ & $5.1 \times 10^{1}$ & $(0.05-5) \times 10^{-3}$ & $3.3 \mathrm{~min}-5.55 \mathrm{~h}$ \\
$\mathrm{O}_{3}$ & $10^{-9}$ & $8.2 \times 10^{5}$ & $0.8 \times 10^{-3}$ & $20.8 \mathrm{~min}$ \\
$\mathrm{OH}$ & $10^{-14}-10^{-12}$ & $4.0 \times 10^{8}$ & $(0.004-0.4) \times 10^{-3}$ & $41.6 \mathrm{~min}-2.9 \mathrm{days}$ \\
$\mathrm{O}_{2}{ }^{1} \Delta_{\mathrm{g}}$ & $10^{-14}-10^{-12}$ & unknown & $(0.004-0.4) \times 10^{-3}$ & $41.6 \mathrm{~min}-2.9 \mathrm{days}$ \\
$\mathrm{O}_{2}$ & $2.7 \times 10^{-4}$ & unknown & $(0.000003) \times 10^{-3}$ & 3858 days
\end{tabular}

${ }^{a}$ Rate constant is unknown; therefore, a value indentical to that for $\mathrm{OH}$ was used. ${ }^{b}$ Asymptotic value of apparent first-order rate constant from Figure 7.15 of ref 118 for $\mathrm{pH}<5$.

Table 9. Initial Dissolution Rate, Fraction of Iron Present as Iron(II), and Solubility Obtained after $1 \mathrm{~h}$ of Dissolution ${ }^{101}$

\begin{tabular}{lllcc}
\hline & \multicolumn{1}{c}{ loess } & goethite $(\mathrm{FeOOH})$ & $\begin{array}{c}\text { vermiculite }[\mathrm{clay:} \\
\text { hematite }\left(\mathrm{Fe}_{2} \mathrm{O}_{3}\right)\end{array}$ & $\begin{array}{c}\left.(\mathrm{MgFeAl})_{3}(\mathrm{AlSi})_{4} \mathrm{O}_{10}(\mathrm{OH})_{2} \cdot 4 \mathrm{H}_{2} \mathrm{O}\right] \\
(+\mathrm{II})\end{array}$ \\
\hline oxidation state & $(+\mathrm{II})(+\mathrm{III})$ & $(+\mathrm{III})$ & $(+\mathrm{III})$ & $2.06 \times 10^{-8}$ \\
dissolution rate at pH 2 $\left(\mathrm{mol} \mathrm{L}^{-1} \mathrm{~s}^{-1}\right)$ & $1.09 \times 10^{-9}$ & $1.27 \times 10^{-9}$ & $3.64 \times 10^{-10}$ & $4.98 \times 10^{-10}$ \\
dissolution rate at pH 4.7 $\left(\mathrm{mol} \mathrm{L}^{-1} \mathrm{~s}^{-1}\right)$ & $1.69 \times 10^{-10}$ & $6.23 \times 10^{-11}$ & $3.3410^{-10}$ & 100 \\
iron(II)/total dissolved iron at pH 2 $\%)$ & 77.6 & 65.8 & 61.9 & $\mathrm{NA}$ \\
iron(II)/total dissolved iron at pH 4.7 $(\%)$ & 39.2 & $\mathrm{NA}$ & $\mathrm{NA}$ & 4.01 \\
max solubility at pH 2 $(\%)$ & 0.340 & 0.029 & 0.022 & 0.170 \\
max solubility at pH 4.7 $(\%)$ & 0.080 & 0.003 & 0.006 & \\
\hline
\end{tabular}

atmospheric aqueous phases. Measurements of the fraction of iron(II) (Table 6) show the importance of the photolytic pathway in the daytime production of that oxidation state.

As shown before, the only iron source in the various atmospheric aqueous phases is from the dissolution of the particulate phase. Iron is present in the solid phase under its two oxidation states of + II and + III. For example, the crystalline species present in the particulate phase, such as goethite or hematite, correspond to iron under its +III oxidation state, whereas vermiculite (an argillaceous mineral) is composed of iron(II). These various mineralogical iron forms can coexist within a single aerosol particle and thus trigger iron speciation in the particulate phase. Iron speciation in the particulate phase is at this time very poorly documented. ${ }^{37,46,47,49,171}$

The problem is to find whether the speciation that takes place in the particulate phase is preserved in the solution obtained after the dissolution process. Most of the dissolution experiments were carried out on complex natural aerosol samples with unknown iron speciation. In this kind of experiment the evolution of speciation from the particulate phase to the liquid phase cannot be followed. Before the analysis of iron(II) concentrations in solution, it would be worthwhile to dissolve mineral samples with known iron speciation. Sofikitis ${ }^{101}$ performed such dissolution experiments in acidified Milli-Q water for various types of minerals with known iron speciation: goethite, hematite, and vermiculite, as well as loess, which is a mixture of various crystalline species. Table 9 summarizes these results at various $\mathrm{pH}$ values, showing the initial dissolution rates, the ratio of iron(II) over dissolved iron obtained $1 \mathrm{~h}$ after dissolution, and the maximal solubility.

On the one hand, almost all of the iron in vermiculite is dissolved under its +II oxidation state; the iron oxidation state in the particulate phase is preserved in the solution obtained. On the other hand, the iron in solution coming from goethite and hematite is in its +II oxidation state, whereas these aerosol particles are composed of iron(III). Thus, speciation in solution depends on the mineralogical composition of the particulate phase. In addition, the more acidic the solution is, the higher are the iron dissolution rates, as explained previously (cf. section 2.2). Afterward, in the atmospheric aqueous phase iron speciation will be modified due to its chemical reactivity.

Modeling studies have sought to predict the predominant iron oxidation state for different photolytic and chemical conditions. Siefert et al., ${ }^{29}$ using a simple chemical kinetic model, showed that iron(II) would be the predominant chemical form of iron during daylight conditions and iron(III) during nighttime conditions. These results are in agreement with iron speciation measurements they performed in the atmospheric liquid phase at different locations in the United States. Ervens et al., ${ }^{172}$ using an explicit multiphase chemical box model, found the highest iron(III) concentration during the night for the urban scenario, which testifies to a photochemical iron oxidation cycle. This has been confirmed by the study of Deguillaume et al., ${ }^{23}$ which indicates that the iron(II)/iron(III) ratio is strongly dependent on photolysis for the three simulated chemical scenarios. Modeling seems to simulate the global tendency of iron speciation in atmospheric liquid phase, but this speciation depends on so many factors that it looks rather difficult to model with precision. The iron cycle suggested by Behra and Sigg ${ }^{25}$ for atmospheric water (Figure 8) highlights the complexity of physicochemical processes involved in the iron speciation: photolysis, chemical, and dissolution processes.

Therefore, further laboratory investigations and in situ measurements are needed to characterize iron speciation accurately.

\subsubsection{Copper and Manganese Speciation}

Little information is available on copper and manganese speciation in atmospheric liquid phases. 


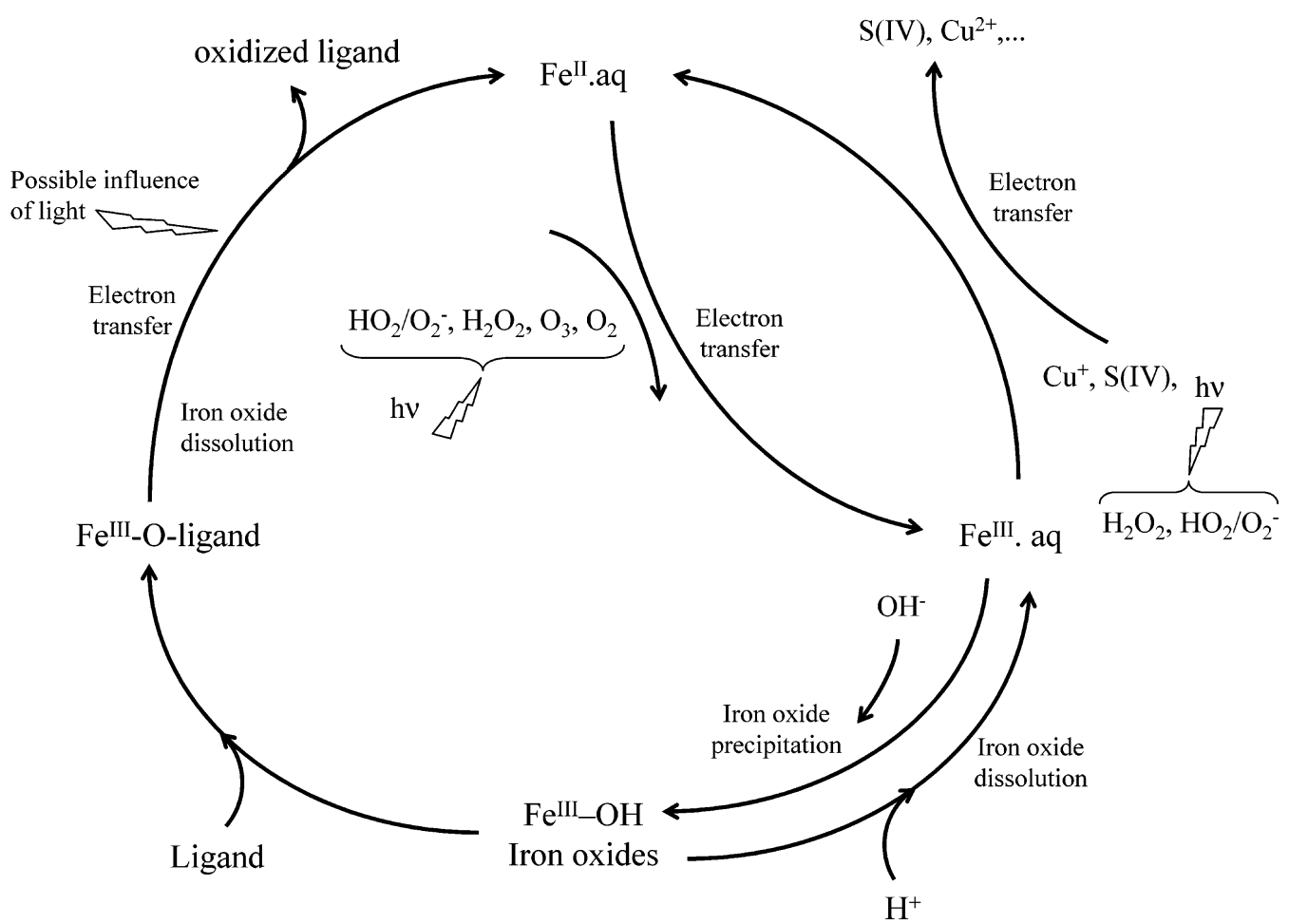

Figure 8. Reaction scheme for iron(II)/iron(III) in the dark and/or in the presence of light for atmospheric water. Reprinted with permission from Nature (http://www.nature.com), ref 25. Copyright 1990 Nature Publishing Group.

Table 10. Measured Copper(I)/[Copper(I) + Copper(II)] Ratio in the Atmospheric Liquid Phases (Minimum-Maximum and/or Average Value)

\begin{tabular}{|c|c|c|c|c|c|}
\hline location & air mass type & aqueous phase & date & $\begin{array}{c}\mathrm{Cu}(\mathrm{I}) /[\mathrm{Cu}(\mathrm{I})+ \\
\mathrm{Cu}(\mathrm{II})](\%)\end{array}$ & ref \\
\hline Wilmington NC & $\begin{array}{l}\text { all data } \\
\text { coastal } \\
\text { continental } \\
\text { other }\end{array}$ & rain & Aug 25, 2002-Sept 24, 2002 & $\begin{array}{l}30 \\
32 \\
22 \\
40\end{array}$ & Kieber et al. ${ }^{136}$ \\
\hline Dübendorf, Switzerland & urban & fog & Oct $89-$ Jan 90 & $\begin{array}{l}4-90 \\
63\end{array}$ & Xue et al. ${ }^{133}$ \\
\hline San Pedro Hill, CA & $\begin{array}{l}\text { marine with anthro- } \\
\text { pogenic influence }\end{array}$ & fog/stratus cloud & & $<25-<59$ & Siefert et al. ${ }^{29}$ \\
\hline Whiteface Mountain NY & continental & & & $<25-<100$ & \\
\hline
\end{tabular}

Copper interacts mainly with $\mathrm{HO}_{x}$ chemistry in atmospheric liquid phases via the following redox reactions with $\mathrm{HO}_{2} / \mathrm{O}_{2}{ }^{-}$radicals:

$$
\begin{array}{r}
\mathrm{HO}_{2}+\mathrm{Cu}^{2+} \rightarrow \mathrm{Cu}^{+}+\mathrm{O}_{2}+\mathrm{H}^{+}, k_{1}=1.0 \times \\
10^{8} \mathrm{M}^{-1} \mathrm{~s}^{-1}\left(\text { Rabani et al. }{ }^{173}\right) \\
\mathrm{O}_{2}{ }^{-}+\mathrm{Cu}^{+}+2 \mathrm{H}^{+} \rightarrow \mathrm{Cu}^{2+}+\mathrm{H}_{2} \mathrm{O}_{2}, k_{2}=9.4 \times \\
10^{9} \mathrm{M}^{-1} \mathrm{~s}^{-1}\left(\text { von Piechowski et al. }{ }^{164}\right)
\end{array}
$$

A rough calculation using only these two reactions makes it possible to evaluate the [copper(I)]/[copper(II)] ratio at a stationary state after reactions 6 and 7 in the same way as for iron

$$
\frac{[\operatorname{copper}(\mathrm{I})]}{[\operatorname{copper}(\mathrm{II})]}=\frac{k_{6}}{k_{7}} 10^{\mathrm{p} K_{\mathrm{a}}-\mathrm{pH}}
$$

where $\mathrm{p} K_{\mathrm{a}}=4.8$ for the acid/base pair $\mathrm{HO}_{2} / \mathrm{O}_{2}{ }^{-}$ (Bielski et al. ${ }^{174}$ ).

For typical $\mathrm{pH}$ values of atmospheric liquid phases, this ratio varies from 0.7 at a $\mathrm{pH}$ of 3 to 0.007 at a $\mathrm{pH}$ of 5 at $25^{\circ} \mathrm{C}$. This simple calculation shows that in acidic atmospheric liquid phases, it should be possible to find copper in both oxidation states, whereas in less acidic phases, copper should mainly be present in its + II oxidation state.

Copper chemistry in atmospheric liquid water is more complex. Indeed, due to the presence of oxygen and other oxidants, copper(I) is not thermodynamically stable in atmospheric water. Table 10 summarizes available measurements of the fraction of copper present as copper(I) in atmospheric liquid phases.

The study by Xue et al. ${ }^{133}$ reported high copper(I) concentrations in fog water samples. A qualitative explanation of these observations was put forward on the basis of the then limited knowledge of copper reactivity in atmospheric water: Copper(I) may be formed via reduction by sulfite at high $\mathrm{pH}$, via reduction by organic compounds, or via various radical and photochemical reactions in the presence of light. The copper(I) that is formed can be complexed by excess sulfite to prevent its rapid reoxidation to copper(II). This was the hypothesis proposed by Xue et al. ${ }^{133}$ to explain the copper(I) accumulation 
that they had observed in fog water samples. The study of Siefert et al. ${ }^{29}$ also turned up significant concentrations of copper(I) in fog and cloud waters. Spokes et al. ${ }^{134}$ deduced from measurements of free copper ions and organic matter in rainwater that $>99 \%$ of total dissolved copper is complexed by organic matter, yielding a low free copper ion concentration of $\sim 10^{-11}-10^{-12} \mathrm{M}$ for $\mathrm{Cu}^{2+}$.

More recently, the study of Kieber et al. ${ }^{136}$ has determined the temporal and seasonal variability of total copper, dissolved copper, copper(II), and copper(I) concentrations in rainwater, including the identification of free and complexed forms. This study shows a relatively large abundance of reduced copper with respect to dissolved copper in rainwater, as was observed for iron. Two hypotheses can explain these high copper(I) concentrations: the $\mathrm{H}_{2} \mathrm{O}_{2} / \mathrm{O}_{2}$ pair controls the redox potential in rainwater, with $\mathrm{H}_{2} \mathrm{O}_{2}$ acting as a reductant rather than as an oxidant; 147 and the $\mathrm{O}_{2} / \mathrm{H}_{2} \mathrm{O}$ pair controls the redox potential in rainwater, leading to oxidant accumulation, but an appreciable amount of reduced metal remains because of the photoreduction of organically complexed forms. ${ }^{121,175}$ The observed concentrations of dissolved organic carbon, as well as the identification of free copper, show that a significant portion, but not all, of the dissolved copper(I) in rainwater is strongly complexed. This suggests that the second hypothesis is the more probable. The study by Kieber et al. ${ }^{136}$ is the only one that endeavors to evaluate the diurnal and seasonal variation of copper speciation in atmospheric liquid phases. The copper(I) concentration in all rainwater samples is almost always constant under any photolysis conditions (day versus night), which is consistent with the earlier discussion of copper(I) complexation. Moreover, samples show an increase in both copper(II) and iron(II) concentrations, coupled with a decrease in iron(III), from morning to afternoon hours. This is followed in the early to late evening hours by a decrease in copper(II) concentrations and a simultaneous increase in iron(III). To explain this apparent inverse behavior of copper(II) and iron(III), Kieber et al. ${ }^{136}$ proposed a mechanism of photodissolution under ambient sunlight conditions of particulate iron oxohydroxides containing adsorbed copper(II): ${ }^{25,168}$

$$
\begin{aligned}
\mathrm{FeOOH}_{(\mathrm{s})} / \mathrm{Cu}(\mathrm{II})_{(\mathrm{ad})}+h v+\mathrm{DOC} & \rightarrow \\
\mathrm{Fe}(\mathrm{II})_{(\mathrm{aq})} & +\mathrm{Cu}(\mathrm{II})_{(\mathrm{aq})}
\end{aligned}
$$

The concomitant increase of copper(II) and iron(II) concentrations during the morning shows copper(II) and iron(II) cycling to be coupled in a way consistent with the proposed mechanism (eq 8). The constant behavior of copper(I), including the presence of complexing organic agents, is also consistent with this mechanism. Kieber et al. ${ }^{136}$ stated that the subsequent decrease of copper(II) in the late afternoon and evening hours, associated with an increase in iron(III), is explained by the formation of iron(III) oxyhydroxide species followed by the adsorption of copper(II), implying that mechanism 8 should be reversible. However, the reversible behavior of this mechanism is probably unlikely because it implies that copper and iron speciations are driven only by dissolution and precipitation processes. Moreover, it is well-known that the chemical reactivity plays a key role in iron and copper speciations in the atmospheric liquid phase (see section 4).

The observed seasonal variation of copper by Kieber et al. ${ }^{136}$ shows the highest copper(II) concentration associated with the highest copper(II)/copper(I) ratio in the summer, suggesting that copper(I) photooxidation processes are probably the driving mechanism of copper chemistry. In conclusion, the study of Kieber et al. ${ }^{136}$ showed that observed copper(II) and iron(III) behavior may be the result of mechanism 8 and that the observed copper(I) stationary concentrations are linked to photo-oxidation processes associated with the presence of organic complexing agents. All of these studies reveal the high complexity of evaluating copper speciation and our lack of knowledge.

Simultaneously with field campaigns for the experimental investigation of copper speciation, several modeling studies have sought to assess copper speciation in atmospheric liquid phases. Siefert et al. ${ }^{29}$ using a chemical kinetic model developed for fog and stratus clouds, predicted that copper(II) is always greater than copper(I) under both day- and nighttime conditions. Under daytime conditions, copper(I) reaches a pseudo-steady-state concentration up to 100 times the copper(II) concentration. Under nighttime conditions, copper(I) concentration decreases quickly due to the rapid oxidation of copper(I) by both $\mathrm{H}_{2} \mathrm{O}_{2}$ and $\mathrm{O}_{2}$. Jans and Hoigné ${ }^{176}$ suggested that the kinetic redox equilibrium for copper speciation is mainly driven by the $\mathrm{O}_{2}{ }^{-}$radical, because reactions with $\mathrm{O}_{2}{ }^{-}$interconvert copper(I) and copper(II), which leads to steady-state copper speciation. Ervens et al. ${ }^{172}$ and Deguillaume et al., ${ }^{23}$ using explicit and extended aqueous chemistry mechanisms, found no diurnal variation in copper speciation. Additionally, these two studies showed that nearly $100 \%$ of the simulated copper is present as copper(II) due to the reaction of $\mathrm{Cu}^{+}$with dissolved oxygen and iron(III). This discrepancy between numerical modeling and measurements of copper speciation is probably due to the lack of the model to represent the organic complexing agents chemistry of copper because field campaigns indicate that dissolved copper is strongly complexed. ${ }^{134,136}$ This underscores our lack of knowledge on the sensitive parameters that govern this speciation.

Few studies have dealt with the evaluation of manganese speciation. Hofmann et al.$^{35}$ showed that manganese in rainwater sampled in Germany is present in positively charged molecular forms, especially under its + II oxidation state. Pehkonen et al. ${ }^{177}$ and Siefert et al. ${ }^{29}$ evaluated the concentrations of manganese(III), manganese(IV), and manganese(II) in atmospheric liquid water sampled at different locations in the United States. Oxidized manganese(III) and manganese(IV) concentrations were often below the detection limit, and a large fraction of manganese in the + II oxidation state was observed. The authors suggest that there exist important reductive pathways for manganese(III) and manga- 


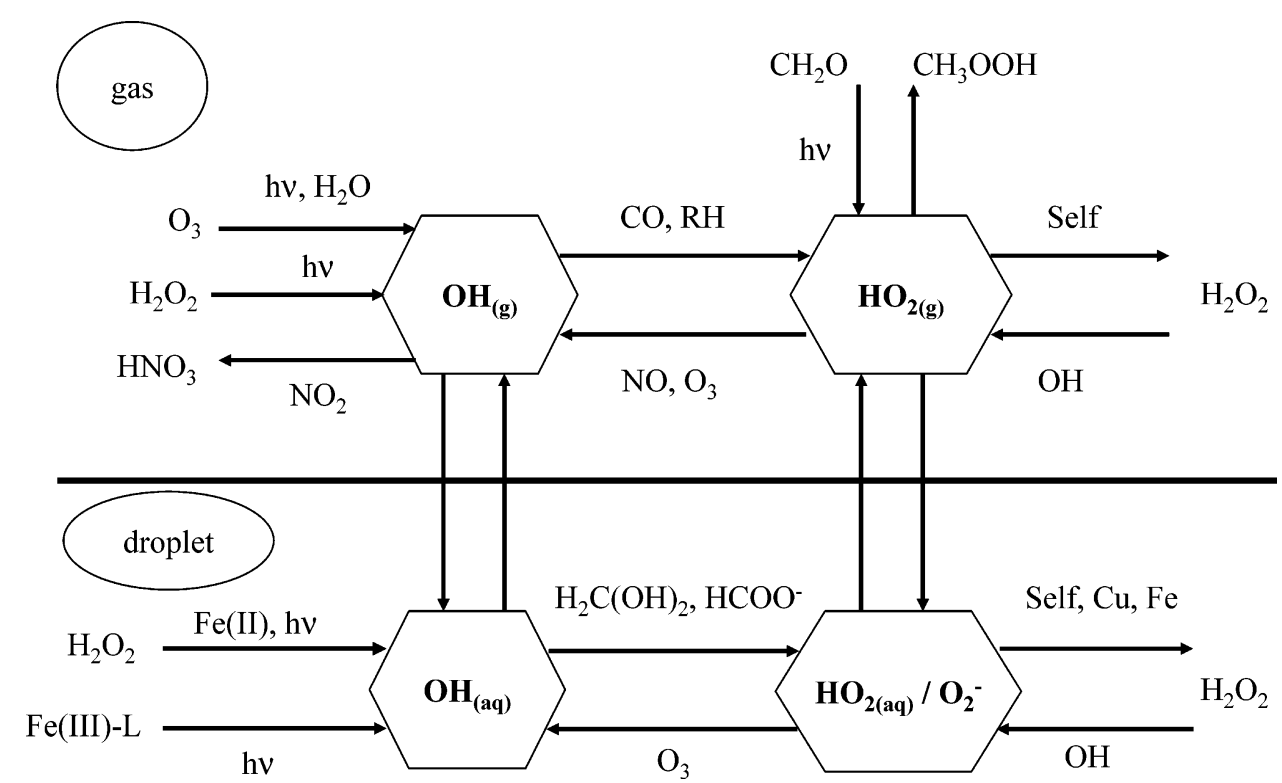

Figure 9. Chemistry of $\mathrm{OH}$ and $\mathrm{HO}_{2}$ in clouds. Major reaction pathways are indicated (adapted from Jacob ${ }^{182}$ ).

nese(IV) that lead to an increase in the amount of reduced manganese, the form needed for the catalytic oxidation of sulfur(IV). As for iron and copper, some modeling studies have sought to assess copper speciation in atmospheric liquid phases. The kinetic model of Siefert et al. ${ }^{29}$ predicted that manganese(II) would be predominant under daylight and nighttime conditions, with manganese(III) increasing during the daytime. Herrmann et al. ${ }^{22}$ and Deguillaume et al. ${ }^{23}$ have shown that the predominant oxidation state of manganese is +II, mainly due to the reaction between $\mathrm{Mn}^{3+}$ and $\mathrm{H}_{2} \mathrm{O}_{2}$. The modeling studies appear to corroborate this observation, but further in situ measurements are necessary to confirm the explanation of manganese speciation drawn from the model.

The importance of iron, copper, and manganese in tropospheric chemistry is linked to sulfur chemistry, because iron acts as a catalyst in the oxidation of sulfur(IV) into sulfur(VI), and to $\mathrm{HO}_{x}$ chemistry, which plays a role in the production of free radicals in the atmospheric aqueous phase. ${ }^{20,60,119,133,178-181} \mathrm{We}$ will now attempt to describe this reactivity within the atmospheric aqueous phase. Several laboratory studies and in situ measurements have sought to work out the mechanisms of iron reactivity, and modeling studies make it possible to gauge the impact of this reactivity on the chemistry going on in atmospheric liquid phases.

\section{Reactivity}

After describing in detail the source of transition metal ions in the atmospheric liquid phase, a discussion on their reactivity in the atmospheric liquid phase will constitute the main focus of this review. The reactivity of transition metals depends on numerous parameters, such as their oxidation state, their state of complexation, and the $\mathrm{pH}$.

Because of their concentration and reactivity, the most intensely studied transition metals in atmospheric liquid phases are iron $(\mathrm{Fe})$, copper $(\mathrm{Cu})$, and manganese $(\mathrm{Mn})$. In this section we will attempt to describe their reactivity in order to assess their potential impact on multiphase chemistry and in particular on radical and sulfur chemistry.

\subsection{Iron Reactivity in the Atmospheric Liquid Phase}

\subsubsection{Reactivity with $\mathrm{HO}_{x}$ Radicals}

Figure 9 summarizes current knowledge of tropospheric $\mathrm{HO}_{x}$ chemistry in clouds. ${ }^{182}$

Modeling studies of multiphase cloud chemistry, supplemented with laboratory measurements of chemical reactivity, make it possible to assess the $\mathrm{HO}_{x}$ chemistry in cloudy air. ${ }^{19,20,22,23,156,172,183-186}$ Photolysis of iron(III) complexes [Fe(III)-L in Figure 9] and the Fenton reaction [Fe(II) $+\mathrm{H}_{2} \mathrm{O}_{2}$ in Figure 9] lead to $\mathrm{OH}$ radical formation. Iron, in both oxidized and reduced states, triggers the formation of $\mathrm{OH}$ radicals; iron acts as a "catalyst" for $\mathrm{OH}$ radical formation in hydrometeors because it is regenerated. Following the release of organic ligands by the photoreduction of iron(III) complexes, ligands can reform new iron(III) complexes, or they can react with $\mathrm{O}_{2}$, producing $\mathrm{HO}_{2} / \mathrm{O}_{2}{ }^{-}$radicals, or they can reduce other iron(III) species, or finally they can form a reduced organic radical with a shortened carbon chain (degradation). The evolution of these reduced radicals depends on the competition between their reactions with the dissolved iron(III) and with the dissolved oxygen. On the one hand, if most of the reducing radicals react with iron(III), iron(II) is produced; on the other hand, if the reaction with $\mathrm{O}_{2}$ is prevalent, oxidants such as $\mathrm{O}_{2}^{-}, \mathrm{HO}_{2}, \mathrm{H}_{2} \mathrm{O}_{2}$, and $\mathrm{OH}$ are formed and can then react with iron(II) and iron(III) in a complex chemical mechanism as described in Figure 9. Although the iron reactivity seems to be well described, some reactions are still subject to controversy as to their relative importance or even their chemical pathways.

Photolysis of iron(III) complexes is known to be a potential source of $\mathrm{HO}_{x}$ radicals in solution. Evans and $\mathrm{Uri}^{187}$ were the first to study photochemical 


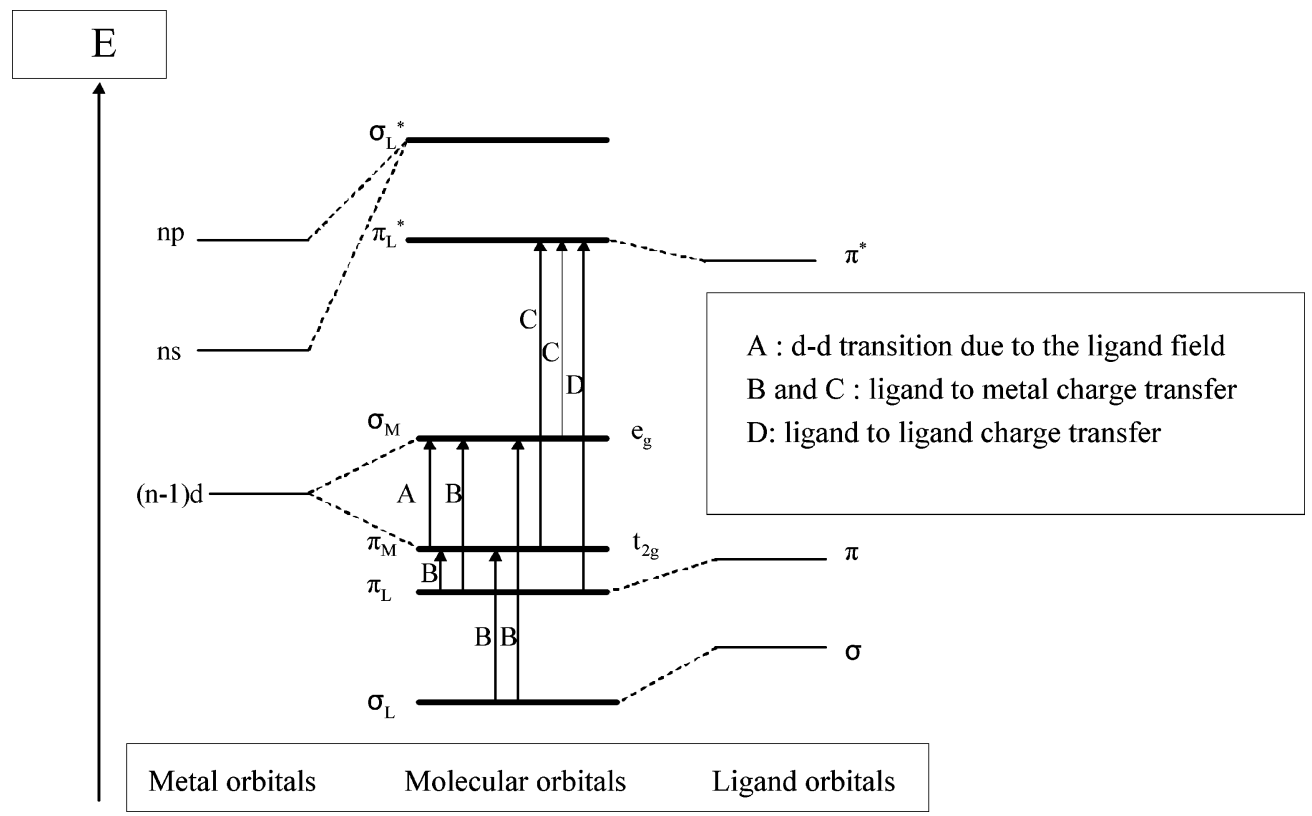

Figure 10. Qualitative energy diagram of orbital molecular of a transition metal complex.

processes occurring during the irradiation of acidic solutions of $\mathrm{FeCl}_{3}$. Thereafter, Bates and $\mathrm{Uri}^{188}$ showed that ferric ions irradiated by ultraviolet light were able to oxidize organic compounds in acidic solutions. The agent responsible for this oxidation was assumed to be the $\mathrm{OH}$ radical produced by photolysis of the ferric ion:

$$
\mathrm{Fe}^{3+}+h v+\mathrm{H}_{2} \mathrm{O} \rightarrow \mathrm{Fe}^{2+}+\mathrm{OH}+\mathrm{H}^{+}
$$

At this stage there occur transmissions of ligandto-metal charge transfer, and these are characteristic of the coordination complexes in which ligands are found fixed onto a metal center. Figure 10 represents the qualitative energy diagram of a molecular orbital of an iron-like transition metal.

When a transition metal complex is irradiated with a photon energy corresponding to the ligand-to-metal charge transfer, an excited state is produced in which the ligand and metal are, respectively, oxidized and reduced (reactions 10 and 11 ).

$$
\begin{gathered}
\mathrm{Fe}(\mathrm{III})-\mathrm{L}+h v \rightarrow[\mathrm{Fe}(\mathrm{III})-\mathrm{L}]^{*} \\
{\left[\mathrm{Fe}(\mathrm{III})-\mathrm{L}^{*} \leftrightarrow\left[\mathrm{Fe}(\mathrm{II})-\mathrm{L}^{*}\right]_{\text {cage }}\right.} \\
{\left[\mathrm{Fe}(\mathrm{II})-\mathrm{L}^{*}\right]_{\text {cage }} \leftrightarrow \mathrm{Fe}(\mathrm{II})+\mathrm{L}^{\bullet}}
\end{gathered}
$$

A deactivation of the excited state may then lead either to a release of the oxidized ligand and reduced metal or to a return of the transition metal complex in its initial state by giving off energy (reaction 12).

Among the first studies carried out on the photochemical reactions in aqueous solutions containing the ferric ions, some are mainly interested in quantum yields of formation of the iron(II) and hydroxyl radicals and with the influence of certain factors (the wavelength of irradiation, $\mathrm{pH}$, etc). These studies were carried out in acid solutions, with concentrations in iron(III) of $10^{-3}-10^{-6} \mathrm{M}$ and concentrations of traps of hydroxyl radicals of $10^{-1}-10^{-3} \mathrm{M}$. Trap-

\begin{tabular}{|c|c|c|c|c|}
\hline \multicolumn{2}{|c|}{ solution } & $\begin{array}{l}\text { irradiation } \\
(\mathrm{nm})\end{array}$ & $\Phi_{\mathrm{Fe}(\mathrm{II})}$ & ref \\
\hline \multirow{4}{*}{\multicolumn{2}{|c|}{$\begin{array}{l}{\left[\mathrm{Fe}^{3+}\right]_{0}=1.010^{-4} \mathrm{M}} \\
92 \%[\mathrm{Fe}(\mathrm{OH})]^{2+} \\
{\left[\mathrm{Fe}^{3+}\right]_{0}=1.010^{-4} \mathrm{M}} \\
10 \%[\mathrm{Fe}(\mathrm{OH})]^{2+}\end{array}$}} & 313 & 0.08 & Mazellier et al. ${ }^{190}$ \\
\hline & & 365 & 0.055 & \\
\hline & & 313 & 0.02 & Mazellier et al. 190 \\
\hline & & 365 & 0.008 & \\
\hline solution & $\lambda \underset{(\mathrm{nm})}{\operatorname{irradiation}}$ & $\Phi_{\mathrm{OH}}$ & & ref \\
\hline \multirow[t]{3}{*}[\mathrm{Fe}(\mathrm{H}_{2}\mathrm{O})_{6}]{$^{3+}$} & $\leq 310$ & 0.05 & Benkel & berg and Warneck ${ }^{191}$ \\
\hline & 254 & 0.065 & Langfo & rd and Carey ${ }^{344}$ \\
\hline & 254 & 0.046 & Lee an & d Yoon 345 \\
\hline \multirow[t]{6}{*}[\mathrm{Fe}(\mathrm{OH})]{$^{2+}$} & 313 & $0.14-0.19$ & Baxen & lale et al. ${ }^{346}$ \\
\hline & 280 & 0.31 & Baxen & lale et al. ${ }^{346}$ \\
\hline & 313 & 0.14 & Faust & and Hoigné ${ }^{116}$ \\
\hline & 360 & 0.017 & Faust & and Hoigné ${ }^{116}$ \\
\hline & $280-370$ & $0.312-0.074$ & Benkel & berg and Warneck ${ }^{191}$ \\
\hline & 254 & 0.69 & Lee an & d Yoon ${ }^{345}$ \\
\hline$\left[\mathrm{Fe}(\mathrm{OH})_{2}\right]^{+}$ & $280-360$ & $0.300-0.071$ & Benkel & berg et al. ${ }^{347}$ \\
\hline
\end{tabular}

Table 11. (A) $\Phi_{\mathrm{Fe}(\mathrm{II})}$ under Different Experimental Conditions and (B) $\Phi_{\mathrm{OH}}$ of the Different Iron(III) Complexes

ping, with alcohol terbutylic or 2-propanol, for instance, is an important method to measure quantum yields of the formation of $\mathrm{OH}$ radicals or iron(II). Indeed, the use of these scavengers allows the reverse reaction between $\mathrm{OH}$ and iron(II) to be avoided and therefore the exact quantum yield to be obtained. ${ }^{189}$ Table 11A indexes the results of the studies on iron(II) formation when aqueous solutions of iron(III) are irradiated. The values of these quantum yields depend on the wavelength of excitation and the nature of the monomeric species of iron(III) present in solution. The monomeric complex $[\mathrm{Fe}(\mathrm{OH})]^{2+}$ is the most photoactive complex of iron(III) in terms of iron(II) formation. Indeed, under an irradiation of 313 $\mathrm{nm}$, as the percentage of $[\mathrm{Fe}(\mathrm{OH})]^{2}+$ decreases, the quantum yield of iron(II) formation also decreases: from 0.08 per $92 \%$ of $[\mathrm{Fe}(\mathrm{OH})]^{2+}$, it passes to 0.02 per $10[\mathrm{Fe}(\mathrm{OH})]^{2+} .190$

Table 11B lists the results of the studies on hydroxyl radical formation during irradiation of an aqueous iron(III) solution. The quantum yield of $\mathrm{OH}$ radical formation produced by photolysis of $[\mathrm{Fe}-$ 
$(\mathrm{OH})]^{2+}$ is much greater than for photolysis of the other monomeric species of iron(III). Discrepancies between measurements of Benkelberg and Warneck $^{191}$ at $370 \mathrm{~nm}$ and Faust and Hoigné ${ }^{116}$ at 360 $\mathrm{nm}$ could be due to different experimental conditions such as $\mathrm{pH}$ and concentration of scavengers.

From measurements of quantum yield at various wavelengths, Benkelberg and Warneck ${ }^{191}$ established the empirical relationship

$$
\Phi_{\mathrm{OH}}=\frac{a}{1+\exp \left(\lambda-\lambda_{0}\right) / b}+c
$$

with $a=0.359 \pm 0.08, b=21.95 \pm 4.6, c=0.054 \pm$ 0.01 , and $\lambda_{0}=300.7 \pm 9.1 \mathrm{~nm}$.

$\mathrm{OH}$ radicals are seen to be formed more efficiently when the wavelength of irradiation is shorter, that is, when photon energy is higher. This observation is consistent with the fact that more kinetic energy is required for the ejection of the hydroxyl radicals from the solvent cage than for the electron transition. This excess of energy will increase as excitation wavelengths shorten, causing a rise in the production of the hydroxyl radicals. ${ }^{25,191}$

These results suggest that in aqueous solutions with $\mathrm{pH}$ between 2.5 and 5.0 the most photoreactive species is the complex $[\mathrm{Fe}(\mathrm{OH})]^{2+}$.

The studies carried out on the cross sections of iron(III) complexes by Graedel and Weschler ${ }^{19}$ and by Benkelberg and Warneck ${ }^{191}$ made it possible to compile cross sections as a function of wavelength (see Table 12).

The photolysis of $\mathrm{Fe}(\mathrm{OH})^{2+}$ cations represents a source of $\mathrm{OH}$ radicals, and this contribution is important becau se of its high reaction rate. ${ }^{140}$

$$
\mathrm{Fe}(\mathrm{OH})^{2+}+h v \rightarrow \mathrm{Fe}^{2+}+\mathrm{OH}
$$

Weschler et al. ${ }^{119}$ and Faust and Hoigné ${ }^{116}$ were the first to have shown that photolysis of the Fe$(\mathrm{OH})^{2+}$ complex was a source of $\mathrm{OH}$ in the atmospheric liquid phases. Graedel et al. ${ }^{178}$ highlighted the catalytic effect of iron in the oxidation processes taking place in cloud droplets. According to this study, photolysis of the ferric complexes is the primary source of free $\mathrm{OH}$ radicals in the droplets during the daytime, even at low iron concentrations, and this yields iron(II) concentrations that are close to the iron(III) concentrations. Thereafter, some studies show that this source is not fast enough to be really significant. ${ }^{20,151}$ Using a one-dimensional model, Jacob et al. ${ }^{20}$ concluded that the relative contribution of iron(III) complex photolysis to aqueous-phase $\mathrm{OH}$ production is minor. Weschler et al. ${ }^{119}$ used values for cross sections and quantum yields that were too low and assumed that there was no radiative enhancement within the droplets. This yielded small values for the photolysis rates of iron complexes, which explains the negligible impact of iron photolysis on them. More recent absorption cross sections and $\mathrm{OH}$ quantum yields of iron complexes are larger. ${ }^{191}$ Irradiating cloud water from Whiteface Mountain, NY, Arakaki and Faust ${ }^{151}$ concluded that iron complex photolysis is negligible as an $\mathrm{OH}$ production pathway independent of $\mathrm{H}_{2} \mathrm{O}_{2}$. Indepen-

\begin{tabular}{|c|c|}
\hline \multicolumn{2}{|c|}{ (A) $\mathrm{Fe}^{3+}$ Cross Sections (Benkelberg and Warneck ${ }^{191}$ ) } \\
\hline$\lambda(\mathrm{nm})$ & $\sigma\left(\mathrm{cm}^{2} /\right.$ molccule $) \times 10^{21}$ \\
\hline 280 & 1311.6 \\
\hline 290 & 549.5 \\
\hline 300 & 212.5 \\
\hline 310 & 79.4 \\
\hline 320 & 23.7 \\
\hline 330 & 5.3 \\
\hline \multicolumn{2}{|c|}{ (B) $\mathrm{Fe}(\mathrm{OH})^{2+}$ Cross Sections (Benkelberg and Warneck ${ }^{191}$} \\
\hline$\lambda(\mathrm{nm})$ & $\sigma\left(\mathrm{cm}^{2} /\right.$ molecule $) \times 10^{19}$ \\
\hline 280 & 28.5 \\
\hline 290 & 32.5 \\
\hline 300 & 32.9 \\
\hline 310 & 30.3 \\
\hline 320 & 26 \\
\hline 330 & 20.6 \\
\hline 340 & 15.2 \\
\hline 350 & 10.5 \\
\hline 360 & 6.9 \\
\hline 370 & 4.3 \\
\hline \multicolumn{2}{|c|}{ (C) $\left[\mathrm{Fe}(\mathrm{OH})_{2}\right]^{+}$Cross Sections (Weschler et al. ${ }^{119}$ ) } \\
\hline$\lambda(\mathrm{nm})$ & $\sigma\left(\mathrm{cm}^{2} /\right.$ molecule $) \times 10^{18}$ \\
\hline 290 & 9 \\
\hline 300 & 10 \\
\hline 310 & 10 \\
\hline 320 & 8 \\
\hline 330 & 6 \\
\hline 340 & 4 \\
\hline 350 & 3 \\
\hline 360 & 1 \\
\hline 370 & 0.9 \\
\hline 380 & 0.5 \\
\hline 390 & 0.2 \\
\hline 400 & 0 \\
\hline
\end{tabular}

Table 12. Fe Cross Sections in Aqueous Solution

dently, direct measurements of $\mathrm{HO}_{x}$ radical concentration after the irradiation of cloud water sampled in different locations in the eastern United States ${ }^{192}$ indicated little correlation between radical quantity and iron concentration. More recent modeling studies, ${ }^{23,172}$ using a multiphase chemistry box model, have shown that the contribution of complex Fe$(\mathrm{OH})^{2+}$ photolysis to the production of $\mathrm{OH}$ in droplets depends on environmental conditions, with the contribution increasing from the marine to the urban scenario. These various studies emphasize the potential impact of this photolytic pathway in the production of $\mathrm{OH}$ radicals and its dependence on many factors, such as iron concentrations, concentrations of oxidizing and complexing species, the intensity of the actinic flux, and the $\mathrm{pH}$ value. Depending on all of these parameters, this production pathway of the $\mathrm{OH}$ radical may or may not be significant. The most favorable conditions are high iron concentration, high actinic flux, $\mathrm{pH}$ values between 3 and 4 , and low concentrations of complexing species. Because of the large number of parameters, only a combination of in situ measurements, laboratory experiments, and modeling studies are able to determine the significance of this $\mathrm{OH}$ production pathway.

The oxidation of organic substrates catalyzed by both iron(II) and hydrogen peroxide is called "Fenton chemistry", on the basis of an article by Fenton ${ }^{193}$ that deals with tartaric acid oxidation in the presence of $\mathrm{H}_{2} \mathrm{O}_{2}$ and iron(II). The Fenton reaction of iron(II) 
with $\mathrm{H}_{2} \mathrm{O}_{2}$ can contribute significantly to the production of $\mathrm{OH}$ radicals, even though its reaction rate is weak ( $\sim 50 \mathrm{M}^{-1} \mathrm{~s}^{-1}$ at $25{ }^{\circ} \mathrm{C}$, Dunford $\left.{ }^{194}\right)$. However, the importance of the Fenton reaction in the production of $\mathrm{OH}$ radicals in solution is still subject to controversy. The mechanism by which hydrogen peroxide is degraded by iron(II) is still uncertain and under debate. Several studies have attempted to resolve this discrepancy. Recently, two major studies examined the Fenton reaction and the various possible associated reaction mechanisms. ${ }^{33,194}$ Theoretical studies by Ensing and Baerends, ${ }^{195}$ Buda et al., ${ }^{196}$ and Ensing et al. ${ }^{197}$ have sought to determine the most probable mechanism for Fenton chemistry through simulations of molecular dynamics. All of these studies on Fenton chemistry are in agreement as to the evolution of the mixture. When iron(II) is in excess over hydrogen peroxide, no iron(III) or oxygen is produced; when hydrogen peroxide is in excess over iron(II), oxygen is produced, and iron(II) is regenerated.

However, these studies differ in the chemical mechanism proposed to explain the observations. Barb et al. ${ }^{198,199}$ suggested the following kinetic mechanism:

$$
\begin{gathered}
\mathrm{Fe}^{2+}+\mathrm{H}_{2} \mathrm{O}_{2} \rightarrow \mathrm{Fe}^{3+}+\mathrm{OH}+\mathrm{OH}^{-} \\
\mathrm{Fe}^{2+}+\mathrm{OH} \rightarrow \mathrm{Fe}^{3+}+\mathrm{OH}^{-} \\
\mathrm{OH}+\mathrm{H}_{2} \mathrm{O}_{2} \rightarrow \mathrm{HO}_{2}+\mathrm{H}_{2} \mathrm{O} \\
\mathrm{HO}_{2}+\mathrm{Fe}^{2+} \rightarrow \mathrm{Fe}^{3+}+\mathrm{HO}_{2}^{-} \\
\mathrm{HO}_{2}+\mathrm{Fe}^{3+} \rightarrow \mathrm{Fe}^{2+}+\mathrm{O}_{2}+\mathrm{H}^{+} \\
\text {and/or } \mathrm{O}_{2}^{-}+\mathrm{Fe}^{3+} \rightarrow \mathrm{Fe}^{2+}+\mathrm{O}_{2}
\end{gathered}
$$

When iron(II) is in excess, the germane reactions are reactions 14 and 15, which convert iron(II) into iron (III) without any production of oxygen. In this case, reaction 14 is the limiting step, implying stationary state production of $\mathrm{OH}$ and an identical conversion rate of iron(II) into iron(III) via reactions 14 and 15 . When hydrogen peroxide is in excess, the mechanism to be considered includes reactions 14 , $16,17,18$, and 18', which reproduce the formation of oxygen and the observed iron(II) regeneration. This mechanism is based on the assumption that the reaction of hydrogen peroxide with iron(II) produces $\mathrm{OH}$ radicals and iron(III). $\mathrm{OH}$ radical production via the Fenton reaction has been questioned in several studies suggesting that the reaction between $\mathrm{H}_{2} \mathrm{O}_{2}$ and iron(II) produces the ferryl ion [iron(IV)], which is then the active intermediate species in the Fenton chemistry. Ferryl ion reactivity has been studied in detail by Logager et al. ${ }^{200}$ and Jacobsen et al. ${ }^{201,202}$ Initially, Logager et al. ${ }^{200}$ studied ferryl ion production via the reaction between ozone and iron(II). Later, Jacobsen et al. ${ }^{201,202}$ studied the reactivity of the ferryl ion with inorganic and organic species present in the atmospheric liquid phases. Bray and Gorin ${ }^{203}$ were the first to suggest that the ferryl ion is the active intermediate in the Fenton chemistry, postulating that iron(II) and iron(III) are connected through the following equilibrium:

$$
2 \mathrm{Fe}^{3+}+\mathrm{H}_{2} \mathrm{O} \leftrightarrow \mathrm{Fe}^{2+}+\mathrm{FeO}^{2+}+2 \mathrm{H}^{+}
$$

When hydrogen peroxide is in excess, they explained the observed oxygen production and iron(II) regeneration by the two following reactions:

$$
\begin{gathered}
\mathrm{Fe}^{2+}+\mathrm{H}_{2} \mathrm{O}_{2} \rightarrow \mathrm{FeO}^{2+}+\mathrm{H}_{2} \mathrm{O} \\
\mathrm{FeO}^{2+}+\mathrm{H}_{2} \mathrm{O}_{2} \rightarrow \mathrm{Fe}^{2+}+\mathrm{H}_{2} \mathrm{O}+\mathrm{O}_{2}
\end{gathered}
$$

When iron(II) is in excess, they explained the observed production of iron(III) and the absence of oxygen production by the two following reactions:

$$
\begin{gathered}
\mathrm{Fe}^{2+}+\mathrm{H}_{2} \mathrm{O}_{2} \rightarrow \mathrm{FeO}^{2+}+\mathrm{H}_{2} \mathrm{O} \\
\mathrm{FeO}^{2+}+\mathrm{Fe}^{2+}\left(+2 \mathrm{H}^{+}\right) \rightarrow 2 \mathrm{Fe}^{3+}+\mathrm{H}_{2} \mathrm{O}
\end{gathered}
$$

This last disproportionation reaction of iron(IV) with iron(II) was not considered in Bray and Gorin's paper $^{203}$ but was proposed by Cahill and Taube. ${ }^{204}$ If reaction 20 is slow and reaction 22 is fast, the ferryl ion is in stationary state and the conversion rate of iron(II) into iron(III) is given by

$$
v=2 k_{7}\left[\mathrm{Fe}^{2+}\right]\left[\mathrm{H}_{2} \mathrm{O}_{2}\right]
$$

with $k_{7}=52.4 \pm 0.9 \mathrm{M}^{-1} \mathrm{~s}^{-1}\left(\mathrm{Kremer}^{205}\right)$.

More recent studies have shown that the Fenton chemistry mechanism cannot be restricted to the mechanisms of Barb et al. ${ }^{198,199}$ or Bray and Gorin. ${ }^{203}$ Indeed, Gozzo ${ }^{33}$ showed that the Fenton reaction produces $\mathrm{OH}$ radicals only under particular conditions (equimolar concentrations of diluted reagents in water and $\mathrm{pH} 2$ ). $\mathrm{Gozzo}^{33}$ explained this $\mathrm{OH}$ production at low $\mathrm{pH}$ value by a mechanism intermediate between those of Barb et al. ${ }^{198,199}$ and Bray and Gorin: ${ }^{203}$ The reaction of iron(II) with hydrogen peroxide produces the ferryl ion, but this ion is a weak acid in equilibrium with its combined base $\mathrm{Fe}-$ $(\mathrm{OH})^{3+}$ :

$$
\mathrm{FeO}^{2+}+\mathrm{H}^{+} \leftrightarrow \mathrm{Fe}(\mathrm{OH})^{3+}\left(\mathrm{p} K_{\mathrm{a}} \approx 2\right)
$$

At low $\mathrm{pH}$, this equilibrium moves toward $\mathrm{Fe}-$ $(\mathrm{OH})^{3+}$ formation, which according to $\mathrm{Gozzo}^{33}$ is unstable and should decompose to yield the $\mathrm{OH}$ radical

$$
\left(\mathrm{Fe}^{\mathrm{IV}}=\mathrm{O}\right)^{2+}+\mathrm{H}^{+} \rightarrow\left(\mathrm{Fe}^{\mathrm{IV}}-\mathrm{OH}\right)^{3+} \rightarrow \mathrm{Fe}^{\mathrm{III}}+\mathrm{OH}
$$

where $\mathrm{Fe}^{\mathrm{IV}}$ and $\mathrm{Fe}^{\mathrm{III}}$ can be free or complexed iron.

This study suggests that the active intermediates in the Fenton chemistry (ferryl ion or $\mathrm{OH}$ radical) depend not only on the $\mathrm{pH}$ value but also on relative iron(II) and hydrogen peroxide initial concentrations. 


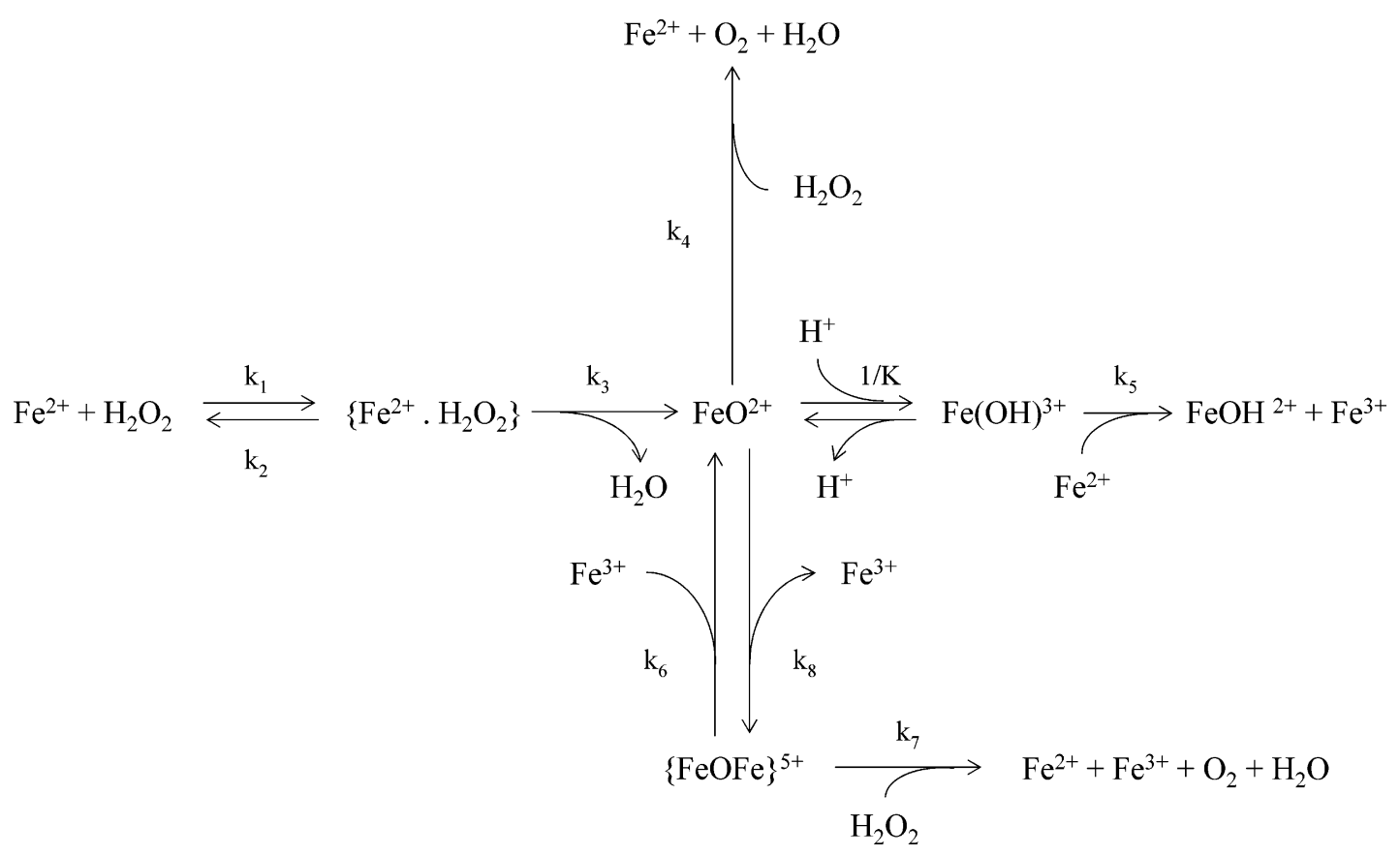

Figure 11. Proposed chemical mechanism of the Fenton reaction. Reprinted with permission from ref 205 . Copyright 2003 American Chemical Society.

Similarly, the study of Hug and Leupin ${ }^{206}$ suggested that the active intermediate depends on $\mathrm{pH}$, and they proposed the following mechanism:

$$
\begin{aligned}
& {\left[\mathrm{Fe}^{\mathrm{II}}\left(\mathrm{H}_{2} \mathrm{O}\right)_{6}\right]^{2+}+} \mathrm{H}_{2} \mathrm{O}_{2} \rightarrow \\
& {\left[\left(\mathrm{H}_{2} \mathrm{O}\right)_{5} \mathrm{Fe}^{\mathrm{II}}-\mathrm{O}_{2} \mathrm{H}_{2}\right]^{2+}+\mathrm{H}_{2} \mathrm{O} }
\end{aligned}
$$

The complex $\left[\left(\mathrm{H}_{2} \mathrm{O}\right)_{5} \mathrm{Fe}^{\mathrm{II}}-\mathrm{O}_{2} \mathrm{H}_{2}\right]^{2+}$ quickly decomposes into an intermediate compound with an unknown chemical structure:

$$
\left[\left(\mathrm{H}_{2} \mathrm{O}\right)_{5} \mathrm{Fe}^{\mathrm{II}}-\mathrm{O}_{2} \mathrm{H}_{2}\right]^{2+} \rightarrow \mathrm{INT}
$$

This intermediate compound with its combined base INT- $\mathrm{OH}$ is a weak acid in equilibrium:

$$
\mathrm{INT}-\mathrm{OH}+\mathrm{H}^{+} \leftrightarrow \mathrm{INT}
$$

This weak acid and its combined base follow two different degradation pathways:

$$
\begin{gathered}
\mathrm{INT} \rightarrow \mathrm{Fe}^{\mathrm{III}}(\mathrm{OH})^{2+}+\mathrm{OH} \\
\mathrm{INT}-\mathrm{OH} \rightarrow \mathrm{Fe}^{\mathrm{IV}}
\end{gathered}
$$

Thus, depending on the $\mathrm{pH}$ value, the active intermediate is the $\mathrm{OH}$ radical or the ferryl ion.

Successive studies by Kremer ${ }^{205,207,208}$ attempted to work out a detailed reaction mechanism for the Fenton chemistry that refuted the presence of the $\mathrm{OH}$ radical as the active intermediate. The last study, incorporating their previous results, presented a new reaction mechanism (Figure 11) that takes into consideration the observed $\mathrm{pH}$ dependence of the Fenton reaction. The authors based the construction of this mechanism on the following four experimental observations: (1) no evolution of the $\mathrm{O}_{2}$ concentration over time when $\mathrm{Fe}^{2+}$ is in excess over $\mathrm{H}_{2} \mathrm{O}_{2},(2) \mathrm{Fe}^{2+}$ regeneration coupled with $\mathrm{O}_{2}$ formation when $\mathrm{H}_{2} \mathrm{O}_{2}$ is in excess over $\mathrm{Fe}^{2+}$, (3) an increase in the rate of $\mathrm{O}_{2}$ formation as the $\mathrm{pH}$ goes up, and (4) a rise in the rate of $\mathrm{O}_{2}$ formation as the initial $\mathrm{Fe}^{3+}$ increases.

In Figure 11, the ferryl ion is in equilibrium with its combined base $[\mathrm{Fe}(\mathrm{OH})]^{3+}$, as suggested by Gozzo. ${ }^{33}[\mathrm{Fe}(\mathrm{OH})]^{3+}$ reacts with $\mathrm{Fe}^{2+}$ to produce iron(III) again, rather than an $\mathrm{OH}$ radical, as was proposed by Gozzo, ${ }^{33}$ who used organic compounds as indicators of the presence of the $\mathrm{OH}$ radical to demonstrate that this radical is formed in the Fenton chemistry under specific conditions. Meanwhile, theoretical studies investigated the most probable reaction pathways for the Fenton chemistry. These studies showed that the ferryl ion is the most probable product of the reaction between iron(II) and hydrogen peroxide $^{195}$ and that for many organic substrate oxidations the ferryl ion can function as the active intermediate in the Fenton chemistry. ${ }^{197}$ Moreover, the study by Buda et al. ${ }^{196}$ showed that the most probable chemical pathways explaining the $\mathrm{O}_{2}$ formation observed during laboratory experiments are

$$
\begin{gathered}
\mathrm{FeO}^{2+}+\mathrm{H}_{2} \mathrm{O}_{2} \rightarrow \mathrm{Fe}(\mathrm{OH})^{2+}+\mathrm{HO}_{2} \\
\mathrm{Fe}(\mathrm{OH})^{2+}+\mathrm{HO}_{2} \rightarrow \mathrm{Fe}^{2+}+\mathrm{O}_{2}+\mathrm{H}_{2} \mathrm{O}
\end{gathered}
$$

The result of these two reactions is equivalent to reaction 21 , which is also considered $\left(R_{4}\right.$ reaction in Figure 11) in Kremer's diagram. ${ }^{205}$ However, the currently available studies on iron reactivity with $\mathrm{HO}_{2}$ and its combined base, the superoxide ion $\mathrm{O}_{2}{ }^{-}$ (Rush and Bielski ${ }^{31}$ and references therein), showed that the reaction of iron(III) with the $\mathrm{HO}_{2}$ radical is slower (kinetic constant of $<10^{3} \mathrm{M}^{-1} \mathrm{~s}^{-1}$ ) than the reaction with the superoxide ion.

Finally, the $\mathrm{pH}$-dependent pathways represent the most promising mechanism for determining whether the active intermediate in the Fenton chemistry is the $\mathrm{OH}$ radical or the ferryl ion. ${ }^{33,206}$ The mechanism 
proposed by Hug and Leupin ${ }^{206}$ seems to provide a correct explanation for the various experimental observations of the Fenton chemistry. However, the nature of the intermediate (INT) proposed in this study is currently unknown. Up to now, all available Fenton chemistry mechanisms have failed to give a complete, detailed reaction mechanism explaining the experimental observations.

Modeling studies on the radical pathways in the Fenton chemistry have sought to appraise the relative importance of the Fenton reaction on $\mathrm{OH}$ production for different chemical scenarios. Ervens et al. ${ }^{172}$ showed that the Fenton reaction is predominant for urban and rural scenarios, for example, given sufficient initial iron concentrations. Deguillaume et al. ${ }^{23}$ have emphasized the fact that the relative contribution of the Fenton reaction depends on the $\mathrm{H}_{2} \mathrm{O}_{2}$ regime. Under polluted conditions, $\mathrm{H}_{2} \mathrm{O}_{2}$ is efficiently consumed by $\mathrm{S}(\mathrm{IV})$, leading to low $\mathrm{H}_{2} \mathrm{O}_{2}$ concentration; this is not the case in the rural scenario. Despite the fact that the initial iron concentration is lower in the rural data, the relative contribution of the Fenton reaction to $\mathrm{OH}$ production is nevertheless higher in rural than in urban conditions.

The reactions of $\mathrm{HO}_{2} / \mathrm{O}_{2}{ }^{-}$with iron compete with the reaction between $\mathrm{O}_{2}{ }^{-}$and $\mathrm{O}_{3},{ }^{21,209,210}$ which represents an efficient ozone sink in the aqueous phase for $\mathrm{pH}$ values $>5$ and consequently in the gas phase as well. ${ }^{2}$ If the iron concentration in the aqueous phase is higher than that of ozone, the $\mathrm{HO}_{2} /$ $\mathrm{O}_{2}{ }^{-}$radicals react mainly with iron. The result is that the concentration in $\mathrm{HO}_{2} / \mathrm{O}_{2}{ }^{-}$is reduced by a factor of at least 2 when transition metals are taken into account, and the destruction of ozone by the superoxide ion in the aqueous phase is eliminated. ${ }^{182}$ This makes this pathway, in comparison with the others, a negligible producer of $\mathrm{OH}$ radicals. ${ }^{169}$ Matthijsen et al. ${ }^{209}$ undertook to evaluate the influence of iron and copper on tropospheric ozone by simulating different chemical scenarios with an air parcel model. Under average continental conditions, they showed that when iron and copper are taken into account, aqueous-phase ozone destruction decreases by up to $70 \%$ and that the aqueous-phase destruction of $\mathrm{H}_{2} \mathrm{O}_{2}$ increases by up to $5 \%$, resulting in a significant aqueous-phase concentration of $\mathrm{OH}$. Under polluted continental conditions, they demonstrated that the destruction of $\mathrm{O}_{3}$ is controlled by the reaction of $\mathrm{O}_{3}$ with iron(II) and that, depending on iron concentrations, $\mathrm{O}_{3}$ destruction can be very rapid. Sedlak et al. ${ }^{28}$ showed that for a given iron concentration the Fenton reaction contribution to $\mathrm{HO}_{x}$ radical production is negligible in comparison with the $\mathrm{HO}_{x}$ sink consisting of reactions of iron with $\mathrm{HO}_{2} / \mathrm{O}_{2}{ }^{-}$radicals. Thus, they concluded that the major effect of the iron chemistry is to eliminate the ozone destruction cycle in the aqueous phase. Matthijsen et al. ${ }^{210}$ used a threedimensional atmospheric model coupled with modules describing gas chemistry, aqueous chemistry, and emissions (model LOTTOS) to investigate the influence of clouds on ozone at the regional scale (Europe). They showed that iron and copper reactions change the aqueous-phase reaction pathways sub- stantially, leading to an ozone sink in droplets that is 4 times smaller than when copper and iron are not considered. Iron(II) is also oxidized by ozone in the aqueous phase, and this reaction is still subject to controversy. The first studies on the reactivity of iron(II) with ozone suggested that this oxidation produced iron(III) as well as an OH radical. Thereafter, Logager et al. ${ }^{200}$ highlighted that this reaction leads to the formation of the ferryl ion $\mathrm{FeO}^{2}+$ (iron under its +IV oxidation state). The kinetic constants and the activation energies for the reactions of the ferryl ion with certain organic and inorganic compounds that are present in atmospheric liquid phases were measured by Jacobsen et al. ${ }^{201,202}$ In the aqueous phase the ferryl ion is potentially important because of its strong oxidation capacity, and consequently it could modify the redox iron cycle in cloud droplets. However, Ervens et al. ${ }^{172}$ and Deguillaume et al. ${ }^{23}$ using a multiphase chemistry box model on academic scenarios, showed that the contribution of this compound to the redox cycle of iron is not significant. Since then, Deguillaume et al. ${ }^{211}$ have shown by running sensitivity tests on the potential active Fenton chemistry intermediaries $(\mathrm{OH}$ radical versus ferryl ion) that the ferryl ion can indeed play a significant role in the redox iron cycle, especially during the night.

In conclusion, $\mathrm{OH}$ production in the aqueous phase is partly driven by iron reactivity. On the one hand, for maritime clouds with low iron concentrations, $\mathrm{OH}$ radical production will be predominantly due to the reaction between ozone and $\mathrm{O}_{2}{ }^{-}$and to the mass transfer of $\mathrm{OH}$ radicals from the gas phase. ${ }^{23,172} \mathrm{On}$ the other hand, for continental clouds the sources of $\mathrm{OH}$ are numerous, and the respective contributions of each one depend on the concentrations of chemical species in the aqueous phase, the $\mathrm{pH}$ value, the actinic flux, etc. ${ }^{23,172}$

\subsubsection{Reactivity with S Compounds}

The multiphase chemistry of sulfur compounds leads to the conversion of S(IV) into S(VI), a process extensively investigated within the framework of the environmental problem known as acid rain.9,27 The conversion of sulfite into sulfate in atmospheric liquid phases occurs via

- direct oxidation of sulfite by hydrogen peroxide, ozone, organic peroxides, or pernitric acid $\mathrm{HNO}_{4}$;

- an indirect oxidation pathway initiated by $\mathrm{OH}$, $\mathrm{Cl}_{2}{ }^{-}$, and $\mathrm{NO}_{3}$ radicals and propagated by $\mathrm{SO}_{3}{ }^{-}, \mathrm{SO}_{4}{ }^{-}$, and $\mathrm{SO}_{5}{ }^{-}$radicals; and

- oxidation by dissolved oxygen, catalyzed by transition metals and in particular by iron.

Titoff ${ }^{212}$ first showed that the oxidation of sulfur(IV) to sulfur(VI) is catalyzed by ions of transition metals such as copper, iron, or manganese and that it is difficult to eliminate traces of such metals from aqueous solutions. In fact, the reaction can be quenched by the addition of metal complexing agents, ${ }^{213,214}$ so that the claim by some investigators to have observed the uncatalyzed reaction must be viewed with caution. Connick et al. ${ }^{215}$ recently reassessed the problem and presented new evidence for a noncatalyzed pathway. The observed rate was too 
slow to be of any significance in clouds. Most of the studies exploring the metal-catalyzed oxidation of sulfur(IV) have focused on iron as the catalyst. Hegg and Hobbs ${ }^{216}$ and Martin ${ }^{217}$ reviewed empirical rate laws derived from laboratory studies; Brandt and van Eldik ${ }^{27}$ provided an updated, extensive review of the literature on this chemical pathway.

The iron-oxygen-S(IV) system is now relatively well-known ${ }^{218-222}$ and is described by the following chain mechanism:

$$
\begin{gathered}
\mathrm{Fe}(\mathrm{III})+\mathrm{HSO}_{3}{ }^{-} \rightarrow \mathrm{Fe}(\mathrm{II})+\mathrm{SO}_{3}{ }^{-}+\mathrm{H}^{+} \\
\mathrm{SO}_{3}{ }^{-}+\mathrm{O}_{2} \rightarrow \mathrm{SO}_{5}{ }^{-} \\
\mathrm{SO}_{5}{ }^{-}+\mathrm{Fe}(\mathrm{II})+\mathrm{H}^{+} \rightarrow \mathrm{HSO}_{5}{ }^{-}+\mathrm{Fe}(\mathrm{III}) \\
\mathrm{HSO}_{5}{ }^{-}+\mathrm{Fe}(\mathrm{II}) \rightarrow \mathrm{SO}_{4}{ }^{-}+\mathrm{OH}^{-}+\mathrm{Fe}(\mathrm{III}) \\
\mathrm{SO}_{4}{ }^{-}+\mathrm{Fe}(\mathrm{II}) \rightarrow \mathrm{SO}_{4}{ }^{2-}+\mathrm{Fe}(\mathrm{III})
\end{gathered}
$$

The catalytic efficiency of iron in the oxidation of sulfur(IV) into sulfur(VI) depends on its speciation. ${ }^{27}$ Therefore, as has been shown above in the discussion of iron speciation, iron's ability to catalyze the conversion of sulfur(IV) into sulfur(VI) depends on the intensity of the actinic flux, the oxidant concentrations $\left(\mathrm{O}_{3}, \mathrm{OH}, \mathrm{O}_{2}, \mathrm{H}_{2} \mathrm{O}_{2}, \mathrm{HO}_{2} / \mathrm{O}_{2}{ }^{-}\right.$, etc. $)$, the concentration in reducing agents $\left[\mathrm{HO}_{2} / \mathrm{O}_{2}{ }^{-}\right.$, sulfur(IV), etc.], and the concentration of complexing agents (oxalate, formate, etc.). ${ }^{169,223}$

Moreover, iron in solution under its +III oxidation state forms an $\left[\mathrm{Fe}\left(\mathrm{SO}_{4}\right)\right]^{+}$complex with sulfate ions, which is photolyzed forming iron(II) and sulfate radical:

$$
\left[\mathrm{Fe}\left(\mathrm{SO}_{4}\right)\right]^{+}+h v \rightarrow \mathrm{Fe}^{2+}+\mathrm{SO}_{4}^{-}
$$

Benkelberg and Warneck ${ }^{191}$ determined the quantum yield of $\mathrm{SO}_{4}^{-}$radical formation by photolysis of the complex $\left[\mathrm{Fe}\left(\mathrm{SO}_{4}\right)\right]^{+}$. This quantum yield varies from $7.28 \times 10^{-3}$ to $1.51 \times 10^{-3}$ for wavelengths varying from 280 to $350 \mathrm{~nm}$. Depending on the intensity of the actinic flux, the sulfato complex will accumulate or not and will reduce more or less the efficiency of the iron-oxygen-S(IV) system.

If iron(II) predominates over iron(III), the catalytic cycle of the oxidation of sulfur(IV) into sulfur(VI) is hindered until iron(III) (the active catalyst) has been produced from iron(II). ${ }^{223}$ Grgić et al., ${ }^{224}$ Ziajka et al., ${ }^{221}$ and Nović et al. ${ }^{225}$ showed that an equilibrium is established between iron(II) and iron(III) during the conversion of sulfur(IV) into sulfur(VI). As previously detailed, iron is involved in a set of chemical and/or photochemical reactions resulting in a rapid iron(II)-iron(III) cycle. This iron redox cycle makes it very complex to evaluate iron's catalytic ability in the oxidation cycle of sulfur(IV) into sulfur(VI). The efficiency of this catalytic cycle is linked to the interactions between iron and $\mathrm{SO}_{5}{ }^{-}, \mathrm{HSO}_{5}{ }^{-}$, and $\mathrm{SO}_{4}{ }^{-}$ radicals and between iron and the other chemical compounds present in the atmospheric aqueous phase. Dissolved organic compounds (DOCs) are likely to reduce the efficiency of the catalytic cycle due to their reactivity with sulfate radicals ${ }^{26,226}$ and to the formation of organic complexes between DOCs and iron(III). Grgić et al., ${ }^{223,227}$ Sedlak and Hoigné, ${ }^{228,229}$ Wolf et al., ${ }^{230}$ and Zuo and Zhan ${ }^{231}$ have studied the inhibiting effect of the formation of iron(III) complexes on the iron catalytic cycle; whereas oxalate shows a significant effect, acetate and formate seem to have a negligible effect due to their lower complexation constants. Because of the interactions between the sulfate radical and DOCs, the efficiency of the catalytic cycle is reduced, and under typical atmospheric cloud conditions the contribution of these chemical pathways is in general negligible as compared to the total formation of sulfuric acid in the atmospheric liquid phases. ${ }^{169}$ This catalytic cycle can become significant under particular conditions, especially in continental clouds or fogs in which there is low photochemical activity. ${ }^{232}$ The box modeling study of Pandis et al. ${ }^{233}$ showed that the iron catalysis of sulfate production in fog droplets is favored at night, when hydrogen peroxide and ozone concentrations are low. Warneck et al. ${ }^{234}$ used a box model of a small sunlit cumulus cloud to explore the efficiency of various chemical cloud reactions contributing to the oxidation of sulfur(IV). They showed that the reaction of iron(III) with $\mathrm{HSO}_{3}{ }^{-}$, which can trigger the chain oxidation of sulfur(IV), turns out to be unimportant under these conditions, because iron(III) is rapidly converted to iron(II) by reacting with $\mathrm{HO}_{2} / \mathrm{O}_{2}{ }^{-}$and copper(I). Ervens et al. ${ }^{172}$ and Deguillaume et al. ${ }^{23}$ showed that the direct oxidation of sulfur(IV) by $\mathrm{H}_{2} \mathrm{O}_{2}$ is the chief contributor to sulfur(VI) production, whereas the indirect pathway through iron catalysis is insignificant.

However, iron can also have an indirect role on the oxidation of sulfur(IV) due to its role in the hydrogen peroxide production, which is an effective oxidant of sulfur(IV). Zuo and Hoigné, ${ }^{180}$ Faust and Zepp, ${ }^{235}$ and Pehkonen et al. ${ }^{48}$ showed that photolysis of iron(III)oxalato complexes produces $\mathrm{H}_{2} \mathrm{O}_{2}$, which efficiently converts sulfur(IV) into sulfur(VI). This indirect role makes it more complicated to evaluate the impact of iron on the conversion of sulfur(IV) into sulfur(VI).

Heterogeneous photocatalytic effects may also play a role in converting sulfur(IV) to sulfur(VI) (see Brandt and van Eldik ${ }^{27}$ and references therein). Cho and Carmichael ${ }^{236}$ showed that iron oxide can chemisorb sulfur dioxide, converting it to sulfate at the gas-solid interface. Laboratory experiments showed that $\alpha-\mathrm{Fe}_{2} \mathrm{O}_{3}$ (hematite) is photocatalytically active in the oxidation of sulfur(IV), whereas $\gamma-\mathrm{Fe}_{2} \mathrm{O}_{3}$ (maghemite) has little effect. ${ }^{237}$ These iron oxides can be photoactivated by visible light, and iron oxohydroxides may be also involved. The order of reactivity is $\alpha-\mathrm{Fe}_{2} \mathrm{O}_{3}>\gamma-\mathrm{FeOOH} \approx \beta-\mathrm{FeOOH} \gg \alpha-\mathrm{FeOOH} .{ }^{238}$ More laboratory investigations are needed to understand this potential heterogeneous photocatalytic effect in cloudy conditions.

\subsubsection{Reactivity with Soluble Organic Compounds}

The chemistry of oxygenated VOCs in the aqueous phase can interact with the chemistry of iron via the formation of organic complexes. ${ }^{119}$ Zuo and Hoigné, ${ }^{180}$ on the basis of some irradiation experiments on 
synthetic solutions, concluded that the consumption of oxalic acid in the photochemical cycle of iron(III)/ iron(II)-oxalato complexes can represent a major oxalic acid sink in the atmosphere and leads to carbon dioxide radical anion and eventually to carbon dioxide formation. The complexes formed between iron(III) and the carboxylate ions (formate, acetate, and oxalate) can be photolyzed to form iron(II) and the organic anion, which is then oxidized. .8, $120,180,235,239^{2}$

$$
\begin{aligned}
& \mathrm{Fe}(\mathrm{III})-\mathrm{Org}+h v \rightarrow \mathrm{Fe}(\mathrm{II})+\text { Org (radical) } \\
& \text { Org (radical) }+\mathrm{O}_{2} \rightarrow \mathrm{O}_{2}^{-}+\text {Org (oxidized) }
\end{aligned}
$$

Oxalate is found in atmospheric waters at concentrations that approach micromolar levels. ${ }^{26,29,240-243}$ Due to a high complex-formation constant of iron(III)-oxalate, a fraction of the dissolved iron(III) is present as iron (oxalate 1), $\mathrm{Fe}\left(\mathrm{C}_{2} \mathrm{O}_{4}\right)^{+}$, iron (oxalate 2), $\mathrm{Fe}\left(\mathrm{C}_{2} \mathrm{O}_{4}\right)_{2}{ }^{-}$, or iron (oxalate 3 ), $\mathrm{Fe}\left(\mathrm{C}_{2} \mathrm{O}_{4}\right)_{3}{ }^{3-} .180,244$ All three complexes absorb light with a similar absorption band that extends from the UV-A into the visible region. Even at a spectral region of high overlap with tropospheric sunlight (e.g., at $360 \mathrm{~nm}$ ), they still exhibit a molar extinction value of $\sim 1000$ $\mathrm{cm}^{-1} \mathrm{M}^{-1}$. In the presence of oxygen their photolysis in dilute solution indirectly forms $\mathrm{O}_{2}{ }^{-}$and iron(II). ${ }^{245}$ For the 2- and 3-oxalato complexes, a high absorption coefficient is combined with high photolysis quantum efficiency. ${ }^{246}$ Zuo and Hoigné ${ }^{180}$ showed that photolysis of the iron-oxalato complexes is $\sim 100$ times faster than that of the complex $[\mathrm{Fe}(\mathrm{OH})]^{2+}$ because of the differences between the UV-visible absorption spectra of these complexes. Therefore, photolysis of ironoxalato complexes is a potential source of iron(II) and $\mathrm{O}_{2}{ }^{-}$in atmospheric waters.

A laboratory study carried out by Arakaki and Faust ${ }^{151}$ using cloud water sampled at Whiteface Mountain showed that the diurnal iron(II)/iron(III) cycle is driven by reaction 38 and the Fenton reaction, which are major $\mathrm{OH}$ radical sources during the day. Siefert et al. ${ }^{247}$ irradiated aqueous solutions of aerosols sampled at different sites in the United States. They attributed the observed iron(II) production after irradiation to photolysis of the iron-oxalato complexes. On the basis of the production rate measured during irradiation, they concluded that reactions 38 and 39 are responsible for an $\mathrm{HO}_{x}$ production of $\sim 10^{6}-10^{7}$ molecules $\mathrm{cm}^{-3} \mathrm{~s}^{-1}$ in summertime conditions at noon, which is similar to $\mathrm{HO}_{x}$ production in the gas phase. ${ }^{248}$ It is, however, possible that part of the iron(II) production measured by Siefert et al. ${ }^{247}$ comes from the reaction between iron(III) and $\mathrm{O}_{2}{ }^{-}$, which does not produce $\mathrm{HO}_{x}$. Pehkonen et al. ${ }^{48}$ showed that the photolysis of iron-carboxylate complexes could be an important degradation pathway of atmospheric carboxylic acids. The degradation products include carboxylic acids with shortened carbon chains and hydrogen peroxide. ${ }^{48,180,247,249,250}$ Previous studies had shown that the major source of hydrogen peroxide in the atmosphere is driven by reactions in the gas phase. ${ }^{251,252}$ However, Zuo and Hoigné $^{180}$ showed that iron(III)-carboxylate complex photolysis could play an important role in the production of $\mathrm{H}_{2} \mathrm{O}_{2}$ in the aqueous phase and, therefore,

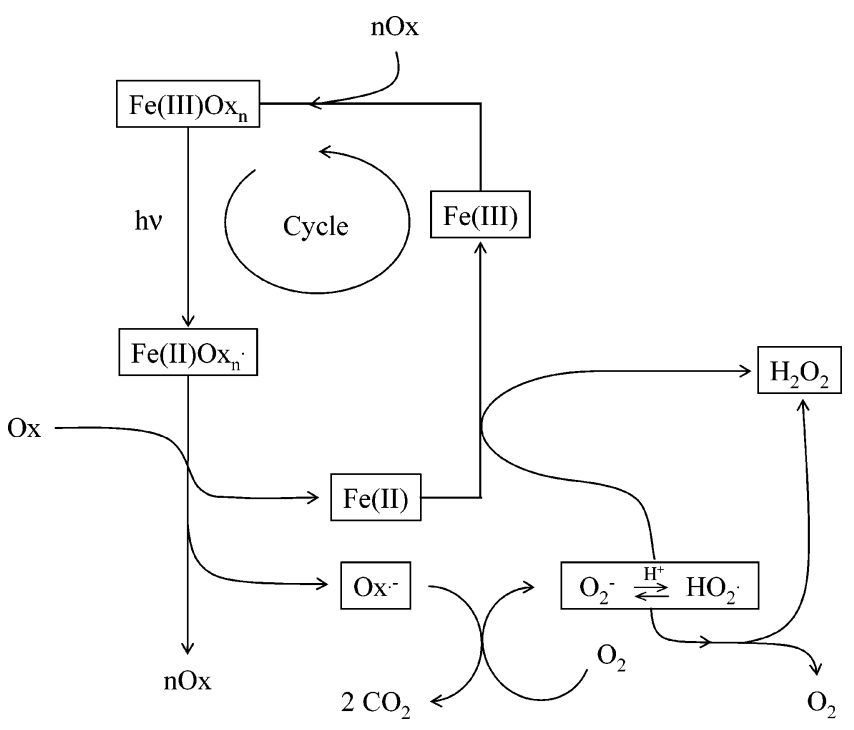

Figure 12. Scheme for the photochemical/chemical cycling of iron and formation of $\mathrm{H}_{2} \mathrm{O}_{2}$. Reprinted with permission from ref 180. Copyright 1992 American Chemical Society.

in the gas phase. The general mechanism of iron(III)-oxalato complex decomposition and associated hydrogen peroxide formation is summarized in Figure 12 , where the iron(III)-oxalato complex is represented by $\mathrm{Fe}(\mathrm{III}) \mathrm{Ox}_{n}$. Photolysis of the iron(III)oxalato complex produces an $\mathrm{Ox}^{-}\left(\mathrm{C}_{2} \mathrm{O}_{4}^{-}\right)$radical, which reacts with the dissolved oxygen to form an $\mathrm{O}_{2}{ }^{-}$radical, leading finally to the formation of hydrogen peroxide.

In a recent study Kieber et al. ${ }^{175}$ irradiated authentic rainwater with simulated sunlight to determine the different photochemical production pathways of iron(II). They indicated that the photolysis of iron(III) hydroxide and oxalate complexes is a potentially significant source of iron(II) in rainwater, but results suggest that another iron(III) ligand is responsible for much of the observed photochemical production of iron(II). They proposed that the complexation of iron(III) by humic-like substances can be significant because they are rapidly photodegraded under ambient sunlight conditions ${ }^{253}$ (cf. section 3.1.1).

Furthermore, iron chemistry leads to an $\mathrm{OH}$ production in the aqueous phase that can induce stronger VOC oxidation and thus produce $\mathrm{HO}_{2} / \mathrm{O}_{2}{ }^{-}$radicals that yield a higher level of $\mathrm{H}_{2} \mathrm{O}_{2}{ }^{23,178,231}$. Jans and Hoigné ${ }^{176}$ showed that photolysis of high concentrations of iron(III) oxalate complexes in aqueous phase represents an expanded source of $\mathrm{O}_{2}{ }^{-}$that grows to a level comparable with or greater than the $\mathrm{O}_{2}{ }^{-}$ contributed by the gas phase.

Recently, Stemmler and von Gunten ${ }^{254}$ investigated the $\mathrm{OH}$ oxidation of 2-butoxyethanol, used as a model species, in the presence of iron and/or copper in the aqueous phase to study the interactions between peroxyl radicals and transition metals. They showed that the presence of transition metals can induce an efficient catalysis of the reactions between the peroxyl and the $\mathrm{HO}_{2}$ radical or with that radical's combined base $\mathrm{O}_{2}{ }^{-}$, which produces organic hydroperoxides. The production of organic hydroperoxides is then strongly dependent on the solution $\mathrm{pH}$, the 


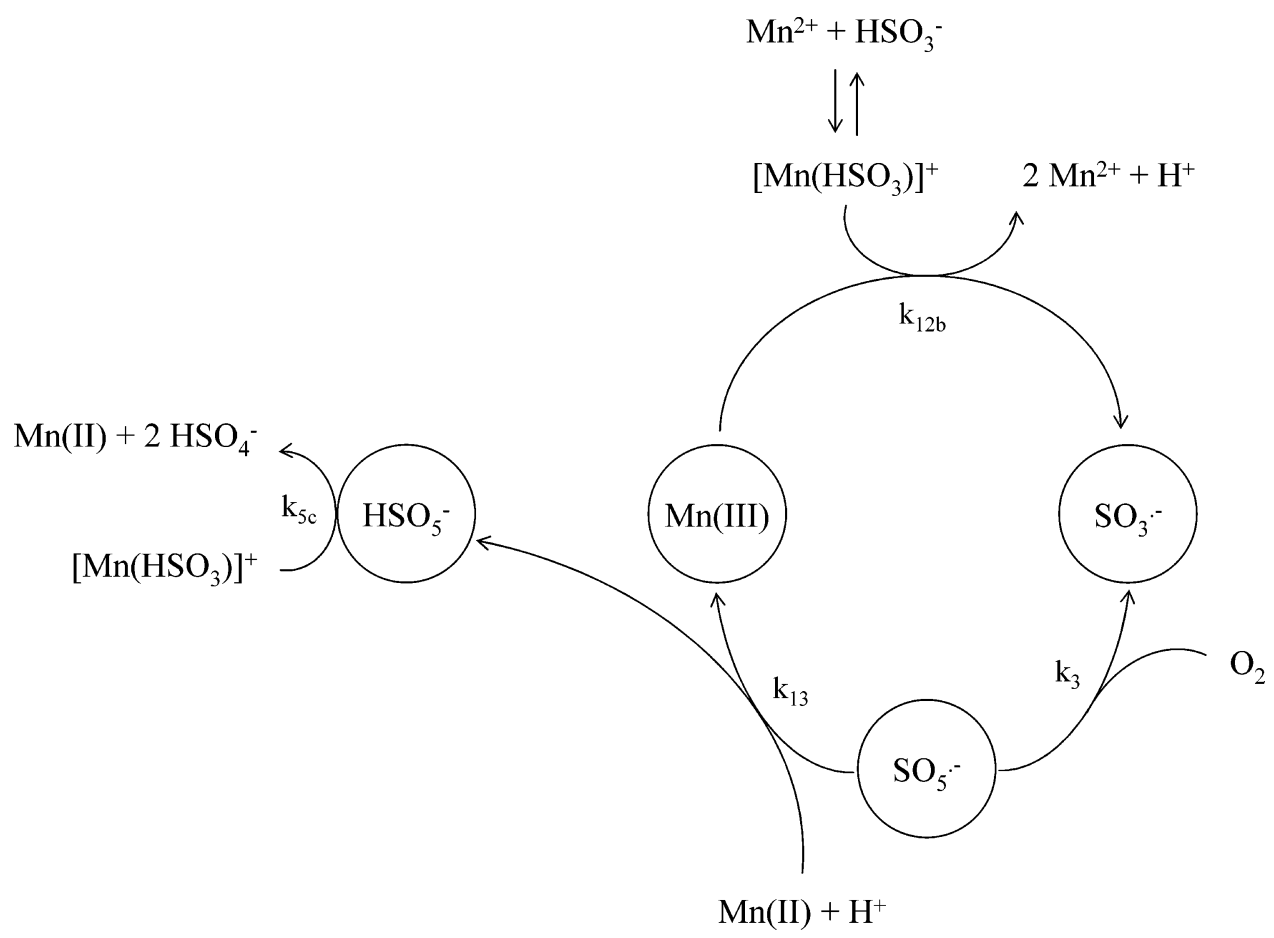

Figure 13. Proposed mechanism for the manganese(III/II)-catalyzed autoxidation of hydrogen sulfite. Reprinted with permission from ref 130. Copyright 1995 Elsevier Science and Technology (http://www.elsevier.com).

concentrations of $\mathrm{HO}_{2}$ radical, iron(II), and copper(I) [a more effective catalyst for these reactions than iron(II)]. They also showed that the formation of transition metal complexes with oxalate tends to reduce this production of organic hydroperoxides. Studies in the laboratory carried out by Khaikin et al. ${ }^{255}$ highlighted a direct reaction between iron(II) and $\mathrm{RO}_{2}$ peroxyl radicals through the formation of an intermediate complex $\mathrm{RO}_{2}-\mathrm{Fe}^{3+}$, which then decomposes into iron(III). The higher the initial $\mathrm{Fe}^{2+}$ concentration and $\mathrm{pH}$ value, the faster this decomposition proceeds. Iron can also interact with organic hydroperoxides directly through "Fenton-like" reactions. These kinds of reactions have been recently studied under atmospheric conditions for methyl hydroperoxide (MHP) and ethyl hydroperoxide (EHP). ${ }^{256}$ In this study, the kinetic constants for reactions of MHP and EHP with the ferrous ion were determined, and the values obtained are in the same range as the kinetic constant of the Fenton-like reaction with iron(II) with $\mathrm{H}_{2} \mathrm{O}_{2}$. Analysis of the major products of these reactions shows that alkoxyl radicals appear and are rearranged in the aqueous phase before reacting with oxygen to form peroxyl radicals. These radicals can then decompose to form aldehydes and $\mathrm{HO}_{2}$ radicals, or they can react with themselves to give the corresponding acids and hydrogen peroxide, or they can react with $\mathrm{HO}_{2}$ radicals to yield the corresponding hydroxy hydroperoxides. Chevallier et al. ${ }^{256}$ have predicted that these reactions should influence iron(II)/iron(III) cycles and $\mathrm{HO}_{x}$ multiphase chemistry.

The three studies cited above are the only ones to have examined the interactions between transition metals, peroxyl radicals, and organic hydroperoxides, which is why to date the interactions between oxygenated VOCs in the aqueous phase and transition metals are still poorly known.

\subsection{Copper and Manganese Reactivity in the Atmospheric Liquid Phase}

Because of its low reactivity, in particular with $\mathrm{HO}_{2} / \mathrm{O}_{2}{ }^{-}$radicals, and its weak concentration in atmospheric liquid phases, as demonstrated by available modeling studies on cloud chemistry, ${ }^{20,22,23,172,178}$ manganese does not seem to play a significant role in $\mathrm{HO}_{x}$ chemistry.

However, Graedel et al. ${ }^{178}$ indicated that the mechanism of manganese-catalyzed sulfur(IV) oxidation could be an important source of sulfate in droplets, particularly at $\mathrm{pH}<4$ and relatively low concentrations of hydrogen peroxide. Berglund et al. ${ }^{257}$ first suggested that manganese(II) behaves in the same way as iron(II) in the catalysis of sulfur(IV) oxidation and attempted to work out a chemical mechanism describing interactions between manganese and sulfur chemistry. On the basis of their experimental observations [induction period, manganese(II) and (III) dependence, sulfur dependence, oxygen dependence, $\mathrm{pH}$ dependence, etc.] and correlated with previous studies, ${ }^{179,257-265}$ Berglund et al. ${ }^{130}$ proposed a chemical mechanism at $\mathrm{pH} 2.4$ for the manganesecatalyzed autoxidation of hydrogen sulfite (see Figure 13).

Berglund et al. ${ }^{130}$ proposed that in a first step manganese(II) forms a hydrogen sulfite complex [Mn$\left(\mathrm{HSO}_{3}{ }^{+}\right)$] in this way

$$
\mathrm{Mn}^{2+}+\mathrm{HSO}_{3}{ }^{-} \rightarrow\left[\mathrm{Mn}\left(\mathrm{HSO}_{3}\right)^{+}\right]
$$

From their point of view, this is the only way to explain the saturation of the reaction rate observed for increasing concentrations of manganese(II). In the second reaction step, $\left[\mathrm{Mn}\left(\mathrm{HSO}_{3}\right)^{+}\right]$reacts with manganese(III) to form $\mathrm{SO}_{3}{ }^{-}$radicals. These radicals rapidly react with dissolved molecular oxygen, pro- 


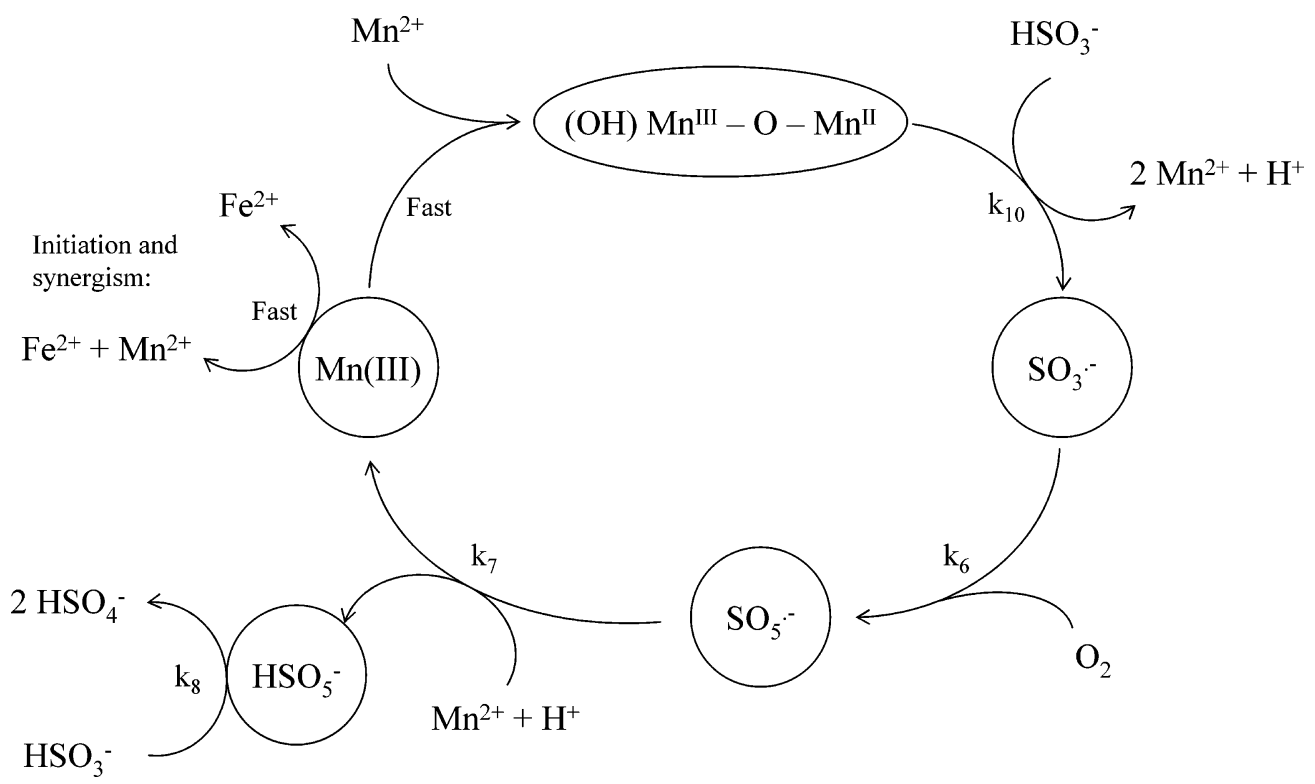

Figure 14. Revised mechanism for the manganese(III/II)-catalyzed autoxidation of hydrogen sulfite. Reprinted with permission from ref 131. Copyright 1998 American Chemical Society.

ducing $\mathrm{SO}_{5}^{-}$radicals. Reaction between $\mathrm{SO}_{5}^{-}$and manganese(II) regenerates manganese(III) and forms $\mathrm{HSO}_{5}{ }^{-}{ }^{266} \mathrm{Hydrogen}$ peroxomonosulfate oxidizes the complex $\left[\mathrm{Mn}\left(\mathrm{HSO}_{3}\right)^{+}\right]$to produce sulfur(IV) as the final product. This mechanism was revised by Fronaeus et al. ${ }^{131}$ on the basis of previous comprehensive kinetic studies and thermodynamic data for ironmanganese redox processes and manganese(II) and manganese(III) protolysis equilibriums (see Figure 14).

The catalytically active manganese species was concluded to be an oxo-bridged (or hydroxo-bridged) mixed-valence complex of composition $(\mathrm{OH}) \mathrm{Mn}^{\mathrm{III}}$ $\mathrm{OMn}^{\mathrm{II}}(\mathrm{aq})$ formed via rapid reaction of $\mathrm{Mn}^{2+}$ with hydrolyzed manganese(III) aqua hydroxo complexes. This complex initiates a chain reaction via formation of a precursor complex with $\mathrm{HSO}_{3}{ }^{-}$, within which rapid bridged electron transfer from sulfur(IV) to manganese(III) takes place, resulting in the formation of chain-propagating sulfite $\mathrm{SO}_{3}{ }^{-}$radicals. Moreover, their thermodynamic calculations confirm the conclusions of their kinetic measurements: A mixedvalence complex is formed, but its composition is still uncertain. This study emphasizes that there are still uncertainties in the mechanism of aqueous phase sulfur(IV) oxidation by manganese-catalyzed oxygen.

Even though the concentrations of copper are typically 10 times lower than iron concentrations in atmospheric liquid water, copper can have a significant influence on $\mathrm{HO}_{x}$ chemistry because it reacts more quickly than iron with $\mathrm{HO}_{2} / \mathrm{O}_{2}{ }^{-}$radicals ${ }^{141,228}$ (reactions 4 and 5). Available modeling studies of cloud chemistry suggest that the reaction of copper with $\mathrm{HO}_{2} / \mathrm{O}_{2}{ }^{-}$radicals leads to $\mathrm{HO}_{x}$ destruction, entailing, for polluted clouds, a decrease of ozone production in the gas phase. ${ }^{21,210}$ Moreover, the effect of copper on radical chemistry can be important in the efficient conversion of $\mathrm{HO}_{2} / \mathrm{O}_{2}{ }^{-}$radicals into hydrogen peroxide $\mathrm{e}^{23,172}$ via the reaction of copper(I) with the superoxide ion (reaction). Jans and Hoigné ${ }^{176}$ showed that copper is the main sink for $\mathrm{O}_{2}{ }^{-}$in droplets that contain dissolved copper at concentrations of a few nanomolars. Because reactions with $\mathrm{O}_{2}{ }^{-}$interconvert copper(I) and copper(II) cyclically, [copper(I)]/[copper(II)] is kept at a steady-state ratio. Thus, a significant fraction of the total copper is always present as copper(I). During daylight the reaction of ozone with copper(I) to produce the $\mathrm{OH}$ radical represents a major $\mathrm{O}_{3}$ sink. There consequently occurs an indirect $\mathrm{O}_{2}{ }^{-}-\mathrm{Cu}(\mathrm{I})-\mathrm{OH}$ reaction cycle that is driven by $\mathrm{O}_{3}$ and releases $\mathrm{OH}$ radicals.

As has been seen earlier, the redox iron cycle has great influence on aqueous $\mathrm{HO}_{x}$ chemistry. Through the direct interaction between iron and copper via reaction 41 below, copper chemistry has an indirect effect on $\mathrm{HO}_{x}$ concentrations, because it controls iron speciation. ${ }^{22,178}$ Sedlak and Hoigné, ${ }^{228}$ using a simple box model, noted that this direct reaction between iron(III) and copper(I) causes the [iron(II)]/[iron(III)] ratio to increase as the [copper(I)]/[copper(II)] ratio decreases:

$$
\begin{aligned}
\mathrm{Fe}^{3+}+\mathrm{Cu}^{+} \rightarrow \mathrm{Fe}^{2+}+\mathrm{Cu}^{2+}, k= \\
1.3 \times 10^{7} \mathrm{M}^{-1} \mathrm{~s}^{-1}\left(\text { Buxton et } \text { al. }^{32}\right)
\end{aligned}
$$

This reaction partly explains the iron speciation simulated by some models of cloud chemistry. ${ }^{20,22,23,172,178}$ Graedel et al. ${ }^{178}$ showed that the reduction of iron(III) is driven by the $\mathrm{Cu}^{+}$ion and $\mathrm{HO}_{2} / \mathrm{O}_{2}{ }^{-}$radicals during the night and by the $\mathrm{Cu}^{+}$ ion and the photolysis of iron(III) complexes during the day.

Leaving aside complexation with organics, studies by Sedlak and Hoigné, ${ }^{229}$ Hoigné and Bühler, ${ }^{267}$ and Sedlak et al. ${ }^{28}$ showed that if the copper/iron ratio exceeds $1-2 \%$, then the copper(I)/copper(II) pair becomes the predominant superoxide radical sink within the droplet, altering the $\mathrm{HO}_{x}$ and iron(II)/iron(III) redox cycles. Copper reacts with hydrogen peroxide much like iron in the Fenton reaction.

The reality of the oxidation of copper(I) by $\mathrm{H}_{2} \mathrm{O}_{2}$ in Fenton-like reactions in aqueous solution has been 
debated. ${ }^{268-274}$ In particular, the possible involvement of copper(III) in the production of $\mathrm{OH}$ radicals was evoked. ${ }^{270,272,275}$ Johnson et al. ${ }^{270}$ suggested that $\mathrm{H}_{2} \mathrm{O}_{2}$ can oxidize $\mathrm{Cu}^{+}$directly to $\mathrm{Cu}_{(\mathrm{II})}^{\mathrm{III}}$ :

$$
\mathrm{Cu}_{(\text {aq })}^{+}+\mathrm{H}_{2} \mathrm{O}_{2}\left(+2 \mathrm{H}^{+}\right) \rightarrow \mathrm{Cu}_{(\text {aq })}^{\mathrm{III}}+2 \mathrm{H}_{2} \mathrm{O}
$$

However, they neglected the following equilibrium based on the work of Meyerstein et al. ${ }^{276}$

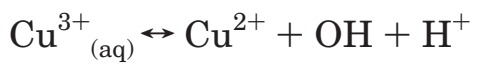

which shifts to the right in acidic solutions. Masarwa et al. ${ }^{272}$ explained the production of $\mathrm{OH}$ at low $\mathrm{pH}$ by the shifting of equilibrium 43 to the right. Eberhardt et al. ${ }^{273}$ showed that in neutral or weakly acidic solutions, $\mathrm{Cu}^{3+}$ produced via $\mathrm{Cu}^{2+}+\mathrm{OH}$ does not hydroxylate aromatic compounds. They concluded that in the reaction of $\mathrm{Cu}^{+}$with $\mathrm{H}_{2} \mathrm{O}_{2}$, the $\mathrm{OH}$ radical is the major reactive species with aromatic compounds and is generated in the Fenton-like reaction

$$
\mathrm{Cu}^{+}+\mathrm{H}_{2} \mathrm{O}_{2} \rightarrow \mathrm{Cu}^{2+}+\mathrm{OH}+\mathrm{OH}^{-}
$$

with $k=7.0 \times 10^{3} \mathrm{M}^{-1} \mathrm{~s}^{-1}$ (Berdnikov ${ }^{269}$ ).

The more recent study by Urbanski and Beresewicz ${ }^{277}$ confirmed the $\mathrm{OH}$ production for neutral or weakly acidic solutions. Moreover, in the same way as for iron, the oxidation of copper(I) by $\mathrm{H}_{2} \mathrm{O}_{2}$ in Fenton-like reactions seems to involve an active intermediate copper(III), ${ }^{270,272,275,274,278}$ but the nature and the $\mathrm{p} K_{\mathrm{a}}$ of this intermediate are still uncertain. Modeling studies show that this pathway of $\mathrm{OH}$ radical production is not negligible in cloud droplets. ${ }^{23}$ As is the case for iron, further laboratory investigations seem to be necessary to clarify the chemical process of the copper Fenton reaction.

Moreover, Spokes et al. ${ }^{134}$ analyzed rainwater sampled in the United Kingdom, where total copper concentrations were between 0.01 and $0.03 \mu \mathrm{M}$, natural ligand concentrations in the same range, and free $\mathrm{Cu}^{2+}$ ion concentrations between only $10^{-5}$ and $10^{-6} \mu \mathrm{M}$, showing that copper is largely complexed. At these concentrations, dissolved copper cannot play a significant role in $\mathrm{HO}_{x}$ chemistry. This study emphasizes that the impact of copper on $\mathrm{HO}_{x}$ chemistry is dependent on the presence of natural ligands in the atmospheric liquid phase.

In addition, the coexistence of several transition metals in the aqueous phase can have a synergistic effect on sulfur(IV) oxidation by improving the efficiency of the catalytic cycle. ${ }^{130,131,257,259,262,265,279-281}$ For instance, sulfur(IV) oxidation catalyzed by a mixture of iron and manganese is more efficient than sulfur(IV) oxidation catalyzed by only one of these two metals. 282

Most of the studies on copper deal with the homogeneous copper(II) catalysis in sulfur(IV) oxidation. ${ }^{27,137-139,283-289}$

Bäckström ${ }^{283}$ argued that reduction of copper(I) by sulfur(IV) is the initial step in the copper(II)catalyzed free radical oxidation of sulfur(IV).

$$
\mathrm{Cu}(\mathrm{II})+\mathrm{SO}_{3}{ }^{2-} \rightarrow \mathrm{Cu}(\mathrm{I})+\mathrm{SO}_{3}{ }^{-}
$$

The relatively slow sulfur(IV) to copper(II) electrontransfer rates make this reaction an improbable initiation step for the copper(II)-catalyzed chain reaction proposed by Bäckström. ${ }^{283}$

Veprek-Siska and Lunak ${ }^{286}$ reported that the cupric ion is immediately and quantitatively reduced by sulfite to the cuprous ion, and they proposed that the metal-catalyzed autoxidation of sulfur(IV) proceeds via the formation of sulfite-cuprous intermediates rather than a free chain reaction. However, Lunak et al. ${ }^{288}$ found that 2-propanol cuprous complexes act as an inhibitor of copper(II)-catalyzed sulfur(IV) autoxidation. Their mechanism involves the reduction of copper(II) to copper(I) by sulfur(IV), followed by the formation of sulfito-2-propanol cuprous complexes. The first systematic study of the kinetics of the reduction of copper(II) by sulfur(IV) in the absence of $\mathrm{O}_{2}$ was done by Zeck and Carlyle. ${ }^{287}$ They assumed that the rate of disappearance of copper(II) was given by a second-order equation of the following form:

$$
-\mathrm{d}[\mathrm{Cu}(\mathrm{II})] / \mathrm{d} t=k[\mathrm{Cu}(\mathrm{II})][\mathrm{S}(\mathrm{IV})]
$$

The study of Conklin and Hoffmann ${ }^{137}$ showed that copper(II) forms transient complexes such as $\mathrm{CuSO}_{3}$ with $\mathrm{S}(\mathrm{IV})$ in solution. They calculated that at $\mathrm{pH}$ $3.5,15 \%$ of the copper(II) exists as a copper(I)-sulfito complex and that at $\mathrm{pH} 6.3,98.5 \%$ of the copper(II) is complexed by sulfite. The formation of a complex appears to be a necessary step in the mechanism of sulfur(IV) oxidation for thermodynamic reasons. Conklin and Hoffmann ${ }^{138}$ studied the redox chemistry of copper(II)-sulfur(IV) complexes. The reduction of copper(II) is shown to proceed via $\mathrm{Cu}_{2} \mathrm{II}_{3}{ }^{2+}$ and $\mathrm{Cu}_{2} \mathrm{SO}_{3} \mathrm{OH}^{+}$intermediates; copper(I), $\mathrm{SO}_{4}{ }^{2-}$, and a mixed-valence compound, $\mathrm{Cu}^{\mathrm{II}} \mathrm{SO}_{3} \mathrm{Cu}_{2} \mathrm{SO}_{3} \cdot 2 \mathrm{H}_{2} \mathrm{O}$, are determined to be the principal products. The possible influence of atmospheric stability and copper-sulfito complexes on sulfur(IV) to sulfur(VI) conversion is still unknown. Grgic et al. ${ }^{263}$ showed that copper(II) is catalytically active at $\mathrm{pH}$ 7. It appears that the copper(II) ion is not a sufficiently strong oxidizing agent to generate chain carriers from the sulfur(IV) species at low $\mathrm{pH}$ values, whereas at high $\mathrm{pH}$ the copper(II) ion readily converts the sulfite ion into a sulfite free radical.

Because copper is present as oxides in the aqueous particulate phase, some studies have looked into the heterogeneous catalysis of these oxides in sulfur(IV) oxidation. ${ }^{290,291}$ Copper oxides exhibit different catalytic activities due to the different bond strengths of oxygen at the metal surface. For instance, Prasad et al. ${ }^{292}$ observed no significant oxidation of sulfur(IV) oxides when using $\mathrm{CuO}$ as catalyst in the absence of oxygen. Manoj et al. ${ }^{291}$ showed that cupric oxide $\left(\mathrm{Cu}_{2} \mathrm{O}\right)$ coming from aerosol particles scavenged by fog and cloud droplets can catalyze the oxidation of sulfite into sulfate via a heterogeneous pathway, with an induction period, and a conversion rate of $0.19 \%$ per hour under typical atmospheric conditions. The authors conclude that $\mathrm{Cu}_{2} \mathrm{O}$ catalysis may not be significant in the acidification of rain, because the lifetime of the raindrop (1-5 min) is shorter than the induction period, whereas it is important in mist, fog, 
and cloud droplets, which have a much longer lifetime. The results further suggest that the presence of organic acids and complexing anions shortens the induction period and favors the catalysis that releases copper(II) ions.

Moreover, it is assumed that copper can significantly influence the interactions of sulfur(IV) with other transition metals such as iron through its efficient reactivity with $\mathrm{HO}_{2} / \mathrm{O}_{2}{ }^{-}$radicals ${ }^{293}$ (cf. section 4.2). The modeling study of Deguillaume et al. ${ }^{23}$ showed that the reaction of $\mathrm{Cu}^{+}$with oxygen leads to high $\mathrm{HO}_{2} / \mathrm{O}_{2}{ }^{-}$concentration in the aqueous phase, which results in continuous $\mathrm{H}_{2} \mathrm{O}_{2}$ formation through reactions of $\mathrm{HO}_{2} / \mathrm{O}_{2}{ }^{-}$with iron(II) and $\mathrm{Cu}^{+}$. Iron is mainly present as iron(II) during the day, and the $\mathrm{Cu}^{+}$concentration is maintained by the reaction of $\mathrm{Cu}^{2+}$ with the $\mathrm{HO}_{2} / \mathrm{O}_{2}{ }^{-}$radical. The contribution of iron and copper to sulfur(IV) oxidation through the efficient production of $\mathrm{H}_{2} \mathrm{O}_{2}$ is, in this instance, indirect.

Iron and manganese are the most effective catalysts in the oxidation of sulfur(IV) in aqueous solution. ${ }^{27}$ Numerical and/or laboratory studies have undertaken to compare the contribution of manganese and iron to sulfur autoxidation. Graedel et al. ${ }^{178}$ calculated that the contributions of iron(III) and manganese(II) to the oxidation of sulfur(IV) at $\mathrm{pH} 4$ are $6-8$ and $22-29 \%$, respectively. In contrast, Cocks and McElroy ${ }^{294}$ reported an oxidation state 10 times smaller for the manganese(II)-catalyzed pathway than for iron(III) catalysis at $\mathrm{pH}$ 4. According to Warneck, ${ }^{295}$ the catalytic activities of iron(III) and manganese(II) are almost equal at $\mathrm{pH} 4$.

Thus, like iron, copper and manganese are thought to catalyze the oxidation of sulfur(IV) into sulfur(VI) via homogeneous and heterogeneous pathways. Further laboratory investigations are needed to characterize these chemical mechanisms accurately, and numerical studies are necessary to evaluate the role of those mechanisms in sulfur(IV) to sulfur(VI) conversion within the atmospheric liquid phase.

\subsection{Proposed Chemical Mechanism for in Cloud Chemistry Model}

The mechanism proposed here, rounded out with inorganic and organic chemistry processes occurring in clouds (presented by Leriche et al. ${ }^{296}$ and by Ervens et al. ${ }^{172}$ ), can be used in cloud chemistry models. This mechanism includes 99 reactions, 6 photolysis reactions, and 4 equilibria that describe the chemistry of iron, manganese, and copper with $\mathrm{HO}_{x}$ radicals, sulfur compounds, nitrogen compounds, chlorine compounds, carbonates, and water-soluble organic compounds. The aim of this mechanism is to present an exhaustive list of reactions involving iron, copper, and manganese in atmospheric liquid phases with the chemical species involved in atmospheric aqueous chemistry. Whereas iron reactivity is well documented, data concerning copper and manganese reactivity are still meager, both for reaction mechanisms and for kinetic constants.

Tables 13 and 14 present iron reactions to be included in a multiphase atmospheric model. The chemical pathways of the Fenton reaction between hydrogen peroxide and iron(II) are still subject to controversy (see section 4.1.1), and the classic radical pathway is thought to drive mechanism R1. Photolysis of the iron(III) complexes also involves the formation of $\mathrm{OH}$ radicals (J1, J2, J3). On the other hand, the reaction of iron(III) and iron(II) with the $\mathrm{O}_{2}{ }^{-} / \mathrm{HO}_{2}$ radicals represents an efficient $\mathrm{HO}_{x}$ sink (R3-R7). Iron(II) is oxidized by ozone, and this reaction is also prone to controversy. Early studies on the reactivity of iron(II) with ozone showed that this oxidation produces iron(III) as well as an $\mathrm{OH}$ radical. ${ }^{297}$ More recently, Logager et al. ${ }^{200}$ emphasized that this reaction leads to the formation of the ferryl ion $\mathrm{FeO}^{2+}$ and an oxygen molecule (R11). Jacobsen et al. ${ }^{201,202}$ studied the reactivity of the ferryl ion with inorganic and organic species present in the atmospheric liquid phases (R2, R8, R10, R12-R16, R19, R22, R23, R30, R32-R34). Reaction between the ferryl ion and iron(II) yields either a dimer $\mathrm{Fe}(\mathrm{OH})_{2} \mathrm{Fe}^{4+}$ or $\mathrm{Fe}^{3+}$ directly (R13 and R14). The formation of this dimer is favored at higher temperatures. This species then forms iron(III) (R15 and R16). According to Jacobsen et al., ${ }^{202}$ for rainwater with a $\mathrm{pH}$ of $\sim 3$ the ferryl ion can be regarded as a temporary sink of $\mathrm{OH}$ radicals, whereas for more acidic droplets, this compound reacts in solution like a full-fledged species. The reactivity of the peroxyl radicals with iron was studied by Khaikin et al. ${ }^{255}$ The peroxyl radical $\mathrm{CH}_{3} \mathrm{O}_{2}$ reacts with iron(II) and forms an intermediate complex $\mathrm{FeCH}_{3} \mathrm{O}_{2}{ }^{2+}$ (R37), which decomposes to give methyl hydroperoxide (MHP) and iron(III) (R38 and R39). The formation (R45-R50) and photolysis processes of the ironoxalato complexes are considered to be an efficient pathway for the reduction of iron(III) (J5, J6).

Iron(III) is a catalyst in the autoxidation of sulfur(IV) to sulfur(VI) (cf. section 4.1.2). The general mechanism of iron-catalyzed sulfur(IV) oxidation is represented by reactions R24-R27, accompanied by reaction 34 .

In addition, iron(III) and the sulfate ion $\mathrm{SO}_{4}{ }^{2-}$ are in equilibrium with the complex $\left[\mathrm{Fe}\left(\mathrm{SO}_{4}\right)\right]^{+}(\mathrm{R} 51$ and R52). This complex produces an $\mathrm{SO}_{4}^{-}$radical (J4) when photolyzed, or it is oxidized by the $\mathrm{O}_{2}{ }^{-}$radicals (R28), leading in both cases to the formation of iron(II) and sulfate. ${ }^{31}$

Table 15 presents the copper reactions to be considered in a multiphase atmospheric model. Although the copper concentrations are lower than those of iron, copper plays a significant role in the aqueous $\mathrm{HO}_{x}$ chemistry because of its reactivity with the $\mathrm{O}_{2}-/ \mathrm{HO}_{2}$ radicals (cf. section 4.2.). Copper(II) is reduced by the $\mathrm{O}_{2}{ }^{-} / \mathrm{HO}_{2}$ radicals to copper(I) (R61 and R62). In the same way, copper(I) is oxidized into copper(II) by $\mathrm{O}_{2}{ }^{-} / \mathrm{HO}_{2}$ radicals, producing hydrogen peroxide $\mathrm{H}_{2} \mathrm{O}_{2}$ (R59 and $\mathrm{R} 60$ ).

Finally, Tables 16 and 17 present the manganese reactions to be considered in a multiphase atmospheric model. Manganese interacts mainly with the $\mathrm{HO}_{x}$ and sulfur chemistry. In $\mathrm{HO}_{x}$ chemistry the reaction of manganese(II) with $\mathrm{O}_{2}{ }^{-} / \mathrm{HO}_{2}$ radicals is still under discussion. Jacobsen et al. ${ }^{298}$ highlighted the formation of a manganese(II)-superoxide complex $\mathrm{MnO}_{2}{ }^{+}$in solution. They were interested in the role of this complex in the oxidation of manganese- 
Table 13. Iron Chemistry

\begin{tabular}{|c|c|c|c|c|c|}
\hline reagents & products & no. & $\begin{array}{c}\text { kinetic } \\
\text { constant } \\
\left(\mathrm{M}^{-n+1} \mathrm{~s}^{-1}\right)\end{array}$ & $\begin{array}{c}\text { activation } \\
\text { energy } \\
E_{\mathrm{a}} / R(\mathrm{~K})\end{array}$ & ref \\
\hline $\mathrm{Fe}^{3+}+h v+\mathrm{H}_{2} \mathrm{O}$ & $\mathrm{Fe}^{2+}+\mathrm{OH}+\mathrm{H}^{+}$ & J1 & calcd & & Benkelberg and Warneck ${ }^{191}$ \\
\hline $\mathrm{Fe}(\mathrm{OH})^{2+}+h v$ & $\mathrm{Fe}^{2+}+\mathrm{OH}$ & J2 & calcd & & Benkelberg and Warneck ${ }^{191}$ \\
\hline $\mathrm{Fe}(\mathrm{OH})_{2}++h v$ & $\mathrm{Fe}^{2+}+\mathrm{OH}+\mathrm{OH}^{-}$ & J3 & calcd & & Weschler et al., ${ }^{119}$ Benkelberg et al. ${ }^{347}$ \\
\hline $\mathrm{Fe}\left(\mathrm{SO}_{4}\right)^{+}+h v$ & $\mathrm{Fe}^{2+}+\mathrm{SO}_{4}^{-}$ & $\mathrm{J} 4$ & calcd & & Benkelberg and Warneck ${ }^{191}$ \\
\hline$\left[\mathrm{Fe}\left(\mathrm{C}_{2} \mathrm{O}_{4}\right)_{2}\right]^{-}+h v$ & $\mathrm{Fe}^{2+}+\mathrm{C}_{2} \mathrm{O}_{4}^{2-}+\mathrm{C}_{2} \mathrm{O}_{4}^{-}$ & J5 & calcd & & Faust and Zepp 235 \\
\hline$\left[\mathrm{Fe}\left(\mathrm{C}_{2} \mathrm{O}_{4}\right)_{3}\right]^{3-}+h v$ & $\mathrm{Fe}^{2+}+2 \mathrm{C}_{2} \mathrm{O}_{4}^{2-}+\mathrm{C}_{2} \mathrm{O}_{4}^{-}$ & J6 & calcd & & Faust and Zepp ${ }^{235}$ \\
\hline $\mathrm{H}_{2} \mathrm{O}_{2}+\mathrm{Fe}^{2+}$ & $\mathrm{Fe}^{3+}+\mathrm{OH}+\mathrm{OH}^{-}$ & $\mathrm{R} 1$ & 52.4 & 5050 & Kremer ${ }^{205}$ Christensen et al. ${ }^{348}$ \\
\hline $\mathrm{H}_{2} \mathrm{O}_{2}+\mathrm{FeO}^{2+}$ & $\mathrm{Fe}^{3+}+\mathrm{HO}_{2}+\mathrm{OH}^{-}$ & $\mathrm{R} 2$ & $9.5 \times 10^{3}$ & 2800 & Jacobsen et al. ${ }^{201}$ \\
\hline $\mathrm{O}_{2}^{-}+\mathrm{Fe}^{2+}+2 \mathrm{H}^{+}$ & $\mathrm{H}_{2} \mathrm{O}_{2}+\mathrm{Fe}^{3+}$ & R3 & $1.0 \times 10^{7}$ & & Rush and Bielski ${ }^{31}$ \\
\hline $\mathrm{HO}_{2}+\mathrm{Fe}^{2+}+\mathrm{H}^{+}$ & $\mathrm{Fe}^{3+}+\mathrm{H}_{2} \mathrm{O}_{2}$ & $\mathrm{R} 4$ & $1.2 \times 10^{6}$ & 5050 & Jayson et al. ${ }^{170}$ \\
\hline $\mathrm{O}_{2}^{-}+\mathrm{Fe}^{3+}$ & $\mathrm{Fe}^{2+}+\mathrm{O}_{2}$ & R5 & $1.5 \times 10^{8}$ & & estimated from Rush and Bielski ${ }^{31}$ \\
\hline $\mathrm{O}_{2}^{-}+\mathrm{Fe}(\mathrm{OH})^{2+}$ & $\mathrm{Fe}^{2+}+\mathrm{O}_{2}+\mathrm{OH}^{-}$ & R6 & $1.5 \times 10^{8}$ & & Rush and Bielski ${ }^{31}$ \\
\hline $\mathrm{O}_{2}^{-}+\mathrm{Fe}(\mathrm{OH})_{2}{ }^{+}$ & $\mathrm{Fe}^{2+}+\mathrm{O}_{2}+2 \mathrm{OH}^{-}$ & R7 & $1.5 \times 10^{8}$ & & estimated from Rush and Bielski ${ }^{31}$ \\
\hline $\mathrm{HO}_{2}+\mathrm{FeO}^{2+}$ & $\mathrm{Fe}^{3+}+\mathrm{O}_{2}+\mathrm{OH}^{-}$ & $\mathrm{R} 8$ & $2.0 \times 10^{6}$ & & Jacobsen et al. ${ }^{201}$ \\
\hline $\mathrm{OH}+\mathrm{Fe}^{2+}$ & $\mathrm{Fe}(\mathrm{OH})^{2+}$ & R9 & $4.6 \times 10^{8}$ & 1100 & Christensen and Sehested ${ }^{349}$ \\
\hline $\mathrm{OH}+\mathrm{FeO}^{2+}+\mathrm{H}^{+}$ & $\mathrm{Fe}^{3+}+\mathrm{H}_{2} \mathrm{O}_{2}$ & $\mathrm{R} 10$ & $1.0 \times 10^{7}$ & & Logager et al. ${ }^{200}$ \\
\hline $\mathrm{O}_{3}+\mathrm{Fe}^{2+}$ & $\mathrm{FeO}^{2+}+\mathrm{O}_{2}$ & $\mathrm{R} 11$ & $8.2 \times 10^{5}$ & & Logager et al. ${ }^{200}$ \\
\hline $\mathrm{FeO}^{2+}+\mathrm{H}_{2} \mathrm{O}$ & $\mathrm{Fe}^{3+}+\mathrm{OH}+\mathrm{OH}^{-}$ & $\mathrm{R} 12$ & $1.3 \times 10^{-2}$ & 4100 & Jacobsen et al. ${ }^{201}$ \\
\hline $\mathrm{FeO}^{2+}+\mathrm{Fe}^{2+}+\mathrm{H}_{2} \mathrm{O}$ & $2 \mathrm{Fe}^{3+}+2 \mathrm{OH}^{-}$ & $\mathrm{R} 13$ & $7.2 \times 10^{4}$ & 840 & Jacobsen et al. ${ }^{201}$ \\
\hline $\mathrm{FeO}^{2+}+\mathrm{Fe}^{2+}+\mathrm{H}_{2} \mathrm{O}$ & $\mathrm{Fe}(\mathrm{OH})_{2} \mathrm{Fe}^{4+}$ & R14 & $1.8 \times 10^{4}$ & 5050 & Jacobsen et al. ${ }^{201}$ \\
\hline $\mathrm{Fe}(\mathrm{OH})_{2} \mathrm{Fe}^{4+}$ & $2 \mathrm{Fe}^{3+}+2 \mathrm{OH}^{-}$ & $\mathrm{R} 15$ & 0.49 & 8800 & Jacobsen \\
\hline $\mathrm{Fe}(\mathrm{OH})_{2} \mathrm{Fe}^{4+}+\mathrm{H}^{+}+\mathrm{H}^{+}$ & $2 \mathrm{Fe}^{3+}+2 \mathrm{H}_{2} \mathrm{O}$ & $\mathrm{R} 16$ & 2 & 5650 & Jacobsen et al. ${ }^{201}$ \\
\hline $\mathrm{Cl}_{2}^{-}+\mathrm{Fe}^{2+}$ & $\mathrm{Fe}^{3+}+2 \mathrm{Cl}^{-}$ & $\mathrm{R} 17$ & $1.0 \times 10^{7}$ & 3060 & Thornton and Laurence ${ }^{350}$ \\
\hline $\mathrm{Cl}_{2}^{-}+\mathrm{Fe}^{2+}$ & $\mathrm{FeCl}^{2+}+\mathrm{Cl}^{-}$ & $\mathrm{R} 18$ & $4.0 \times 10^{6}$ & 3700 & Thornton and Laurence ${ }^{350}$ \\
\hline $\mathrm{Cl}^{-}+\mathrm{FeO}^{2+}+\mathrm{H}^{+}$ & $\mathrm{Fe}^{3+}+\mathrm{ClOH}^{-}$ & R19 & 100 & & Jacobsen et al. ${ }^{202}$ \\
\hline $\mathrm{NO}_{3}+\mathrm{Fe}^{2+}$ & $\mathrm{Fe}^{3+}+\mathrm{NO}_{3}^{-}$ & $\mathrm{R} 20$ & $8.0 \times 10^{6}$ & & Pikaev et al. ${ }^{351}$ \\
\hline $\mathrm{NO}_{2}+\mathrm{Fe}^{2+}$ & $\mathrm{Fe}^{3+}+\mathrm{NO}_{2}^{-}$ & $\mathrm{R} 21$ & $3.1 \times 10^{4}$ & & Epstein et al. ${ }^{352}$ \\
\hline $\mathrm{HNO}_{2}+\mathrm{FeO}^{2+}$ & $\mathrm{Fe}^{3+}+\mathrm{NO}_{2}+\mathrm{OH}^{-}$ & $\mathrm{R} 22$ & $1.1 \times 10^{4}$ & 4150 & Jacobsen et al. ${ }^{202}$ \\
\hline $\mathrm{NO}_{2}^{-}+\mathrm{FeO}^{2+}+\mathrm{H}^{+}$ & $\mathrm{Fe}^{3+}+\mathrm{NO}_{2}^{-}+\mathrm{OH}^{-}$ & $\mathrm{R} 23$ & $1.0 \times 10^{5}$ & & Jacobsen et al. ${ }^{202}$ \\
\hline $\mathrm{HSO}_{3}^{-}+\mathrm{Fe}(\mathrm{OH})^{2+}$ & $\mathrm{Fe}^{2+}+\mathrm{SO}_{3}^{-}+\mathrm{H}_{2} \mathrm{O}$ & $\mathrm{R} 24$ & 30 & & Ziajka et al. ${ }^{221}$ \\
\hline $\mathrm{SO}_{5}^{-}+\mathrm{Fe}^{2+}+\mathrm{H}_{2} \mathrm{O}$ & $\mathrm{Fe}(\mathrm{OH})^{2+}+\mathrm{HSO}_{5}^{-}$ & $\mathrm{R} 25$ & $2.65 \times 10^{7}$ & & Williams $^{353}$ \\
\hline $\mathrm{HSO}_{5}^{-}+\mathrm{Fe}^{2+}$ & $\mathrm{Fe}(\mathrm{OH})^{2+}+\mathrm{SO}_{4}^{-}$ & $\mathrm{R} 26$ & $3.0 \times 10^{4}$ & & Gilbert et al. ${ }^{354}$ \\
\hline $\mathrm{SO}_{4}^{-}+\mathrm{Fe}^{2+}+\mathrm{H}_{2} \mathrm{O}$ & $\mathrm{Fe}(\mathrm{OH})^{2+}+\mathrm{SO}_{4}{ }^{2-}+\mathrm{H}^{+}$ & $\mathrm{R} 27$ & $4.1 \times 10^{9}$ & -2165 & Buxton et al. ${ }^{355}$ \\
\hline $\mathrm{O}_{2}^{-}+\mathrm{Fe}\left(\mathrm{SO}_{4}\right)^{+}$ & $\mathrm{Fe}^{2+}+\mathrm{SO}_{4}^{2-}+\mathrm{O}_{2}$ & $\mathrm{R} 28$ & $1.5 \times 10^{8}$ & & Rush and Bielski ${ }^{31}$ \\
\hline $\mathrm{S}_{2} \mathrm{O}_{8}^{2-}+\mathrm{Fe}^{2+}+\mathrm{H}_{2} \mathrm{O}$ & $\mathrm{Fe}^{3+}+\mathrm{SO}_{4}^{2-}+\mathrm{SO}_{4}^{-}$ & $\mathrm{R} 29$ & 17 & & Buxton et al. ${ }^{355}$ \\
\hline $\mathrm{HSO}_{3}{ }^{-}+\mathrm{FeO}^{2+}$ & $\mathrm{Fe}^{3+}+\mathrm{SO}_{3}^{-}+\mathrm{OH}^{-}$ & $\mathrm{R} 30$ & $2.5 \times 10^{5}$ & & Jacobsen et al. ${ }^{202}$ \\
\hline $\mathrm{CO}_{3}^{-}+\mathrm{Fe}^{2+}$ & $\mathrm{Fe}^{3+}+\mathrm{CO}_{3}^{2-}$ & $\mathrm{R} 31$ & $2.0 \times 10^{7}$ & & estimated from Herrmann et al. ${ }^{22}$ \\
\hline $\mathrm{HCOOH}+\mathrm{FeO}^{2+}+\mathrm{O}_{2}$ & $\mathrm{Fe}^{3+}+\mathrm{CO}_{2}+\mathrm{HO}_{2}+\mathrm{H}_{2} \mathrm{O}$ & $R 32$ & 160 & 2680 & Jacobsen et al. ${ }^{202}$ \\
\hline $\mathrm{HCOO}^{-}+\mathrm{FeO}^{2+}+\mathrm{O}_{2}+\mathrm{H}^{+}$ & $\mathrm{Fe}^{3+}+\mathrm{CO}_{2}+\mathrm{HO}_{2}$ & R33 & $3.0 \times 10^{5}$ & & Jacobsen et al. ${ }^{202}$ \\
\hline $\mathrm{CH}_{2}(\mathrm{OH})_{2}+\mathrm{FeO}^{2+}+\mathrm{O}_{2}$ & $\mathrm{Fe}^{3+}+\mathrm{HCOOH}+\mathrm{HO}_{2}+\mathrm{OH}^{-}$ & R34 & 400 & 5350 & Jacobsen et al. ${ }^{202}$ \\
\hline $\mathrm{CH}_{3} \mathrm{OOH}+\mathrm{Fe}^{2+}$ & $\mathrm{Fe}^{3+}+\mathrm{OHCH}_{2} \mathrm{O}_{2}+\mathrm{OH}^{-}$ & R35 & $52.4=k_{\mathrm{R} 1}$ & 5050 & Chevallier et al. ${ }^{256}$ \\
\hline $\mathrm{OHCH}_{2} \mathrm{OOH}+\mathrm{Fe}^{2+}+\mathrm{O}_{2}$ & $\mathrm{Fe}^{3+}+\mathrm{HCOOH}+\mathrm{HO}_{2}+\mathrm{OH}^{-}$ & R36 & $52.4=k_{\mathrm{R} 1}$ & 5050 & Chevallier et al. ${ }^{256}$ \\
\hline $\mathrm{CH}_{3} \mathrm{O}_{2}+\mathrm{Fe}^{2+}$ & $\mathrm{CH}_{3} \mathrm{O}_{2} \mathrm{Fe}^{2+}$ & R37 & $8.6 \times 10^{5}$ & & Khaikin et al. ${ }^{255}$ \\
\hline $\mathrm{CH}_{3} \mathrm{O}_{2} \mathrm{Fe}^{2+}$ & $\mathrm{CH}_{3} \mathrm{O}_{2}+\mathrm{Fe}^{2+}$ & R38 & $1.3 \times 10^{3}$ & & Khaikin et al. ${ }^{255}$ \\
\hline $\mathrm{CH}_{3} \mathrm{O}_{2} \mathrm{Fe}^{2+}+\mathrm{H}_{2} \mathrm{O}$ & $\mathrm{Fe}^{3+}+\mathrm{CH}_{3} \mathrm{OOH}+\mathrm{OH}^{-}$ & R39 & 100 & & Khaikin et al. ${ }^{255}$ \\
\hline $\mathrm{CH}_{3} \mathrm{O}_{2} \mathrm{Fe}^{2+}+\mathrm{H}^{+}$ & $\mathrm{Fe}^{3+}+\mathrm{CH}_{3} \mathrm{OOH}$ & $\mathrm{R} 40$ & $3.0 \times 10^{4}$ & & Khaikin et al. ${ }^{255}$ \\
\hline $\mathrm{OHCH}_{2} \mathrm{O}_{2}+\mathrm{Fe}^{2+}$ & $\mathrm{OHCH}_{2} \mathrm{O}_{2} \mathrm{Fe}^{2+}$ & R41 & $5.9 \times 10^{5}$ & & Khaikin et al. ${ }^{255}$ \\
\hline $\mathrm{OHCH}_{2} \mathrm{O}_{2} \mathrm{Fe}^{2+}$ & $\mathrm{OHCH}_{2} \mathrm{O}_{2}+\mathrm{Fe}^{2+}$ & $\mathrm{R} 42$ & $1.3 \times 10^{3}$ & & Khaikin et al. ${ }^{255}$ \\
\hline $\mathrm{OHCH}_{2} \mathrm{O}_{2} \mathrm{Fe}^{2+}+\mathrm{H}_{2} \mathrm{O}$ & $\mathrm{Fe}^{3+}+\mathrm{OHCH}_{2} \mathrm{OOH}+\mathrm{OH}^{-}$ & R43 & 100 & & Khaikin et al. ${ }^{255}$ \\
\hline $\mathrm{OHCH}_{2} \mathrm{O}_{2} \mathrm{Fe}^{2+}+\mathrm{H}^{+}$ & $\mathrm{Fe}^{3+}+\mathrm{OHCH}_{2} \mathrm{OOH}$ & $\mathrm{R} 44$ & $3.0 \times 10^{4}$ & & Khaikin et al. ${ }^{255}$ \\
\hline $\mathrm{C}_{2} \mathrm{O}_{4}^{2-}+\mathrm{Fe}^{3+}$ & $\mathrm{Fe}\left(\mathrm{C}_{2} \mathrm{O}_{4}\right)^{+}$ & $\mathrm{R} 45$ & $7.5 \times 10^{6}$ & & $\begin{array}{l}\text { estimated using stability constant: } \\
\text { Martell and Smith }\end{array}$ \\
\hline $\mathrm{Fe}\left(\mathrm{C}_{2} \mathrm{O}_{4}\right)^{+}$ & $\mathrm{C}_{2} \mathrm{O}_{4}{ }^{2-}+\mathrm{Fe}^{3+}$ & $\mathrm{R} 46$ & $3.0 \times 10^{-3}=k_{\mathrm{R} 48}$ & & estimated \\
\hline $\mathrm{C}_{2} \mathrm{O}_{4}{ }^{2-}+\mathrm{Fe}\left(\mathrm{C}_{2} \mathrm{O}_{4}\right)^{+}$ & $\mathrm{Fe}\left(\mathrm{C}_{2} \mathrm{O}_{4}\right)_{2}^{-}$ & $\mathrm{R} 47$ & $1.89 \times 10^{4}$ & & Martell and Smith ${ }^{356}$ \\
\hline $\mathrm{Fe}\left(\mathrm{C}_{2} \mathrm{O}_{4}\right)_{2}^{-}$ & $\mathrm{C}_{2} \mathrm{O}_{4}{ }^{2-}+\mathrm{Fe}\left(\mathrm{C}_{2} \mathrm{O}_{4}\right)^{+}$ & $\mathrm{R} 48$ & $3.0 \times 10^{-3}$ & & Moorhead and Sutin ${ }^{357}$ \\
\hline $\mathrm{C}_{2} \mathrm{O}_{4}{ }^{2-}+\mathrm{Fe}\left(\mathrm{C}_{2} \mathrm{O}_{4}\right)_{2}^{-}$ & $\mathrm{Fe}\left(\mathrm{C}_{2} \mathrm{O}_{4}\right)_{3}{ }^{3-}$ & $\mathrm{R} 49$ & $4.8 \times 10^{1}$ & & $\begin{array}{l}\text { estimated using stability constant: } \\
\text { Martell and Smith }\end{array}$ \\
\hline $\mathrm{Fe}\left(\mathrm{C}_{2} \mathrm{O}_{4}\right)_{3}{ }^{3-}$ & $\mathrm{C}_{2} \mathrm{O}_{4}{ }^{2-}+\mathrm{Fe}\left(\mathrm{C}_{2} \mathrm{O}_{4}\right)_{2}^{-}$ & R50 & $3.0 \times 10^{-3}=k_{\mathrm{R} 48}$ & & estimated \\
\hline $\mathrm{Fe}^{3+}+\mathrm{SO}_{4}^{2-}$ & $\mathrm{Fe}\left(\mathrm{SO}_{4}\right)^{+}$ & $\mathrm{R} 51$ & $3.2 \times 10^{3}$ & & Jayson et al. ${ }^{358}$ \\
\hline $\mathrm{Fe}\left(\mathrm{SO}_{4}\right)^{+}$ & $\mathrm{Fe}^{3+}+\mathrm{SO}_{4}^{2-}$ & R52 & 27 & & Jayson et al. ${ }^{358}$ \\
\hline $\mathrm{Fe}^{3+}+\mathrm{Cl}^{-}$ & $\mathrm{FeCl}^{2+}$ & R53 & 4.8 & & Xu et al. ${ }^{359}$ \\
\hline $\mathrm{FeCl}^{2+}$ & $\mathrm{Fe}^{3+}+\mathrm{Cl}^{-}$ & R54 & $9.2 \times 10^{-1}$ & & estimated \\
\hline
\end{tabular}

Table 14. Iron Equilibria

\begin{tabular}{|c|c|c|c|c|}
\hline equilibrium & no. & $K(\mathrm{M})$ & $\Delta H / R(\mathrm{~K})$ & ref \\
\hline $\mathrm{Fe}^{3+}+\mathrm{H}_{2} \mathrm{O} \leftrightarrow \mathrm{Fe}(\mathrm{OH})^{2+}+\mathrm{H}^{+}$ & E1 & $6.00 \times 10^{-3}$ & & Brandt and van Eldik ${ }^{27}$ \\
\hline $\mathrm{Fe}(\mathrm{OH})^{2+}+\mathrm{H}_{2} \mathrm{O} \leftrightarrow \mathrm{Fe}(\mathrm{OH})_{2}^{+}+\mathrm{H}^{+}$ & $\mathrm{E} 2$ & $7.60 \times 10^{-4}$ & & Brandt and van Eldik ${ }^{27}$ \\
\hline
\end{tabular}

(II) into manganese(III). It is formed via two chemical pathways, the first one driven by two equilibria (R70 and R71; R73 and R74) and the second one derived from the reaction between hydrogen peroxide and
$[\mathrm{Mn}(\mathrm{OH})]^{2+}(\mathrm{R} 80)$. The $\mathrm{MnO}_{2}{ }^{+}$complex is destroyed by reacting with $\mathrm{HO}_{2}(\mathrm{R} 76)$ and by its self-reaction (R75). In both cases, hydrogen peroxide and manganese(II) are produced. The reactivity of manganese- 
Table 15. Copper Chemistry

\begin{tabular}{|c|c|c|c|c|c|}
\hline reagents & products & no. & $\begin{array}{l}\text { kinetic constant } \\
\left(\mathrm{M}^{-n+1} \mathrm{~s}^{-1}\right)\end{array}$ & $\begin{array}{c}\text { activation energy } \\
E_{\mathrm{a}} / R(\mathrm{~K})\end{array}$ & ref \\
\hline $\mathrm{OH}+\mathrm{Cu}^{+}$ & $\mathrm{Cu}^{2+}+\mathrm{OH}^{-}$ & R55 & $3.0 \times 10^{9}$ & & Goldstein et al. ${ }^{360}$ \\
\hline $\mathrm{O}_{3}+\mathrm{Cu}^{+}+\mathrm{H}^{+}$ & $\mathrm{Cu}^{2+}+\mathrm{OH}+\mathrm{O}_{2}$ & R56 & $3.0 \times 10^{7}$ & & Hoigné and Bühler ${ }^{267}$ \\
\hline $\mathrm{O}_{2}+\mathrm{Cu}^{+}$ & $\mathrm{Cu}^{2+}+\mathrm{O}_{2}^{-}$ & R57 & $4.6 \times 10^{5}$ & & Bjergbakke et al. ${ }^{361}$ \\
\hline $\mathrm{H}_{2} \mathrm{O}_{2}+\mathrm{Cu}^{+}$ & $\mathrm{Cu}^{2+}+\mathrm{OH}+\mathrm{OH}^{-}$ & R58 & $7.0 \times 10^{3}$ & & Berdnikov et al. ${ }^{269}$ \\
\hline $\mathrm{HO}_{2}+\mathrm{Cu}^{+}+\mathrm{H}^{+}$ & $\mathrm{Cu}^{2+}+\mathrm{H}_{2} \mathrm{O}_{2}$ & R59 & $3.5 \times 10^{9}$ & & Berdnikov et al. ${ }^{269}$ \\
\hline $\mathrm{O}_{2}^{-}+\mathrm{Cu}^{+}+2 \mathrm{H}^{+}$ & $\mathrm{Cu}^{2+}+\mathrm{H}_{2} \mathrm{O}_{2}$ & $\mathrm{R} 60$ & $9.4 \times 10^{9}$ & & Von Piechowski et al. ${ }^{164}$ \\
\hline $\mathrm{HO}_{2}+\mathrm{Cu}^{2+}$ & $\mathrm{Cu}^{+}+\mathrm{O}_{2}+\mathrm{H}^{+}$ & R61 & $1.0 \times 10^{8}$ & & Rabani et al. ${ }^{173}$ \\
\hline $\mathrm{O}_{2}^{-}+\mathrm{Cu}^{2+}$ & $\mathrm{Cu}^{+}+\mathrm{O}_{2}^{-}$ & R62 & $8.0 \times 10^{9}$ & & Rabani et al. ${ }^{173}$ \\
\hline $\mathrm{Cl}_{2}^{-}+\mathrm{Cu}^{+}$ & $\mathrm{Cu}^{2+}+2 \mathrm{Cl}^{-}$ & R63 & $1.0 \times 10^{7}=k_{17}$ & 3060 & estimated \\
\hline $\mathrm{SO}_{4}^{-}+\mathrm{Cu}^{+}$ & $\mathrm{Cu}^{2+}+\mathrm{SO}_{4}^{2-}$ & $\mathrm{R} 64$ & $4.1 \times 10^{9}=k_{\mathrm{R} 27}$ & -2165 & estimated \\
\hline $\mathrm{CO}_{3}^{-}+\mathrm{Cu}^{+}$ & $\mathrm{Cu}^{2+}+\mathrm{CO}_{3}^{2-}$ & R65 & $2.0 \times 10^{7}$ & & estimated from Herrmann et al. ${ }^{22}$ \\
\hline $\mathrm{Cu}^{2+}+\mathrm{OH}$ & $\mathrm{Cu}(\mathrm{OH})^{2+}$ & R66 & $3.5 \times 10^{8}$ & & Baxendale et al. ${ }^{362}$ \\
\hline $\mathrm{Cu}(\mathrm{OH})^{2+}$ & $\mathrm{Cu}^{2+}+\mathrm{OH}$ & R67 & $3.0 \times 10^{4}$ & & Meyerstein ${ }^{276}$ \\
\hline
\end{tabular}

Table 16. Manganese Chemistry

\begin{tabular}{|c|c|c|c|c|c|}
\hline reagents & products & no. & $\begin{array}{l}\text { kinetic constant } \\
\left(\mathrm{M}^{-n+1} \mathbf{s}^{-1}\right)\end{array}$ & $\begin{array}{c}\text { activation energy } \\
E_{\mathrm{a}} / R(\mathrm{~K})\end{array}$ & ref \\
\hline $\mathrm{OH}+\mathrm{Mn}^{2+}$ & $\mathrm{Mn}(\mathrm{OH})^{2+}$ & R68 & $2.0 \times 10^{7}$ & & Jacobsen et al. ${ }^{298}$ \\
\hline $\mathrm{O}_{3}+\mathrm{Mn}^{2+}$ & $\mathrm{MnO}^{2+}+\mathrm{O}_{2}$ & R69 & $1.65 \times 10^{3}$ & 4750 & Jacobsen et al. ${ }^{300}$ \\
\hline $\mathrm{Mn}^{2+}+\mathrm{O}_{2}^{-}$ & $\mathrm{MnO}_{2}^{+}$ & $\mathrm{R} 70$ & $9.5 \times 10^{7}$ & & Jacobsen et al. ${ }^{298}$ \\
\hline $\mathrm{MnO}_{2}^{+}$ & $\mathrm{Mn}^{2+}+\mathrm{O}_{2}^{-}$ & $\mathrm{R} 71$ & $7.5 \times 10^{3}$ & & Jacobsen et al. ${ }^{298}$ \\
\hline $\mathrm{Mn}^{2+}+\mathrm{HO}_{2}$ & $\mathrm{MnO}_{2}^{+}+\mathrm{H}^{+}$ & $\mathrm{R} 72$ & $1.45 \times 10^{6}$ & & Jacobsen et al. ${ }^{298}$ \\
\hline $\mathrm{MnO}_{2}{ }^{+}+\mathrm{H}^{+}$ & $\mathrm{Mn}^{2+}+\mathrm{HO}_{2}$ & R73 & $1.4 \times 10^{7}$ & & Jacobsen et al. ${ }^{298}$ \\
\hline $\mathrm{MnO}^{2+}+\mathrm{Mn}^{2+}+2 \mathrm{H}^{+}$ & $2 \mathrm{Mn}^{3+}+\mathrm{H}_{2} \mathrm{O}$ & R74 & $1.0 \times 10^{5}$ & & Jacobsen et al. ${ }^{300}$ \\
\hline $\mathrm{MnO}_{2}^{+}+\mathrm{MnO}_{2}^{+}+2 \mathrm{H}^{+}$ & $2 \mathrm{Mn}^{2+}+\mathrm{H}_{2} \mathrm{O}_{2}+\mathrm{O}_{2}$ & $\mathrm{R} 75$ & $6.0 \times 10^{6}$ & & Jacobsen et al. ${ }^{298}$ \\
\hline $\mathrm{MnO}_{2}{ }^{+}+\mathrm{HO}_{2}+\mathrm{H}^{+}$ & $\mathrm{Mn}^{2+}+\mathrm{H}_{2} \mathrm{O}_{2}+\mathrm{O}_{2}$ & $\mathrm{R} 76$ & $1.0 \times 10^{7}$ & & Jacobsen et al. ${ }^{298}$ \\
\hline $\mathrm{Mn}^{3+}+\mathrm{Mn}^{3+}$ & $\mathrm{Mn}^{2+}+\mathrm{Mn}^{4+}$ & $\mathrm{R} 77$ & $1.0 \times 10^{7}$ & & $\begin{array}{l}\text { estimated from Jacobsen et al. }{ }^{300} \text { and } \\
\text { Rosseinsky }{ }^{301}\end{array}$ \\
\hline $\mathrm{Mn}^{2+}+\mathrm{Mn}^{4+}$ & $\mathrm{Mn}^{3+}+\mathrm{Mn}^{3+}$ & $\mathrm{R} 78$ & $1.0 \times 10^{7}$ & & $\begin{array}{l}\text { estimated from Jacobsen et al. }{ }^{300} \text { and } \\
\text { Rosseinsky }\end{array}$ \\
\hline $\mathrm{H}_{2} \mathrm{O}_{2}+\mathrm{Mn}^{3+}$ & $\mathrm{Mn}^{2+}+\mathrm{HO}_{2}+\mathrm{H}^{+}$ & $\mathrm{R} 79$ & $7.3 \times 10^{4}$ & & Davies et al. \\
\hline $\mathrm{H}_{2} \mathrm{O}_{2}+\mathrm{Mn}(\mathrm{OH})^{2+}$ & $\mathrm{MnO}_{2}{ }^{+}+\mathrm{H}^{+}+\mathrm{H}_{2} \mathrm{O}$ & $\mathrm{R} 80$ & $2.8 \times 10^{3}$ & & Jacobsen et al. ${ }^{298}$ \\
\hline $\mathrm{H}_{2} \mathrm{O}_{2}+\mathrm{Mn}^{4+}$ & $\mathrm{Mn}^{2+}+2 \mathrm{H}^{+}+\mathrm{O}_{2}$ & $\mathrm{R} 81$ & $1.25 \times 10^{8}$ & & estimated from Jacobsen et al..$^{300}$ \\
\hline $\mathrm{NO}_{3}+\mathrm{Mn}^{2+}$ & $\mathrm{Mn}^{3+}+\mathrm{NO}_{3}^{-}$ & R82 & $1.1 \times 10^{6}$ & & Neta and Huie ${ }^{364}$ \\
\hline $\mathrm{Cl}_{2}^{-}+\mathrm{Mn}^{2+}$ & $\mathrm{Mn}^{3+}+2 \mathrm{Cl}^{-}$ & $\mathrm{R} 83$ & $8.5 \times 10^{6}$ & 4090 & Laurence and Thornton ${ }^{365}$ \\
\hline $\mathrm{Cl}_{2}^{-}+\mathrm{Mn}^{2+}$ & $\mathrm{MnCl}_{2}^{+}$ & R84 & $2.0 \times 10^{7}$ & 4090 & Laurence and Thornton ${ }^{365}$ \\
\hline $\mathrm{MnCl}_{2}{ }^{+}$ & $\mathrm{Mn}^{2+}+\mathrm{Cl}_{2}^{-}$ & $\mathrm{R} 85$ & $3.0 \times 10^{5}$ & & Laurence and Thornton ${ }^{365}$ \\
\hline $\mathrm{MnCl}_{2}^{+}$ & $\mathrm{Mn}^{3+}+2 \mathrm{Cl}^{-}$ & $\mathrm{R} 86$ & $2.1 \times 10^{5}$ & 2100 & Laurence and Thornton ${ }^{365}$ \\
\hline $\mathrm{HSO}_{5}^{-}+\mathrm{Mn}^{2+}$ & $\mathrm{Mn}^{3+}+\mathrm{SO}_{4}^{-}+\mathrm{OH}^{-}$ & $\mathrm{R} 87$ & $3.0 \times 10^{4}=k_{\mathrm{R} 26}$ & & estimated \\
\hline $\mathrm{SO}_{4}^{-}+\mathrm{Mn}^{2+}$ & $\mathrm{Mn}^{3+}+\mathrm{SO}_{4}^{2-}$ & $\mathrm{R} 88$ & $1.8 \times 10^{7}$ & 4100 & Buxton et al. ${ }^{355}$ \\
\hline $\mathrm{SO}_{5}^{-}+\mathrm{Mn}^{2+}+\mathrm{H}_{2} \mathrm{O}$ & $\mathrm{Mn}^{3+}+\mathrm{HSO}_{5}^{-}+\mathrm{OH}^{-}$ & $\mathrm{R} 89$ & $1.0 \times 10^{8}$ & & Fronaeus et al. ${ }^{131}$ \\
\hline $\mathrm{Mn}^{2+}+\mathrm{HSO}_{3}^{-}$ & $\mathrm{MnHSO}_{3}^{+}$ & R90 & $3.0 \times 10^{7}$ & & Berglund et al. ${ }^{257}$ \\
\hline $\mathrm{MnHSO}_{3}{ }^{+}$ & $\mathrm{Mn}^{2+}+\mathrm{HSO}_{3}^{-}$ & R91 & $1.0 \times 10^{3}$ & & Berglund et al. ${ }^{257}$ \\
\hline $\mathrm{MnHSO}_{3}{ }^{+}+\mathrm{Mn}^{3+}$ & $2 \mathrm{Mn}^{2+}+\mathrm{SO}_{3}{ }^{-}+\mathrm{H}^{+}$ & R92 & $1.3 \times 10^{6}$ & & Berglund et al. ${ }^{257}$ \\
\hline $\mathrm{CO}_{3}^{-}+\mathrm{Mn}^{2+}$ & $\mathrm{Mn}^{3+}+\mathrm{CO}_{3}{ }^{2-}$ & R93 & $1.5 \times 10^{7}$ & & Cope et al. ${ }^{366}$ \\
\hline
\end{tabular}

Table 17. Manganese Equilibria

\begin{tabular}{|c|c|c|c|c|}
\hline equilibrium & & $K(\mathrm{M})$ & $\Delta H / R(\mathrm{~K})$ & ref \\
\hline $\mathrm{Mn}^{3+}+\mathrm{H}_{2} \mathrm{O} \leftrightarrow \mathrm{Mn}(\mathrm{OH})^{2+}+\mathrm{H}^{+}$ & E3 & $9.3 \times 10^{-1}$ & & Wells and Davies ${ }^{367}$ \\
\hline $\mathrm{Mn}(\mathrm{OH})^{2+}+\mathrm{H}_{2} \mathrm{O} \leftrightarrow \mathrm{Mn}(\mathrm{OH})_{2}^{+}+\mathrm{H}^{+}$ & E4 & $1.0 \times 10^{-5}$ & & Baral et al. ${ }^{368}$ \\
\hline
\end{tabular}

(III) with hydrogen peroxide is correlated with the chemistry between manganese(II) and $\mathrm{O}_{2}{ }^{-} / \mathrm{HO}_{2}$ radicals via this $\mathrm{MnO}_{2}{ }^{+}$complex. According to Jacobsen et al. ${ }^{298}$ these reactions should have an effect on the oxidizing capacity of the atmospheric aqueous phase. In the same way as for iron, manganese is oxidized by ozone in solution. Available information on this reaction is contradictory. Sheng, ${ }^{299}$ reasoning theoretically, contends that the reaction between ozone and manganese(II) produces manganese(III) and an $\mathrm{OH}$ radical. Jacobsen et al. ${ }^{300}$ described a more plausible mechanism based on laboratory studies: $\mathrm{Mn}^{2+}$ reacts with ozone in solution to form the manganyl ion $\mathrm{MnO}^{2+}$ (R69). Manganese is then under its + IV oxidation state with no formation of an $\mathrm{OH}$ radical. This is similar to the mechanism for the formation of the ferryl ion. Then, $\mathrm{MnO}^{2+}$ reacts quickly with $\mathrm{Mn}^{2+}$ to form manganese(III) (R74). Unlike for the ferryl ion, no studies on the reactivity of the manganyl ion with organic and inorganic species in solution are available. Last, the $\mathrm{Mn}^{4+}$ ion is examined in the mechanism, via the equilibrium (R77 and R78), corresponding to the reversible selfreaction of $\mathrm{Mn}^{3+} .202,301$ Jacobsen et al. ${ }^{300}$ (R81) suggested that the reaction of hydrogen peroxide with $\mathrm{Mn}^{4+}$ leads to the formation of manganese(II). In the autoxidation of sulfur(IV) into sulfur(VI), manganese(II) plays a catalytic role in a similar way to iron (R86-R91 + reaction 46). For the initial step, a hydrogen sulfite complex $\left[\mathrm{Mn}\left(\mathrm{HSO}_{3}{ }^{+}\right)\right]$, as described by Berglund et al. ${ }^{257}$ (R90, R91), is envisioned (cf. section 4.1.2). To summarize, despite the uncertain- 
Table 18. Coupled TMI Chemistry

\begin{tabular}{|c|c|c|c|c|c|}
\hline reagents & products & no. & $\begin{array}{l}\text { kinetic constant } \\
\left(\mathrm{M}^{-n+1} \mathrm{~s}^{-1}\right)\end{array}$ & $\begin{array}{c}\text { activation energy } \\
E_{\mathrm{a}} / R(\mathrm{~K})\end{array}$ & ref \\
\hline $\mathrm{Fe}^{3+}+\mathrm{Cu}^{+}$ & $\mathrm{Fe}^{2+}+\mathrm{Cu}^{2+}$ & R94 & $1.3 \times 10^{7}$ & & Buxton et al. ${ }^{32}$ \\
\hline $\mathrm{Fe}(\mathrm{OH})^{2+}+\mathrm{Cu}^{+}$ & $\mathrm{Fe}^{2+}+\mathrm{Cu}^{2+}+\mathrm{OH}^{-}$ & $\mathrm{R} 95$ & $1.3 \times 10^{7}=k_{\mathrm{R} 94}$ & & estimated \\
\hline $\mathrm{Fe}(\mathrm{OH})_{2}{ }^{+}+\mathrm{Cu}^{+}$ & $\mathrm{Fe}^{2+}+\mathrm{Cu}^{2+}+2 \mathrm{OH}^{-}$ & R96 & $1.3 \times 10^{7}=k_{\mathrm{R} 94}$ & & estimated \\
\hline $\mathrm{Mn}^{3+}+\mathrm{Fe}^{2+}$ & $\mathrm{Mn}^{2+}+\mathrm{Fe}^{3+}$ & R97 & $1.3 \times 10^{4}$ & & Davies $^{126}$ \\
\hline $\mathrm{Mn}(\mathrm{OH})^{2+}+\mathrm{Fe}^{2+}$ & $\mathrm{Mn}^{2+}+\mathrm{Fe}(\mathrm{OH})^{2+}$ & R98 & $2.1 \times 10^{4}$ & & Davies $^{126}$ \\
\hline $\mathrm{Mn}^{2+}+\mathrm{FeO}^{2+}+2 \mathrm{H}^{+}$ & $\mathrm{Mn}^{3+}+\mathrm{Fe}^{3+}+\mathrm{H}_{2} \mathrm{O}$ & R99 & $1.0 \times 10^{4}$ & 2700 & Jacobsen et al. ${ }^{202}$ \\
\hline
\end{tabular}

ties in the manganese reactivity, manganese is expected to play a significant role in the catalytic conversion of sulfite into sulfate under low photolytic condition and high manganese concentrations. ${ }^{232}$

Then, reactions between iron(III) and copper(I) that yield iron(II) and copper(II) are taken up (R94-R96) (Table 18). These reactions have high kinetic constants and play a considerable role in the reactivity of iron in solution (cf. section 4.2.).

Even if this mechanism represents the topical knowledge of cloud chemistry, it presents a limitation due to the lack of laboratory data on the organic complexation of transition metal ions. In particular, in the mechanism, the organic complexation of iron is dominated by oxalate, implying that the model likely overestimates the importance of iron-oxalate photochemistry.

\section{Summary and Concluding Remarks}

This paper is concerned with the influence of transition metal ions on heterogeneous chemistry within clouds. Transition metals are initially in the atmospheric particulate phase. Gas reactions involving trace metals may occur directly at the surface of dry particles. However, the major atmospheric chemical effects of transition metals take place through homogeneous aqueous phase chemistry in wet aerosols, cloud droplets, and raindrops. Even at nanomolar concentrations, transition metal ions undergo catalytic and photocatalytic cycles in the liquid atmospheric water. TMI are transferred into liquid phase from solid particles by dissolution processes. Various field experiments report noticeable concentrations (up to $100 \mu \mathrm{M}$ ) for dissolved trace metals in the atmospheric water: rainwater, cloud water, and fog water. Due to their abundance and their reactivity in atmospheric water as well as in aerosol particles, iron $(\mathrm{Fe})$, copper $(\mathrm{Cu})$, and manganese $(\mathrm{Mn})$ are the most investigated transition metals.

In the first part (section 2), this review describes the source of TMI in the atmospheric liquid phases and the way they are transferred. This source is aerosol particles containing transition metals in various chemical forms. Aerosol particles are emitted in the atmosphere from both natural and anthropogenic sources: wind erosion, biomass and waste burning, industrial activities, and motor emissions. The chemical state and the amount of metals emitted depend on the source; there are large differences in composition between aerosol particles produced by combustion processes and those produced by mechanical erosion and sea spray drying. Wind erosion produces mineral aerosol particles in arid and semiarid areas, where metals are present in a mineral matrix, mainly as silicates and oxides, with relative abundance close to the natural soil abundance. Industrial production and combustion processes produce suspended solid particles, the metal-carrying matrices of which can be either mineral or organic. Dissolution processes control the actual amount of transition metals in the atmospheric liquid phases, and those processes depend on many factors. In particular, some innovative laboratory experiments of dissolution processes have been presented in this review. These experiments analyze the various parameters that drive the dissolution processes. The $\mathrm{pH}$ is a key parameter in the dissolution of transition metals because the dissolution of solid particles influences the $\mathrm{pH}$ through the release of neutralizing and acidifying species and the dissolution process is more effective at low $\mathrm{pH}$ values. The physicochemical nature of aerosol particles also affects its solubility. The great diversity of aerosol particles complicates the identification of the chemical bonds in the particles that play an important role in the dissolution processes. Moreover, the transport of aerosol particles, and in particular the mixing and the weathering that occur during this transport, modifies the solubility of aerosols in atmospheric aqueous phases. The weathering of aerosol particles is itself governed by the solubility of the aerosol particles and thus by their physicochemical nature. The kinetics of the solid-phase dissolution competes with chemical kinetics in the homogeneous aqueous phase. Indeed, transition metals, once dissolved in the atmospheric aqueous phase, will react with various compounds such as $\mathrm{HO}_{x}$ radicals, sulfur compounds, and organic compounds. To understand the impact of TMI on atmospheric chemistry, chemical and dissolution kinetics should both be considered in cloud chemistry model to assess their relative contribution. Experimental laboratory studies are designed to assess the dissolution process as a function of environmental conditions. The assessment of the concentrations of dissolved metal is very difficult and requires a real effort to parametrize the effect of each factors. In this context, new laboratory studies may be required, especially under realistic conditions. Indeed, many data available from laboratory experiments have been obtained with particle loadings that are relatively high compared to environmental loadings. Furthermore, the dramatic gradient in $\mathrm{pH}$ and ionic strength sustained by aerosol during cloud process is not realistically simulated. Finally, laboratory simulations up to now did not consider organic ligands or biological activities that will act to enhance metals solubility. In view of these caveats, the attempt to parametrize metals dissolution will be 
limited to some very simple model calculations designed to determine dissolution kinetics, as long as laboratory simulations will be not more realistic.

In the second part (section 3), this paper focuses on available measurements of transition metal ion concentrations and speciations in atmospheric liquid phases. Speciation discriminates the main oxidation states of a chemical species; for instance, iron is essentially present under two oxidation states in liquid atmospheric phases: +II and +III. These measurements in fog and cloud droplets, in raindrops, and in snow show great heterogeneity with higher concentration levels in polluted conditions than in less polluted ones. TMI concentrations depend on many factors, such as meteorological conditions, air mass origin, primary emissions, and droplet properties. More work is needed to correlate TMI concentrations with these environmental parameters. The speciation of TMI among their oxidation states is the key parameter of their reactivity in solution. In the atmospheric liquid phase, the speciation of dissolved iron, copper, and manganese is still subject to major uncertainties. This is especially the case for manganese and copper, for which very few measurements are available. The speciation of iron in atmospheric liquid water exhibits great variability because it depends on many factors such as the concentration level of oxidants (e.g., $\mathrm{HO}_{2} / \mathrm{O}_{2}^{-}, \mathrm{H}_{2} \mathrm{O}_{2}, \mathrm{O}_{3}, \mathrm{OH}, \mathrm{O}_{2}$ ), of reductants $\left[\mathrm{HO}_{2} / \mathrm{O}_{2}{ }^{-}\right.$, sulfur(IV)], of complexing agents (e.g., organic ligands such as oxalate and formate), and of the actinic flux intensity. The trend in iron speciation measurements shows higher concentrations of iron(II) than of iron(III) during the daytime and the opposite at night. To conclude, whatever the goal of the transition metals measurements is, that is, concentration or redox speciation, it is crucial that scientists define and follow some common rules. As shown in this paper, many research groups have worked in this field, but there is no clear connection between their results; thus, it is impossible to compare them directly. The first important point is the notion of solubility of transition metals. The scientific community must clarify the notion of soluble transition metals. Which kind of species should be considered as soluble, that is, complexes or colloids, and which size should be considered as limiting for soluble species? If we want to compare the results between different sites (rural or marine or urban), it is necessary to have the same references. Second, given the rapid (photochemical) redox reactions of iron(III) and iron(II) species, which occur on time scales of a few minutes, it is essential to develop techniques that can rapidly sample and characterize atmospheric waters and aerosols for their iron speciation, ideally within minutes (or less) of sampling. The third important aspect for the optimization and the validation of the results in this field of research is to keep in mind that experimentations must be carried out in a global and multidisciplinary program. The determination of meteorological, physicochemical, and chemical parameters in the same time is essential to reach solid conclusions about the implication of transition metal in the atmosphere. Moreover, the multiplication of the measurements over a long period of time (on the order of years) is also a guarantee of success for such studies. Finally, the precise characterization of transition metals (organic speciation) in the atmosphere will be the challenge for the next decades to clarify and understand better the role of such metal in atmospheric chemistry. Indeed, the chemical structure (aquacomplexes, organic complexes, aggregates, colloids, oxides) in which the metal is present is a key point to know the chemical and photochemical impact on the atmospheric chemistry.

In the last part (section 4), the paper presents the reactivity of TMI in atmospheric liquid phases. Weschler et al. ${ }^{119}$ first attempted to review the complex redox chemistry of transition metals in atmospheric water. They indicated that TMI could play an important role in the radical chemistry of the atmospheric liquid phases via the production of $\mathrm{OH}$ radical by photolysis of iron(III) complexes and via the redox chemistry of TMI with $\mathrm{HO}_{2} / \mathrm{O}_{2}{ }^{-}$radicals and $\mathrm{H}_{2} \mathrm{O}_{2}$. They also emphasized the ability of TMI to catalyze the sulfur(IV) to sulfur(VI) oxidation by dissolved oxygen in solution. Finally, they pointed out that a number of organic processes in atmospheric liquid phases may involve TMI. Following this work, some aspects of the transition metal redox chemistry in atmospheric waters have been investigated through different approaches: laboratory studies, field experiments, and calculations from cloud chemistry models. TMI chemistry leads to the production of $\mathrm{OH}$ radical in the aqueous phase through photolysis of iron(III)hydroxo species, through photolysis of iron(III)organic complexex, and through the Fenton reaction between $\mathrm{H}_{2} \mathrm{O}_{2}$ and iron(II). This last reaction is still subject to much controversy as to whether the chemical mechanism involves the production of $\mathrm{OH}$ radical or the production of an intermediate oxidant species. Further laboratory investigations are needed to characterize the Fenton chemistry precisely. Iron and copper have been shown to be very reactive with $\mathrm{HO}_{2} /$ $\mathrm{O}_{2}{ }^{-}$radicals and to catalyze the self-reaction of $\mathrm{HO}_{2} /$ $\mathrm{O}_{2}{ }^{-}$efficiently, to yield $\mathrm{H}_{2} \mathrm{O}_{2}$. Calculations from cloud chemistry models suggest that depletion of $\mathrm{HO}_{x}$ by reactions between copper and $\mathrm{HO}_{2} / \mathrm{O}_{2}{ }^{-}$radical significantly slows $\mathrm{O}_{3}$ production in polluted clouds. Catalysis of sulfur(IV) autoxidation by iron and manganese has been investigated in many laboratory studies. The coexistence of two or more catalytically active transition metals in atmospheric liquid water exhibits a significant synergy effect on sulfur(IV) autoxidation. Model studies show that catalyzed metal reactions are prevalent in aqueous sulfate formation in fog droplets during the night, when $\mathrm{H}_{2} \mathrm{O}_{2}$ and $\mathrm{O}_{3}$ concentrations are low. Catalyzed sulfur(IV) autoxidation may significantly contribute to the total oxidation of $\mathrm{SO}_{2}$ in continental clouds and in fog droplets under wet conditions with low photochemical activity. At this time, it is still complicated to discern which transition metal is the most important catalyst in the catalytic oxidation of sulfur(IV), and the catalytic activity of TMI measured in the laboratory under known reaction conditions cannot be extrapolated to atmospheric conditions, because the overall reaction process is very sensitive to the 
presence of other oxidants such as $\mathrm{H}_{2} \mathrm{O}_{2}, \mathrm{O}_{3}$, or various radicals. TMI interact directly with organic compounds in aqueous phase in two ways. On the one hand, organic ions, such as formate and oxalate, can complex TMI and then modify their reactivity and their photoreactivity; on the other hand, TMI can interact with peroxyl radicals and organic hydroperoxide compounds via Fenton-like reactions in a way similar to their interaction with hydroperoxyl/ superoxide ion radicals and hydrogen peroxide. TMI, through their direct contribution to $\mathrm{HO}_{x}$ chemistry, also have an indirect effect on organic compounds. On the basis of this review of TMI reactivity, a chemical mechanism for TMI chemistry (for iron, copper, and manganese) in atmospheric liquid phases is proposed for use in cloud chemistry models (see Tables 13-18). This section on reactivity emphasizes several crucial gaps in our knowledge. First, the mechanism of Fenton chemistry still needs to be elucidated. Second, the reactivity of the ferryl ion in atmospheric liquid waters need to be investigated, especially if it is the intermediate in the Fenton chemistry. Finally, further investigations are needed on interactions between TMI and organic compounds such as Fenton-like reactions and complexation.

It should be clear from the present contribution that much work is still needed to solve the uncertainties of TMI chemistry within clouds. There should be a strong degree of interaction among workers performing field measurements, modelers, and those making laboratory measurements. Comparisons between field measurements and numerical model calculations of atmospheric chemistry often reveal discrepancies, spurring further laboratory work. The results of laboratory studies are incorporated into atmospheric models, improving (one hopes ...) their agreement with field measurements. These past 1520 years have seen a real advance in our knowledge of the detailed chemistry of TMI occurring in the atmosphere, and there is no reason to anticipate that this will not continue!

\section{Acknowledgments}

This work was supported by the Programme National de Chimie Atmosphérique (PNCA) of the Institut des Sciences de l'Univers (INSU). We gratefully acknowledge Pascal Bleuyard for his invaluable computer support as well as his input and patience in revising the paper.

\section{References}

(1) Feingold, G.; Kreidenweis, S. J. Geophys. Res. 2000, 105, 24351.

(2) Lelieveld, J.; Crutzen, P. Nature 1990, 343, 227.

(3) Ramanathan, V.; Cess, R. D.; Harrison, E. F.; Minnis, P.; Backstrom, B. R.; Ahmad, E.; Hartmann, D. Science 1989, 143, 57.

(4) Köhler, H. Meteorol. Z. 1921, 38, 168.

(5) Feingold, G.; Kreidenweis, S. J. Geophys. Res. 2002, 107, 4687, doi 10.1029/2002JD002054.

(6) Hegg, D. A. IGACtivities Newsl. 2001, 23, 3.

(7) Twomey, S. Atmos. Environ. 1974, 8, 1251.

(8) Albrecht, B. Science 1989, 245, 1227.

(9) Calvert, J. G.; Lazrus, A.; Kok, G. L.; Heikes, B. G.; Walega, J. G.; Lind, J.; Cantrell, C. A. Nature 1985, 317, 27.

(10) Mégie, G. Ozone, l'équilibre rompu; Presses du CNRS: Paris, France, 1989; 260 pp.
(11) Ruggaber, A.; Dlugi, R.; Bott, A.; Forkel, R.; Hermann, H.; Jacobi, H.-W. Atmos. Environ. 1997, 31, 3137.

(12) Strekowski, R. S.; Remorov, U. R.; George, C. J. Phys. Chem. A 2003, 107, 2497.

(13) Fuzzi, S., et al. Contr. Atmos. Phys. / Beitr. Phys. Atmosph. 1998, 71,3 .

(14) Wobrock, W., et al. Atmos. Res. 2001, 58, 231, doi 10.1016/ S0169-8095(01)00094-1.

(15) Voisin, D.; Legrand, M.; Chaumerliac, N. J. Geophys. Res. 2000, $105,6817$.

(16) Noone, K. J.; Charlson, R. J.; Covert, D. S.; Ogren, J. A.; Heintzenberg, J. Aerosol Sci. Technol. 1983, 10, 517.

(17) Collett, J., Jr.; Oberholzer, B.; Staehelin, J. Atmos. Environ. 1993, 27A, 33 .

(18) Collett, J., Jr.; Iovinelli, R.; Demoz, B. Atmos. Environ. 1995, 29,1145

(19) Graedel, T. E.; Weschler, C. J. Rev. Geophys. Space Phys. 1981, $19,505$.

(20) Jacob, D. J.; Gottlieb, E. W.; Prather, M. J. J. Geophys. Res. 1989 , 94, 12975.

(21) Walcek, C. J.; Yuan, H.; Stockwell, W. R. Atmos. Environ. 1997, 31,1221 .

(22) Herrmann, H.; Ervens, B.; Jacobi, H.-W.; Wolke, R.; Nowacki, P.; Zellner, R. J. Atmos. Chem. 2000, 36, 231.

(23) Deguillaume, L.; Leriche, M.; Monod, A.; Chaumerliac, N. Atmos. Chem. Phys. 2004, 4, 95.

(24) Galloway, J. N.; Gaudry, A. Atmos. Environ. 1984, 18, 2649

(25) Behra, P.; Sigg, L. Nature 1990, 344, 419.

(26) Kotronarou, A.; Sigg, L. Environ. Sci. Technol. 1993, 27, 2725

(27) Brandt, C.; van Eldik, R. Chem. Rev. 1995, 95, 119.

(28) Sedlak, D. L.; Hoigné, J.; David, M. M.; Colvile, R. N.; Seyffer, E.; Acker, K.; Wiepercht, W.; Lind, J. A.; Fuzzi, S. Atmos. Environ. 1997, 31, 2515.

(29) Siefert, R. L.; Johansen, A. M.; Hoffmann, M. R. J. Air Waste Manag. Assoc. 1998, 48, 128.

(30) Moore, K. F.; Sherman, D. E.; Reilly, J. E.; Collett, J. L. Atmos. Environ. 2004, 38, 1389

(31) Rush, J. D.; Bielski, B. H. J. J. Phys. Chem. 1985, 89, 5062.

(32) Buxton, G. V.; Mulazzani, Q. G.; Ross, A. B. J. Phys. Chem. Ref. Data 1995, 24, 1055.

(33) Gozzo, F. J. Mol. Catal. A: Chem. 2001, 171, 1.

(34) Turekian, K. K. Geochemical distribution of the elements. In Encyclopedia of Sciences and Tecnology; McGraw Hill: New York, 1971; Vol. 4.

(35) Hofmann, H.; Hoffmann, P.; Lieser, K. Fresenius' J. Anal. Chem. 1991, 340, 591-597.

(36) Pacyna, J. Source inventories for atmospheric trace metals. In Atmospheric Particles; Harrison, R., Grieken, R. V., Eds.; Wiley: Chichester, U.K., 1998.

(37) Hoffmann, P.; Dedik, A. N.; Ensling, J.; Weinbruch, S.; Weber, S.; Sinner, T.; Gutlich, P.; Ortner, H. M. J. Aerosol Sci. 1996, 27,325 .

(38) Nriagu, J. Nature 1989, 338, 47.

(39) Coudé-Gaussen, G.; Rognon, P.; Coustumer, M. L. Incorporation progressive des poussiéres Sahariennes aux limons des îles orientales. C. R. Acad Sci., Ser. II 1994; Vol. 319, pp 1343-1349.

(40) Rognon, R.; Coudé-Gaussen, G.; Revel, M.; Grousset, F.; Pedemay, P. Sedimentology 1996, 43, 359.

(41) Eltayeb, M. A. H.; Injuk, J.; Maenhaut, W.; Grieken, R. V. J. Atmos. Chem. 2001, 40, 247.

(42) Jickells, T. D., et al. Science 2005, 308, 67.

(43) Hogg, C. S.; Malden, P. J.; Meads, R. E. Miner. Mag. 1975, 40, 89.

(44) Rengasamy, P. Clays Clay Miner. 1976, 20, 265.

(45) Kopcewicz, B.; Kopcewicz, M. Struct. Chem. 1991, 2, 303.

(46) Kopcewicz, B.; Kopcewicz, M. Hyperfine Interact. 1992, 71, 1457.

(47) Kopcewicz, B.; Kopcewicz, M. Atmos. Environ. 2001, 35, 3739

(48) Pehkonen, S. O.; Slefert, R.; Erel, Y.; Webb, S.; Hoffmann, M. R. Environ. Sci. Technol. 1993, 27, 2056.

(49) Weber, S.; Hoffmann, P.; Ensling, J.; Dedik, A. N.; Weinbruch, S.; Miehe, G.; Gütlich, P.; Ortner, H. M. J. Aerosol Sci. 2000, $31,987$.

(50) Lafon, S.; Rajot, J.-L.; Alfaro, S. C.; Gaudichet, A. Atmos. Environ. 2004, 38, 1211

(51) Patel, K.; Shukla, A.; Tripathi, A. N.; Hoffmann, P. Geochim. Cosmochim. Acta 2004, 68, 2623.

(52) Hlavay, J.; Polyak, K.; Molnar, A.; Meszaros, E. Analyst 1998, $123,859$.

(53) Bikkes, M.; Polyak, K.; Hlavay, J. J. Anal. At. Spectrom. 2001, $1116,74$.

(54) Voutsa, D.; Samara, C. Atmos. Environ. 2002, 36, 3583.

(55) Gunst, S.; Weinbruch, S.; Wentzel, M.; Ortner, H. M.; Skogstad, A.; Hetland, S.; Thomassen, Y. J. Environ. Monit. 2000, 2, 65.

(56) Vassilev, S.; Eskenazy, G. M.; Vassileva, C. Fuel Process. Technol. 2001, 72, 103.

(57) Huggins, F. E.; Huffman, G. P.; Robertson, J. D. J. Hazard. Mater. 2000, 74, 1.

(58) Takeda, K.; Marumoto, K.; Minamikawa, T.; Sakugawa, H.; Fujiwara, K. Atmos. Environ. 2000, 34, 4525. 
(59) Desboeufs, K. V.; Sofikitis, A.; Losno, R.; Colin, J. L.; Ausset, P. Chemosphere 2005, 58, 195.

(60) Zhuang, G.; Yi, Z.; Duce, R. A.; Brown, P. R. Global Biochem. Cycles 1992, 6, 161.

(61) Sulzberger, B.; Laubscher, H. Mar. Chem. 1995, 50, 103.

(62) Desboeufs, K. V. Processus de dissolution des aérosols atmosphériques au sein de la goutte d'eau nuageuse. Thèse de Doctorat d'Université, Université Paris VII, 2001.

(63) Hoffmann, P.; Dedik, A. N.; Deutsch, F.; Sinner, T.; Weber, S.; Eichler, R.; Sterkel, S.; Sastri, C. S.; Ortner, H. M. Atmos. Environ. 1997, 31, 2777.

(64) Wilkinson, R. J.; Reynolds, B.; Neal, C.; Hill, S.; Neal, M.; Harrow, M. L. Hydrol. Earth Syst. Sci. 1997, 1, 557.

(65) Colin, J. L.; Jaffrezo, J. L.; Gross, J. M. Atmos. Environ. 1990 $24 A, 537$

(66) Thompson, A. M. Geochem. Cosmochim. Acta 1964, 28, 1273.

(67) Luck, J. M.; Ben Othman, D. Chem. Geol. 2002, 182, 443.

(68) Williams, P. T.; Radojevic, M.; Clarke, A. G. Atmos. Environ. 1988, 22, 1433 .

(69) Jickells, T. D.; Davies, T. D.; Tranter, M.; Landsberger, S.; Jarvis, K.; Abrahams, P. Atmos. Environ. 1992, 26A, 393.

(70) Nimmo, M.; Fones, G. R.; Chester, R. Croat. Chem. Acta 1998, 71,323 .

(71) Freydier, R.; Dupre, B.; Lacaux, J. P. Atmos. Environ. 1998, 32, 749.

(72) Spokes, L. J.; Jickells, T. D.; Lim, B. Geochim. Cosmochim. Acta $\mathbf{1 9 9 4}, 58,3281$.

(73) Chester, R.; Lin, F. J.; Murphy, K. J. T. Environ. Technol. Lett. 1989, $10,887$.

(74) Kyotani, J.; Iwatsuki, M. Atmos. Environ. 2002, 36, 639.

(75) Lindberg, S. E.; Harriss, R. C. J. Geophys. Res. 1983, 88, 5091.

(76) Zhu, X.; Prospero, J. M.; Savoie, F. J. M. D. L.; Brass, G. W. Mar. Chem. 1992, 38, 91.

(77) Al-Momani, I. F. Atmos. Environ. 2003, 37, 4507.

(78) Kieber, R. J.; Peake, B.; Willey, J. D.; Jacobs, B. Atmos. Environ. 2001, 35, 6041.

(79) Statham, P. J.; Chester, R. Geochim. Cosmochim. Acta 1988, $52,2433$.

(80) Losno, R.; Bergametti, G.; Buat-Menard, P. Geophys. Res. Lett. 1988, 15, 1389 .

(81) Chester, R. Sci. Geol. 1990, 88, 23.

(82) Chester, R.; Nimmo, M.; Corcoran, P. A. Mar. Chem. 1997, 58, 293.

(83) Lim, B.; Jickells, T. D.; Colin, J. L.; Losno, R. Global Biogeochem. Cycles 1994, 8, 349.

(84) Pedersen, A. J.; Ottosen, L. M.; Villumsen, A. J. Hazard. Mater. 2003, 100,65

(85) Chester, R.; Nimmo, M.; Fones, G. R.; Keyse, S.; Zhang, J. Atmos. Environ. 2000, 34, 3875

(86) Desboeufs, K. V.; Losno, R.; Vimeux, F.; Cholbi, S. J. Geophys. Res. 1999, 104, 21287.

(87) Stumm, W. Chemical processes at the particle-water interface. In Aquatic Surface Chemistry; Stumm, W., Ed.; Wiley-Interscience: New York, 1987.

(88) Huertas, F. J.; Chou, L.; Wollast, R. Geochim. Cosmochim. Acta 1999, 63,3261 .

(89) Millet, M.; Wortham, H.; Mirabel, P. Atmos. Environ. 1995, 29 , 2625.

(90) Desboeufs, K. V.; Losno, R.; Colin, J. L. Anal. Bioanal. Chem. 2003, 375, 567.

(91) Praharaj, T.; Powell, M. A.; Hart, B. R.; Tripathy, S. Environ. Int. 2002, 27, 609

(92) Loye-Pilot, M. D.; Martin, J. M.; Morelli, J. Nature 1986, 321, 427.

(93) Chester, R.; Keyse, S.; Corcoran, P. A.; Nimmo, M. Factors controlling the solubility of $\mathrm{Pb}$ in rainwaters: the sol id state speciation of $\mathrm{Pb}$ in scavenged aerosols. In Water Pollution Research Report 32, EROS 2000; Martin, J.-M., Barth, H., Eds.; European Commission: Luxembourg, 1995.

(94) Alabdula'aly, A. I.; Khan, M. Arch. Environ. Contam. Toxicol. 2000, 39, 66.

(95) Chester, R.; Nimmo, M.; Keyse, S. The influence of Saharan and Middle eastern desert-derived dust on the trace metal composition of Mediterranean aerosol and rainwaters: an overview. In The Impact of Desert Dust across the Mediterranean; Guerzoni, S., Chester, R., Eds.; Kluwer Academic Publishers: Dordrecht, The Netherlands, 1996.

(96) Lefebvre-Drouet, E.; Rousseau, M. F. Soil Biol. Biochem. 1995, $27,1041$.

(97) Sigg, L.; Stumm, W.; Zobrist, J.; Zürcher, F. Chimia 1987, 41, 159 .

(98) Galloway, J. N.; Thornton, J. D.; Norton, S. A.; Volchok, H. L.; McLean, R. A. N. Atmos. Environ. 1982, 16, 1677.

(99) Benjamin, M. M.; Leckie, J. O. Environ. Sci. Technol. 1981, 15 , 1050.

(100) Velay, J. M.; A., R. L.; Desboeufs, K. V.; Colin, J. L.; Sofikitis, A. Factors influencing iron speciation in atmospheric water. In Proceedings of the EAC 2003, Madrid, Sept, 2003. J. Aerosol Sci. 2003, 34-2, 757 .
(101) Sofikitis, A. Sources et évolution des formes redox du fer en phase aqueuse atmosphèrique. Ph.D. thesis, University of Paris VII, 2004.

(102) Zhu, X.; Prospero, J. M.; Millero, F. J. J. Geophys. Res. 1997, 102, 21297.

(103) Deutsch, F.; Hoffmann, P.; Ortner, H. M. Fresenius' J. Anal. Chem. 1997, 357, 105.

(104) Anderson, J. R.; Buseck, P. R.; Patterson, T. L.; Arimoto, R. Atmos. Environ. 1996, 30, 319.

(105) Levin, Z.; Ganor, E. The effect of desert particles on cloud and rain formation in the eastern Mediterranean. In The Impact of Desert Dust across the Mediterranean; Guerzoni, S., Chester, R., Eds.; Kluwer Academic Publishers: Dordrecht, The Netherlands, 1996

(106) Busek, P. R.; Posfai, M. Proc. Natl. Acad. Sci. U.S.A. 1999, 96, 3372.

(107) Davis, B. L.; Jixiang, G. Atmos. Environ. 2000, 34, 2703.

(108) Gao, Y.; Anderson, J. R. J. Geophys. Res. 2001, 106, 18037.

(109) Song, C. H.; Carmichael, G. R. Atmos. Env. 1999, 33, 2203.

(110) Özsoy, T.; Saydam, A. C. J. Atmos. Chem. 2001, 40, 41

(111) Hamilton-Taylor, J.; Giusti, L.; Davison, W.; Tych, W.; Hewitt, C. N. Colloids Surf. A: Physicochem. Eng. Aspects 1997, 120, 205.

(112) Desboeufs, K. V.; Losno, R.; Colin, J. L. J. Atmos. Chem. 2003, $46,159$.

(113) Kieber, R. J.; Skrabal, S. A.; Smith, C.; Willey, J. D. Environ. Sci. Technol. 2005, 39, 1576.

(114) Flynn, C. M., Jr. Chem. Rev. 1984, 84, 31.

(115) Lopes, L.; de Laat, J.; Legube, B. Inorg. Chem. 2002, 41, 2505.

(116) Faust, B. C.; Hoigné, J. H. Atmos. Environ. 1990, 24A, 79

(117) Sommer, B. A.; Margerum, D. W. Inorg. Chem. 1970, 9, 2517.

(118) Stumm, W.; Morgan, J. In Aquatic Chemistry, 2nd ed.; Wiley: New York, 1981.

(119) Weschler, C. J.; Mandich, M. L.; Graedel, T. E. J. Geophys. Res. 1986, 91,5189 .

(120) Willey, J. D.; Kieber, R. J.; Williams, K. H.; Crozier, J. S.; Skrabal, S. A.; Avery, G. B., Jr. J. Atmos. Chem. 2000, 37, 185.

(121) Kieber, R. J.; Willey, J. D.; Brooks Avery, G., Jr. J. Geophys. Res. 2003, 108, 3277, doi 10.1029/2001JC001031.

(122) Zappoli, S.; Andracchio, A.; Fuzzi, S.; Facchini, M. C.; Gelencsér, A.; Kiss, G.; Krivacsy, Z.; Molnar, A.; Mészaros, E.; Hansson, H.-C.; Rosman, K.; Zebühr, Y. Atmos. Environ. 1999, 33, 2733

(123) Facchini, M. C.; Fuzzi, S.; Zappoli, S.; Andracchio, A.; Gelencsér A.; Kiss, G.; Krivácsy, Z.; Mészáros, E.; Hansson, H.-C.; Alsberg, T.; Zebühr, Y. J. Geophys. Res. 1999, 104, 26821.

(124) Kiss, G.; Tombácz, E.; Varga, B.; Alsberg, T.; Persson, L. Atmos. Environ. 2003, 37, 3783.

(125) Feng, Y.; Möller, D. J. Atmos. Chem. 2004, 48, 217

(126) Davies, G. Coord. Chem. Rev. 1969, 4, 199.

(127) Moffet, J. W.; Zika, R. G. The photochemistry of copper complexes in sea water. In Photochemistry of Environmental Aquatic Systems; Zika, R. G., Cooper, W. J., Eds.; Advances in Chemistry Series 327; American Chemical Society: Washington, DC, 1987; pp 116-130.

(128) Sykora, J. Coord. Chem. Rev. 1997, 159, 95

(129) Achterberg, E. P.; van Elteren, J. T.; Kolar, Z. I. Environ. Sci Technol. 2005, 36, 914

(130) Berglund, J.; Elding, L. I. Atmos. Environ. 1995, 29, 1379

(131) Fronaeus, S.; Berglund, J.; Elding, L. Inorg. Chem. 1998, 37 4939.

(132) Schroeder, W. H.; Dobson, M.; Kane, D. M.; Johnson, N. D. J. Air Pollut. Control Assoc. 1987, 37, 1267.

(133) Xue, H.; Conçalves, M. L. S.; Reutlinger, M.; Sigg, L.; Stumm, W. Environ. Sci. Technol. 1991, 25, 1716.

(134) Spokes, L. J.; Campos, M. L. A. M.; Jickells, T. D. Atmos. Environ. 1996, 30, 3959

(135) Nimmo, M.; Fones, G. R. Atmos. Environ. 1997, 31, 693.

(136) Kieber, R. J.; Skrabal, S. A.; Smith, C.; Willey, J. D. Environ. Sci. Technol. 2004, 38, 3587, doi 10.1021/es030698r.

(137) Conklin, M. H.; Hoffmann, M. R. Environ. Sci. Technol. 1988, 22,883 .

(138) Conklin, M. H.; Hoffmann, M. R. Environ. Sci. Technol. 1988, $22,891$.

(139) Conklin, M. H.; Hoffmann, M. R. Environ. Sci. Technol. 1988 , $22,898$.

(140) Warneck, P. Ber. Bunsenges. Phys. Chem. 1992, 99, 59

(141) Hoigné, J.; Zuo, Y.; Nowell. In Aquatic and Surface Photochemistry; Helz, G. R., Zepp, R., Crosby, D., Eds.; Lewis Publishers Boca Raton, FL, 1994.

(142) Schwanz, M.; Warneck, P.; Preiss, M.; Hoffmann, P. Contr. Atmos. Phys. 1998, 70, 131.

(143) Erel, Y.; Pekhonen, S. O.; Hoffmann, M. J. Geophys. Res. 1993 98,18423 .

(144) Sinner, T.; Hoffmann, P.; Ortner, H. M. Beitr. Phys. Atmos. 1994, $67,353$.

(145) Rao, X.; Collett Jr., J. L. J. Atmos. Chem. 1998, 30, 273.

(146) Deutsch, F.; Hoffmann, P.; Ortner, H. M. J. Atmos. Chem. 2001 $40,87$. 
(147) Kieber, R. J.; Willey, J. D.; Williams, K. H.; Skrabal, S. A.; Avery, G. B. Mar. Chem. 2001, 73, 83.

(148) Fuzzi, S., et al. Tellus 1992, 44B, 448, doi 10.1034/j.16000889.1992.t01-4-00002.x.

(149) Marinoni, A.; Laj, P.; Abida, O.; Mailhot, G. J. Phys. IV Fr. 2003, 107, 823.

(150) Parazols, M.; Marinoni, A.; Amato, P.; Abida, O.; Laj, P.; Mailhot, G. Atmos. Environ. 2005, submitted for publication

(151) Arakaki, T.; Faust, B. C. J. Geophys. Res. 1998, 103, 3487.

(152) Sellegri, K.; Laj, P.; Peron, F.; Dupuy, R.; Legrand, M.; Preunkert, S.; Putaud, J.-P.; Cachier, H.; Ghermandi, G. J. Geophys. Res. 2003, 108, 433, doi 10.1029/2002JD002747.

(153) Arimoto, R.; Duce, R. A.; Hewitt, A. D.; Boldi, R.; Hudson, A. J. Geophys. Res. 1990, 92, 8465.

(154) Halstead, M. J. R.; Cunninghame, R. G.; Hunter, K. A. Atmos. Environ. 2000, 34, 665

(155) Patel, K.; Shukla, A.; Tripathi, A. N.; Hoffmann, P. Water, Air Soil Pollut. 2001, 130, 463

(156) Jacob, D. J. J. Geophys. Res. 1986, 91, 9807.

(157) Miller, D.; Byrd, J.; Perona, M. Water, Air Soil Pollut. 1987, 32 329 .

(158) Siefert, R.; Johansen, A.; Hoffmann, M.; Pehkonen, S. J. Air Waste Manag. Assoc. 1997, 48, 128.

(159) Pruppacher, H. R.; Klett, J. D. Microphysics of Clouds and Precipitation, 2nd ed.; Reidel Publishing: Boston, MA, 1997; 954 pp.

(160) Kogut, M. B.; Voelker, B. M. Environ. Sci. Technol. 2001, 35, 1149.

(161) Zafiriou, O. C.; Voelker, B. M.; Sedlak, D. L. J. Phys. Chem. A 1998, 102, 5693

(162) Voelker, B. M.; Sedlak, D. L.; Zafiriou, O. Environ. Sci. Technol. 2000, 34, 1036.

(163) Goldstone, J. V.; Voelker, B. M. Environ. Sci. Technol. 2000, 34, 1043.

(164) M. Piechowski von, T. N.; Hoignè, T.; Buhler, R. Ber. Bunsenges. Phys. Chem. 1993, 97, 762 .

(165) Pehkonen, S. O.; Erel, Y.; Hoffmann, M. R. Environ. Sci. Technol. 1992, 26, 1731 .

(166) Dedik, A. N.; Hoffmann, P. Atmos. Environ. 1992, 26A, 2545.

(167) Münger, J. W.; Jacob, D. J.; Waldman, J. M.; Hoffmann, M. R. J. Geophys. Res. 1983, 88, 5109.

(168) Faust, B. C. A review of the photochemical redox reactions of iron(III) species in atmospheric, oceanic, and surface waters: influences on geochemical cycles and oxidant formation. In Aquatic Surface and Photochemistry; Helz, G., Ed.; CRC Press: Boca Raton, FL, 1994.

(169) Warneck, P. In Chemistry of the Natural Atmosphere, 2nd ed. Dmowska, R., Holton, J., Rossby, H., Eds.; Academic Press: London, U.K., 2000; Vol. 71.

(170) Jayson, G. G.; Parson, B. J.; Swallow, A. J. J. Chem. Soc. Faraday Trans. 1973, 69, 236.

(171) Wiesinger, G.; Ismail, S. S. Hyperfine Interact. 1990, 57, 2319.

(172) Ervens, B.; George, C.; Williams, J. E.; Buxton, G. V.; Salmon, G. A.; Bydder, M.; Wilkinson, F.; Dentener, F.; Mirabel, P.; Wolke, R.; Herrmann, H. J. Geophys. Res. 2003, 108.

(173) Rabani, J.; Klug-Roth, D.; Lilie, J. J. Phys. Chem. 1973, 77, 1169

(174) Bielski, B. H. J.; Cabelli, D. E.; Arudi, R. L.; Ross, A. B. J. Phys. Chem. Ref. Data 1985, 14, 1041.

(175) Kieber, R. J.; Hardison, D. R.; Whitehead, R. F.; Willey, J. D. Environ. Sci. Technol. 2003, 37, 4610, doi 10.1021/es030345s

(176) Jans, U.; Hoigné, J. Atmos. Environ. 2000, 34, 1069.

(177) Pehkonen, S. O.; Erel, Y.; Siefert, R.; Klewicki, K.; Hoffmann, M. R.; Morgan, J. J. Isr. J. Earth Sci. 1994, 43, 279.

(178) Graedel, T. E.; Mandich, M. L.; Weschler, C. J. J. Geophys. Res. 1986, 91,5205

(179) Martin, L. R.; Hill, M. W. Atmos. Environ. 1987, 21, 1487.

(180) Zuo, Y.; Hoigné, J. Environ. Sci. Technol. 1992, 26, 1014.

(181) Siefert, R. L.; Pehkonen, S. O.; Erel, Y.; Hoffmann, M. R. Geochim. Cosmochim. Acta 1994, 58, 3271.

(182) Jacob, D. J. Atmos. Environ. 2000, 34, 2131.

(183) Chameides, W. L.; Davis, D. D. J. Geophys. Res. 1982, 87, 4863.

(184) Lelieved, J.; Crutzen, P. J. J. Atmos. Chem. 1991, 12, 229.

(185) Losno, R. Phys. Chem. Earth (B) 1999, 24, 281.

(186) Leriche, M.; Voisin, D.; Chaumerliac, N.; Monod, A.; Aumont, B. Atmos. Environ. 2000, 34, 5015, doi 10.1016/S1352-2310(00)00329-0.

(187) Evans, M. G.; Uri, N. Nature 1949, 164, 404

(188) Bates, H. G. C.; Uri, N. J. Am. Chem. Soc. 1953, 75, 2554

(189) Feng, Y.; Nansheng, D. Chemosphere 2000, 41, 1137.

(190) Mazellier, P.; Mailhot, G.; Bolte, M. New J. Chem. 1997, 21, 389

(191) Benkelberg, H. J.; Warneck, P. J. Phys. Chem. 1995, 99, 5214.

(192) Anastasio, C.; Faust, B. C.; Allen, J. M. J. Geophys. Res. 1994, 99,8231

(193) Fenton, H. J. H. J. Chem. Soc. 1894, 65, 899.

(194) Dunford, H. B. Coord. Chem. Rev. 2002, 233/234, 311

(195) Ensing, B.; Baerends, E. J. J. Phys. Chem. A 2002, 106, 7902

(196) Buda, F.; Ensing, B.; Gribau, M. C. M.; Baerends, E. J. Chem. Eur. J. 2003, 9, 3436
(197) Ensing, B.; Buda, F.; Gribnau, M. C. M.; Baerends, E. J. J. Am. Chem. Soc. 2004, 126, 4355 .

(198) Barb, W. G.; Baxendale, J. H.; George, P.; Hargrave, K. R. Trans. Faraday Soc. 1951, 47, 461.

(199) Barb, W. G.; Baxendale, J. H.; George, P.; Hargrave, K. R. Trans. Faraday Soc. 1951, 47, 591

(200) Logager, T.; Holcman, J.; Sehested, K.; Petersen, T. Inorg. Chem. 1992, 31, 3523 .

(201) Jacobsen, F.; Holcman, J.; Sehested, K. Int. J. Chem. Kinet. 1997, $29,17$.

(202) Jacobsen, F.; Holcman, J.; Sehested, K. Int. J. Chem. Kinet. 1998 $30,215$.

(203) Bray, W. C.; Gorin, M. H. J. Am. Chem. Soc. 1932, 54, 2124

(204) Cahill, A. E.; Taube, H. J. Am. Chem. Soc. 1952, 74, 2312.

(205) Kremer, M. L. J. Phys. Chem. A 2003, 107, 1734.

(206) Hug, S. J.; Leupin, O. Environ. Sci. Technol. 2003, 37, 2734.

(207) Kremer, M. L. Phys. Chem. Chem. Phys. 1999, 1, 3595.

(208) Kremer, M. L. J. Inorg. Biochem. 2000, 78, 255.

(209) Matthijsen, J.; Builtjes, P. J. H.; Sedlak, D. H. Meterol. Atmos. Phys. 1995, 57, 43

(210) Matthijsen, J.; Builtjes, P. T. H.; Meijer, E. W.; Boersen, G. Atmos. Environ. 1997, 31, 3227

(211) Deguillaume, L.; Leriche, M.; Chaumerliac, N. Chemosphere 2005, in press.

(212) Titoff, A. Z. Phys. Chem. 1903, 45, 641

(213) Tsunogai, S. Geochem. J. 1971, 5, 175.

(214) Huss, A.; Kim, P. K.; Eckert, C. A. J. Am. Chem. Soc. 1978, 100, 6252.

(215) Connick, R. E.; Zhang, Y.-X.; Lee, S.; Adamic, R.; Chieng, P. Inorg. Chem. 1995, 34, 4543.

(216) Hegg, D. A.; Hoobs, P. V. Atmos. Environ. 1978, 15, 1597.

(217) Martin, L. R. Kinetic Studies of Sulfite Oxidation. In Aqueous Solution Acid Precipitation Series; Calvert, J. G., Teasley, J. I., Eds.; Vol. 3: $\mathrm{SO}_{2}$, $\mathrm{NO}$ and $\mathrm{NO}_{2}$ Oxidation Mechanisms: Atmospheric Considerations; Butterworth Publishers: Boston, MA 1984; pp 63-100

(218) Reddy, K. B.; Coichev, N.; van Eldik, R. J. Chem. Soc., Chem. Commun. 1991, 481.

(219) Reddy, K. B.; van Eldik, R. Atmos. Environ. 1992, 26A, 661.

(220) Brandt, C.; Fábián, I.; van Eldik, R. Inorg. Chem. 1994, 33, 687.

(221) Ziajka, J.; Beer, F.; Warneck, P. Atmos. Environ. 1994, 28, 2549.

(222) Warneck, P.; Ziajka, J. Ber. Bunsenges. Phys. Chem. 1995, 99, 59.

(223) Grgic, I.; Poznic, M.; Bizjak, M. J. Atmos. Chem. 1999, 33, 89

(224) Grgic, I.; Hudnik, V.; Bizjak, M.; Levect, J. Atmos. Environ. 1993, $27 A, 1409$.

(225) Novic, M.; Grgic, I.; Poe, M.; Hudnik, V. Atmos. Environ. 1996 , 30,4191 .

(226) Herrmann, H.; Ervens, B.; Reese, A.; Umschlag, T.; Wicktor, F. Zellner, R. Free radical $\left(\mathrm{NO}_{3}, \mathrm{SO}_{4}^{-}, \mathrm{Cl}_{2}^{-}\right)$oxidation reactions of VOCs and their degradation products in the atmospheric aqueous phase. In Air Pollution Research Report 67: Chemical Mechanism of Atmospheric; Becker, K.-H., Angeletti, G., Eds.; Office for Official Publications of the European Communities: Luxembourg, 1999.

(227) Grgic, I.; Dovzan, A.; Bercic, G.; Hudnik, V. J. Atmos. Chem. 1998, 29, 315

(228) Sedlak, D. L.; Hoigné, J. Atmos. Environ. 1993, 27A, 2173

(229) Sedlak, D. L.; Hoigné, J. Atmos. Environ. 1994, 28, 1898.

(230) Wolf, A.; Deutsch, F.; Hoffmann, P.; Ortner, H. M. J. Atmos. Chem. 2000, 37, 125 .

(231) Zuo, Y.; Zhan, J. Atmos. Environ. 2005, 39, 27.

(232) Warneck, P. Fresenius' J. Anal. Chem. 1991, 340, 585.

(233) Pandis, S. N.; Seinfeld, J. H.; Pilini, C. Atmos. Environ. 1992, 26,2509

(234) Warneck, P. Phys. Chem. Chem. Phys. 1999, 1, 5471.

(235) Faust, B. C.; Zepp, R. G. Environ. Sci. Technol. 1993, 27, 2517.

(236) Cho, S. Y.; Carmichael, G. R. Atmos. Environ. 1986, 20, 1959.

(237) Ansari, A.; Peral, J.; Domenech, X.; Rodriguez, R. Environ. Pollut. 1997, 3, 383.

(238) Turro, N.; Lakshminarasimhan, P.; Jockusch, S.; O’Brien, S. Grandcharov, S.; Redl, F. Nano Lett. 2002, 2, 325.

(239) Pehkonen, S. O. Analyst 1995, 120, 2655.

(240) Norton, R.; Roberts, J.; Huebert, B. Geophys. Res. Lett. 1988, 8 , 235.

(241) Joss, F.; Baltensperger, U. Atmos. Environ. 1991, 25A, 217.

(242) Chebbi, A.; Carlier, P. Atmos. Environ. 1996, 30, 4233.

(243) Laj, P., et al. Atmos. Environ. 1997, 31, 2589.

(244) Vincze, L.; Papp, S. Talanta 1987, 34, 299

(245) Balzani, V.; Carassiti, V. In Photochemistry of Coordination Compounds; Academic Press: London, U.K., 1970.

(246) Vincze, L.; Papp, S. J. Photochem. 1987, 36, 289.

(247) Siefert, R. L.; Webb, S. M.; Hoffmann, M. R. J. Geophys. Res. 1996, 101,14441

(248) McKeen, S. A.; Hsie, E.-Y.; Trainer, M.; Tallamraju, R.; Liu, S. C. J. Geophys. Res. 1991, 96, 809 .

(249) Zuo, Y. Geochim. Cosmochim. Acta 1995, 59, 3123.

(250) Zuo, Y.; Deng, D. Geochim. Cosmochim. Acta 1999, 63, 3451.

(251) Gunz, D. W.; Hoffmann, M. R. Atmos. Environ. 1990, 24A, 1601. 
(252) Thompson, A. M. Science 1992, 256, 1157.

(253) Kieber, R.; Xianliang, Z.; Mopper, K. Limnol. Oceanogr. 1990, 35,1503

(254) Stemmler, K.; Von Gunten, U. Atmos. Environ. 2000, 34, 4253.

(255) Khaikin, G. I.; Alfassi, Z. B.; Huie, R. E.; Neta, P. J. Phys. Chem. 1996, 100,7072

(256) Chevallier, E.; Jolibois, R. D.; Meunier, N.; Carlier, P.; Monod, A. Atmos. Environ. 2004, 38, 921.

(257) Berglund, J.; Fronaeus, S.; Elding, L. I. Inorg. Chem. 1993, 32 , 4527.

(258) Pasiuk-Bronikowska, W.; Bronikowski, T. Chem. Eng. Sci. 1981, $36,215$.

259) Hoffmann, M. R. Jacob, D. J. Kinetics and mechanisms of the catalytic oxidation of dissolved sulfur dioxide in aqueous solution: an application to nighttime fog water chemistry. In Aqueous Solution Acid Precipitation Series; Calvert, J. G., Teasley, J. I., Eds.; Vol. 3: $\mathrm{SO}_{2}, \mathrm{NO}$, and $\mathrm{NO}_{2}$ Oxidation Mechanisms: Atmospheric Considerations; Butterworth: Boston, MA, 1984; pp 101-171.

(260) Collins, K. R. Kinetics of oxidation of aqueous sulfur(IV) as catalyzed by manganous ion. Ph.D. thesis, Georgia Institute of Technology, 1987

(261) Pasiuk-Bronikowska, W.; Bronikowski, T. Chem. Eng. Sci. 1989, 44, 1361

(262) Martin, L. R.; Good, T. W. Atmos. Environ. 1991, 25, 2395.

(263) Grgic, I.; Hudnik, V.; Bizjak, M.; Levect, J. Atmos. Environ. 1991 $25 A, 1591$

(264) Grgic, I.; Hudnik, V.; Bizjak, M.; Levect, J. Atmos. Environ. 1992 $26 A, 1591$.

(265) Coichev, N.; v. R. Eldik. Inorg. Chem. Acta 1991, 185, 2375.

(266) Berglund, J.; Buxton, G. V.; Elding, L. I.; Govan, M. S.; Salmon, G. A. J. Chem. Soc., Faraday Trans. 1994, 90, 3309.

(267) Hoigné, J.; Bühler, R. E. Heterogeneous and Liquid-Phase Processes; Springer-Verlag: Berlin, Germany, 1996.

(268) Koslov, Y.; Berdnikov, N. Russ. J. Phys. Chem. 1973, 47, 338

(269) Berdnikov, V. M. Russ. J. Phys. Chem. 1973, 47, 1060.

(270) Johnson, G. R. A.; Nazhat, N. B.; Saadalla-Nazhat, R. A. J. Chem. Soc., Chem. Commun. 1985, 407.

271) Moffett, J. W.; Zika, R. G. Environ. Sci. Technol. 1987, 21, 804

(272) Masarwa, M.; Cohen, H.; Meyerstein, D.; Hickman, D.; Bakac A.; Espenson, J. J. Am. Chem. Soc. 1988, 110, 4293

(273) Eberhardt, M. K.; Ramirez, G.; Ayala, E. Am. Chem. Soc. 1989 , 54,5922

(274) Sawyer, D. T. Coord. Chem. Rev. 1997, 165, 297.

(275) Maestre, P.; Lambs, L.; Thouvenot, J. P.; Berthon, G. Free Radical Res. 1994, 20, 205

(276) Meyerstein, D. Inorg. Chem. 1971, 10, 638.

(277) Urbanski, N.; Beresewicz, A. Acta Biochim. Pol. 2000, 47, 951.

(278) Strlic, M.; Kolar, J.; Selih, V.-S.; Kocar, D.; Pihlar, B. Acta Chim. Slov. 2003, 50, 619

(279) Ibusuki, T.; Takeuchi, K. Atmos. Environ. 1987, 21, 1555.

(280) Reda, X. Water Sci. Technol. 1988, 20, 45.

(281) van Eldik, R.; Coichev, N.; Bal Reddy, K.; Gerhaard, A. Ber. Bunsenges. Phys. Chem. 1992, 96, 478 .

(282) Grgic, I.; Bercic, G. J. Atmos. Chem. 2001, 39, 155

(283) Bäckström, H. L. J. Z. Phys. Chem., Abt. B 1934, 25B, 122

(284) Barron, C. H.; O'Hern, H. A. Chem. Eng. Sci. 1966, 21, 397.

(285) Carlyle, D. W.; Zeck, O. F. J. Inorg. Chem. 1973, 12, 2978.

(286) Veprek-Siska, J.; Lunak, S. Z. Naturforsch. B: Anorg. Chem., Org. Chem. 1974, 29,689.

(287) Zeck, O. F.; Carlyle, D. W. Inorg. Chem. 1974, 13, 34

(288) Lunak, S.; El-Wakil, A. M.; Vepreck-Siska, J. Collect. Czech Chem. Commun. 1978, 43, 3306.

(289) Jain, U.; Sharma, M.; Rani, A.; Gupta, K. S. Indian J. Chem. 1995, $34 \mathrm{~A}, 971$.

(290) Chen, L. C.; Peoples, S. M.; Carthy, J. F.; Amdur, M. O. Atmos Environ. 1989, 23, 149

(291) Manoj, S. V.; Sharma, M.; Gupta, K. S. Atmos. Environ. 1999 33,1503

(292) Prasad, D. S. N.; Rani, A.; Gupta, K. S. Environ. Sci. Technol. 1992, 26, 1361 .

(293) Herrmann, H.; Ervens, B.; Weise, D. IGACtivities Newsl. 2001 , 23,6

294) Cocks, A. T.; McElroy, W. J. The Role of Transition Metal Ions in Atmospheric Droplet Chemistry; Technical Report TPRD/L 3001/R86; Central Electricity Research Laboratories: Leatherland, U.K., 1986.

(295) Warneck, P. In Formation, Distribution and Chemical Transformation of Air Pollutants; Zellner, R., Ed.; Verlag Chemie: Weinheim, Germany, 1987; Vol. 104.

(296) Leriche, M.; Deguillaume, L.; Chaumerliac, N. J. Geophys. Res. 2003, 108, 4433, doi 10.1029/2002JD002950.

(297) Hoigné, J.; Bader, H.; Haag, W. R.; Staehelin, J. Water Res. 1985 19, 993.

(298) Jacobsen, F.; Holcman, J.; Sehested, K. J. Phys. Chem. A 1997, $101,1324$.

(299) Sheng, H. J. Chem. Technol. Biotechnol. 1993, 56, 163.

(300) Jacobsen, F.; Holcman, J.; Sehested, K. Int. J. Chem. Kinet. 1998 $30,207$.
(301) Rosseinsky, D. R. J. Chem. Soc. 1963, 1181

(302) Morselli, L.; Olivieri, P.; Brusori, B.; Passarini, F. U. Environ. Pollut. 2003, 124, 457.

(303) Gatz, D. F.; Warner, B. K.; Chu, L. C. Solubility of metal ions in rain water. In Deposition both Wet and Dry; Hicks, B. B., Ed.; Ann Arbor Sciences: Ann Arbor, MI, 1984

(304) Guieu, C.; Chester, R.; Nimmo, M.; Martin, J. M.; Guerzoni, S.; Nicolas, E.; Mateu, J.; Keyse, S. Deep-Sea Res. II 1997, 44, 665

(305) Chester, R.; Murphy, K. J. T.; Lin, F. J.; Berry, A. S.; Bradshaw, G. A.; Corcoran, P. A. Mar. Chem. 1993, 42, 107.

(306) Seames, W. S.; Sooroshian, J.; Wendt, J. J. Aerosol Sci. 2002 $33,77$.

(307) Zhu, X.; Prospero, J. M.; Savoie, D. L.; Millero, F. J.; Zika, R. G.; Saltzman, E. S. J. Geophys. Res. 1993, 98, 9039.

(308) Cawse, P.; Peirson, D. H. An Analytical Study of Trace Elements in the Atmospheric Environment; AERE-R 7134; Atmospheric Energy Research Establishment: Harwell, U.K., 1972.

(309) Peirson, D. H.; Cawse, P. A.; Salmon, L.; Cambray, R. S. Nature 1973, 241, 252

(310) Betz, M. Diplomarbeit thesis, Institüt für Meteorologie and Geophysik der Universität, 1976

(311) Beavington, F.; Cawse, P. A. Sci. Total Environ. 1979, 13, 263

(312) Gravenhorst, G.; Beilke, S.; Betz, M.; Georgii, H.-W. In Effect of Acid Precipitation on Terrestrial Ecosystems; Hutchinson, T. C., Havas, M., Eds.; Plenum Publishing: New York, 1980.

(313) Thornton, J. D.; Eisenreich, S. J. Atmos. Environ. 1982, 16, 1945

(314) Church, T. M.; Taramontano, J. M.; Scudlark, J. P.; Jickells, T. D.; Tokos, J. J.; Knap, A. H.; Galloway, J. N. Atmos. Environ. 1984, 18,2657

(315) Waldman, J. M.; Münger, J. W.; Jacob, D. J.; Hoffmann, M. R Tellus 1985, 37B, 91

(316) Chan, W. H.; Tang, J. S.; Chung, H. S.; Lusis, M. A. Water, Air Soil Pollut. 1986, 29, 373.

(317) Radojevic, M.; Clarke, A. G. In Acid Rain: Scientific and Technical Advances: Based on Papers Presented at the Acid Rain Conference in Lisbon, Sept 1-3; Perry, R., Harrison, R., Bell, J., Lester, J., Eds.; Publications Division, Selpter Ltd.: London, U.K., 1987.

(318) Arimoto, R.; Duce, R. A.; Ray, B. J.; Hewitt, A. D.; Williams, J. J. Geophys. Res. 1987, 90, 2391.

(319) Balls, P. Atmos. Environ. 1989, 23, 2751.

(320) Church, T. M.; Veron, A.; Patterson, C. C.; Settle, D.; Erel, Y.; Maring, H. R.; Flegal, A. R. Global Biogeochem. Cycles 1990, 4, 431.

(321) Ross, H. B. Atmos. Environ. 1990, 24A, 1929

(322) Lim, B.; Jickells, T. D.; Davies, T. Atmos. Environ. 1991, 25A, 745 .

(323) Brandt, C.; Lepentsiotis, V.; Paul, A.; Hohmann, H.; van Eldik, R. GIT Fachz. Lab. 1994, 38, 770

(324) Manoj, S. V.; Mishra, C. D.; Sharma, M.; Rani, A.; Jain, R. Bansal, S. P.; Gupta, K. S. Atmos. Environ. 2000, 34, 4479.

(325) Waldman, J. M.; Munger, J. W.; Jacob, D. J.; Flagan, R. C.; Morgan, J. J.; Hoffmann, M. R. Science 1982, 218, 677.

(326) Jacob, D. J.; Waldman, J. M.; Munger, J. W.; Hoffmann, M. R. Tellus 1984, 36B, 272.

(327) Jacob, D. J.; Waldman, J. M.; Munger, J. W.; Hoffmann, M. R. Environ. Sci. Technol. 1985, 19, 730.

(328) Khwaja, H. A. Atmos. Environ. 1995, 29, 127

(329) Hosono, T.; Okochi, H.; Igawa, M. Bull. Chem. Soc. Jpn. 1994 $67,368$.

(330) Wobrock, W., et al. J. Atmos. Chem. 1994, 19, 3.

(331) Bizjak, M.; Divjak, B.; Kosak-Legrisa, E.; Poje, M.; Hudnik, V. GDF93: Aerosol black carbon (soot) and cloud water transition metal concentration. In Proceedings of the EUROTRAC Symposium 94, April 11-15; Garmisch-Partenkirchen, Germany, 1994.

(332) Lindberg, S. E. Turner, R. In Proceedings of the Internation Conference on Heavy Metals in the Environment, Heidelberg, September; CEP Consultants: Edinburgh, U.K., 1983.

(333) Horvath, Z.; Lasztity, A.; Varga, E.; Meszaros, E.; Molnar, A. Talanta 1994, 41, 1165.

(334) Landis, M. S.; Keeler, G. J. Environ. Sci. Technol. 1997, 31, 2610

(335) Garnaud, S.; Mouchel, J. M.; Chebbo, G.; Thevenot, D. R. Sci. Total Environ. 1999, 235, 235

(336) Maneux, E.; Grousset, F. E.; Buat-Ménard, P.; Lavaux, G. Rimmelin, P.; Lapaquellerie, Y. Water, Air Soil Pollut. 1999, 114 95.

(337) Cabon, J. Y. Water, Air Soil Pollut. 1999, 111, 399.

(338) Jambers, W.; Dekov, V.; Van Grieken, R. Sci. Total Environ. 2000, 256, 133 .

(339) Kim, G.; Scudlark, J. R.; Church, T. M. Atmos. Environ. 2000 , $34,3437$.

(340) Roy, S.; Negrel, P. U. Sci. Total Environ. 2001, 277, 225

(341) Deboudt, K.; Flament, P.; Bertho, M.-L. Water, Air Soil Pollut. 2004, 151, 335

(342) Johnson, C. A.; Sigg, L.; Zobrist, J. Atmos. Environ. 1987, 21, 2365

(343) Spokes, L. J.; Jickells, T. D. Aquat. Geochem. 1996, 1, 355

(344) Langford, C. H.; Carey, J. H. Can. J. Chem. 1975, 53, 2430. 
(345) Lee, C.; Yoon, J. Chemosphere 2004, 57, 1449.

(346) Baxendale, J. H.; Bridge, N. K. J. Phys. Chem. 1955, 59, 783.

(347) Benkelberg, H. J.; Schäfer, A.; Warneck, P. Product quantum yields for the photodecomposition of $\mathrm{H}_{2} \mathrm{O}_{2}$ and $\mathrm{Fe}(\mathrm{III})$ complexes in aqueous solution. In Air Pollution Research Report 33: Atmospheric Oxidation Processes; Becker, K.-H., Ed.; European Commission: Brussels, Belgium, 1991; $130 \mathrm{pp}$.

(348) Christensen, H.; Sehested, K.; Logager, T. Radiat. Phys. Chem. 1993, 41, 575 .

(349) Christensen, H.; Sehested, K. Radiat. Phys. Chem. 1981, 18, $723-731$.

(350) Thornton, A. T.; Laurence, G. S. J. Chem. Soc., Dalton Trans 1973, 804.

(351) Pikaev, A. K.; Sibirskaya, G. K.; Shirshov, E. M.; Glazunov, P. Y.; Spitsyn, V. I. Dokl. Phys. Chem. Proc. Acad. Sci. U.S.S.R. 1974, 215, 328.

(352) Epstein, I. R.; Kustin, K.; Simoyi, R. H. J. Am. Chem. Soc. 1982 104, 712 .

(353) Williams, J. Ph. D.thesis, University of Leeds, 1996.

(354) Gilbert, B. C.; Stell, J. K. J. Chem. Soc., Perkin Trans. 1990, 2, 1281.

(355) Buxton, G. V.; Malone, T. N.; Salmon, G. A. J. Chem. Soc., Faraday Trans. 1997, 93, 2893.

(356) Martell, A.; Smith, R. Other organic ligands. In Critical Stability Constants; Plenum Press: New York, 1977; Vol. 3.
(357) Moorhead, E.; Sutin, N. Inorg. Chem. 1966, 5, 1866.

(358) Jayson, G. G.; Parson, B. J.; Swallow, A. J. J. Chem. Soc., Faraday Trans. 1973, 69, 1079.

(359) Xu, F. C.; Krouse, H. R.; Swaddle, T. W. Inorg. Chem. 1985, 24 267.

(360) Goldstein, S.; Czapski, G.; Cohen, H.; Meyerstein, D. Inorg. Chim. Acta 1992, 192, 87.

(361) Bjergbakke, E.; Sehested, K.; Rasmussen, O. L. Radiat. Res. 1976, 66, 433 .

(362) Baxendale, J. H.; Ward, M. D.; Wardman, P. Trans. Faraday Soc. 1971, 67, 2532.

(363) Davies, G.; Kirschenbaum, L. J.; Kustin, K. Inorg. Chem. 1968, $7,146$.

(364) Neta, P.; Huie, R. E. J. Phys. Chem. 1986, 90, 4644.

(365) Laurence, G. S.; Thornton, A. T. J. Chem. Soc., Dalton Trans. 1973, 1637.

(366) Cope, V. W.; Hoffman, M. Z.; Chen, S. J. Phys. Chem. 1978, 82, 2665.

(367) Wells, G. F.; Davies, G. A. J. Chem. Soc. A 1967, 1858

(368) Baral, S.; Lume-Pereira, C.; Janata, E.; Henglein, A. J. Phys. Chem. A 1986, 90, 6025 .

CR040649C 